\title{
NUEVAS APORTACIONES AL CONOCIMIENTO DE LA VEGETACIÓN LUSO-EXTREMADURENSE. ESTUDIO DE LAS SIERRAS DE LAS VILLUERCAS (EXTREMADURA, ESPAÑA) Y SAN MAMEDE (ALTO ALENTEJO, PORTUGAL)
}

\author{
José Alfredo VICENTE ORELLANA* y Antonio GALÁN DE MERA \\ Universidad CEU-San Pablo, Facultad de Farmacia, Departamento de Ciencias Ambientales y \\ Recursos Naturales, Laboratorio de Botánica. \\ Apdo. 67, E-28660 Boadilla del Monte, Madrid, España. \\ *Autor para correspondencia: avicore@ceu.es
}

Recibido el 30 de julio 2007, aceptado para su publicación el 16 febrero de 2008 Publicado "on line" en abril de 2008

\begin{abstract}
RESUMEN. Nuevas aportaciones al conocimiento de la vegetación luso-extremadurense. Estudio de las sierras de las Villuercas (Extremadura, España) y San Mamede (Alto Alentejo, Portugal). La región fronteriza entre España y Portugal muestra aspectos diferentes en cuanto a la utilización del territorio sobre la vegetación y el paisaje, lo que repercute en los complejos de vegetación, aunque nos encontremos en lugares biogeográficamente similares. En la frontera portuguesa altoalentejana abundan los minifundios y el uso del territorio es muy intenso. Por el contrario, en Extremadura, en las cercanías a las Sierras de Las Villuercas, dominan los latifundios con una intensidad de uso menor a la zona estudiada en Portugal. Fruto del estudio de ambos territorios, se presenta el esquema sintaxonómico, así como las principales novedades fitosociológicas encontradas: 2 alianzas (Hyperico perforati-Ferulion communis, Adenocarpion argyrophylli), 9 asociaciones (Sileno acutifoliaeDianthetum lusitani, Feruletum communis, Raphano raphanistri-Diplotaxietum catholicae, Rumici angiocarpi-Coleostephetum myconis, Armerio francoi-Arrhenatheretum sardoi, Festuco multispiculatae-Arrhenatheretum sardoi, Festuco multispiculatae-Agrostietum curtisii, Rubetum ulmifolio-vigoi y Rubetum ulmifolio- caesii), y 12 subasociaciones.
\end{abstract}

Palabras clave. Alto Alentejo, Extremadura, sintaxonomía, vegetación.

ABSTRACT. New additions to the knowledge of the luso-extremadurense vegetation. Study of the Villuercas (Extremadura, Spain) and San Mamede Mountains (Alto Alentejo, Portugal). The border region between Spain and Portugal shows interesting aspects of human activity on vegetation and landscape. These are reflected in the present vegetation patterns. These differences are also present in biogeographical similar territories. In the Alto Alentejo Portuguese border, smallholding (family economy) predominates, and the use of soil is very intensive. On the other hand, in Extremadura, close to the Villuercas Mountains, latifundia are normally observed, with few intensive uses than in Portugal. From the study of vegetation of both zones, here are presented the syntaxonomic scheme and the most repesentative novelties. These novelties are: 2 alliances (Hyperico perforati-Ferulion communis, Adenocarpion argyrophylli), 9 associations (Sileno acutifoliae-Dianthetum lusitani, Feruletum communis, Raphano raphanistri-Diplotaxietum catholicae, Rumici angiocarpiColeostephetum myconis, Armerio francoi-Arrhenatheretum sardoi, Festuco multispiculataeArrhenatheretum sardoi, Festuco multispiculatae-Agrostietum curtisii, Rubetum ulmifolio-vigoi and Rubetum ulmifolio-caesii), and 12 subassociations.

Key words. Alto Alentejo, Extremadura, syntaxonomy, vegetation. 


\section{INTRODUCCIÓN}

La frontera Hispano-Portuguesa muestra aspectos muy interesantes de la actividad humana sobre la vegetación y el paisaje, debido a las diferencias culturales y socioeconómicas que presenta. La frontera más larga $(1200 \mathrm{~km})$ y más antigua de los estados de la Unión Europea (desde el Tratado de Alcañices en 1297), nos ofrece una gran estabilidad a lo largo del tiempo, tras la independencia portuguesa de la Corona de Castilla en la Edad Media. Salvo en algunos momentos, la frontera se ha mantenido como una línea separadora contribuyendo en gran medida al aislamiento y a la instalación de plazas fuertes (Reis Freire, 1989). Las áreas fronterizas portuguesas y españolas se definían a principios del siglo pasado por su especialización pecuaria, destinada en gran medida a un mercado lejano en Lisboa o Madrid (Comisión Europea, 2000; Eurostat, s.f.).

Estas diferencias reseñadas a lo largo del tiempo pueden verse reflejadas hoy día en la distribución de la vegetación natural con las variantes fitosociológicas que se proponen dentro de las asociaciones. En la frontera portuguesa el uso agrícola del suelo es más generalizado, siendo el minifundismo de economía familiar lo más frecuente (Teotonio Pereira \& Reis Gómes, 1983). En Extremadura dominan los grandes espacios abiertos, los latifundios, donde se practica una agricultura y ganadería extensivas que han progresado industrialmente gracias a los Planes de Desarrollo Regional de la Comunidad Europea (Comisión Europea, 2000). Desde el año 1998 venimos realizando estudios fitosociológicos comparativos en dos regiones biogeográficamente similares, pero con aprovechamiento distinto (Vicente Orellana, 2004). Una zona, cercana a la frontera de
Portugal (Alto Alentejo), concretamente en la Sierra de San Mamede, donde dominan las poblaciones pequeñas fortificadas rodeadas por minifundios; y la otra zona en Extremadura situada en la Sierra de Guadalupe en las proximidades de las Villuercas, donde las poblaciones distan bastante unas de otras, siendo abundantes los latifundios.

En las áreas próximas a nuestras zonas de estudio se han descrito numerosas comunidades vegetales (Ladero, 1970a; Malato Beliz, 1979, 1987; Ladero et al. 1990, 1994; Antunes, 1996) aunque sin considerar el uso de los territorios, que nos han permitido describir nuevos sintaxones y observar sus variantes. En este trabajo presentamos las novedades fitosociológicas así como el esquema sintaxonómico de ambos territorios.

\section{MATERIAL Y MÉTODOS}

\section{Área de estudio}

El área estudiada en Extremadura se encuentra en la ladera sur de la Sierra de Guadalupe, en Las Villuercas, mientras que la de Portugal se encuentra en la región del Alto Alentejo, en la ladera occidental de la Serra de San Mamede (fig. 1). La altitud de ambas zonas está comprendida entre los 400 y 1000 m de altura, aunque el relieve es más rugoso en la zona portuguesa. Los materiales datan de los periodos Precámbrico, Cámbrico y Ordovícico, siendo los más frecuentes pizarras, areniscas, granitos y conglomerados (Peinador Fernándes et al. 1973; Correia Perdigão \& Peinador Fernándes, 1976; Mora, 1997; García Navarro \& López Piñeiro, 2002).

Para la caracterización bioclimática, se han consultado los datos de estaciones meteorológicas situadas tanto en la propia zona de estudio como otras cercanas (León 


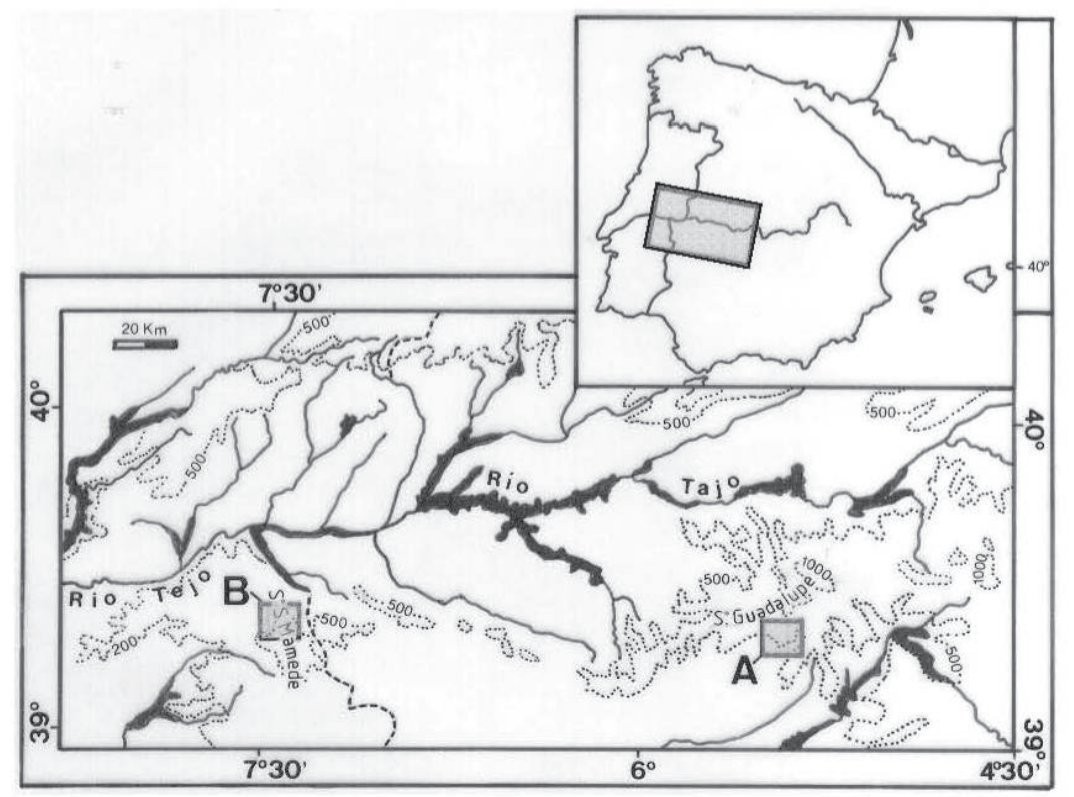

Figura 1. Mapa de las áreas de estudio en el occidente de la Península Ibérica. (Portugal), tomado de Vicente Orellana \& Galán de Mera (2003). Map of the study areas in the western Iberian Peninsula, taken from Vicente Orellana \& Galán de Mera (2003). A: Extremadura (España), B: Alto Alentejo.

Llamazares, 1991a y b; Tormo Molina et al. 1992; Pinto-Gomes et al. 1994; Sánchez Martín, 1994; Devesa Alcaraz, 1995; Instituto Superior de Agronomía, 2003). Para la diagnosis bioclimática se han utilizado el índice de termicidad (It), el índice de continentalidad (Ic) y el índice de termicidad compensado (Itc), según las aproximaciones de Rivas-Martínez (Rivas-Martínez et al. 1990; Rivas-Martínez, 1997; Rivas-Martínez et al. 1999; Rivas-Martínez, 2004). Para la caracterización ombroclimática se han considerado los valores de las precipitaciones. Por tanto, las zonas de estudio se encuentran en el piso mesomediterráneo con ombroclimas que oscilan desde seco a húmedo, siendo más frecuente el subhúmedo. Las zonas más elevadas corresponden ya al piso supramediterráneo, con ombroclima subhúmedo-húmedo. El Ic, muestra el carácter más o menos oceánico de la zona estudiada, con variaciones que van desde el eu-oceánico de las estaciones portuguesas, al semicontinental de las estaciones extremeñas. La termicidad dominante es subcálida (en las zonas de llano), mientras que en las zonas más elevadas es templada.

Biogeográficamente, ambas zonas son muy similares, encontrándose en la provincia Luso-Extremadurense, sector ToledanoTagano y subsector Oretano (Ladero, 1987; Rivas-Martínez, 1987; Ladero et al. 1990; Costa et al. 1998; Ladero \& Amor, 1999. Aunque las dos zonas corresponden al mismo subsector, la extremeña pertenece al distrito Villuerquino, mientras que la altoalentejana al distrito Serra de São Mamede. Estos territorios, muestran una flora característica, que deriva del carácter atlántico del entorno de la Serra de São Mamede y del uso que se ha hecho a lo largo de la historia. El distrito 


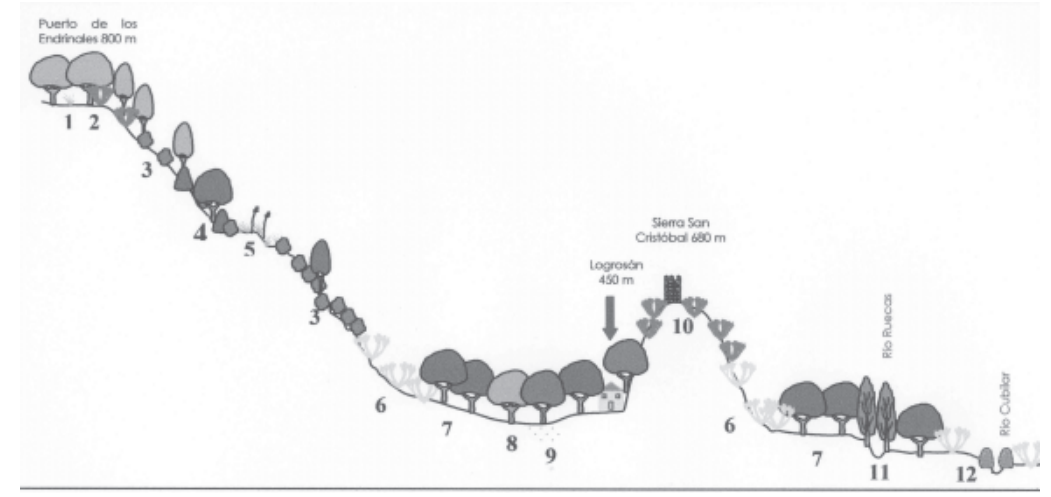

Figura 2. Representación de la vegetación en un transecto N-S en la zona de Extremadura. Representation of a vegetation transect $N-S$ in the study area of Extremadura. 1- Arbuto-Quercetum pyrenaicae adehesado (estate), 2- Arbuto-Quercetum pyrenaicae, 3-Genisto-Cistetum ladaniferi, 4Pyro-Quercetum rotundifoliae, 5-Dauco-Hyparrhenietum sinaicae, 6-Cytiso-Retametum sphaerocarpae, 7- Pyro-Quercetum adehesado (estate), 8- Pyro-Quercetum quercetosum pyrenaicae, 9- Pyro-Quercetum quercetosum suberis, 10- Cytiso-Sarothamnetum eriocarpi, 11- ScrophularioAlnetum glutinosae, 12- Pyro-Securinegetum tinctoriae.

portugués está caracterizado por la presencia de algunos taxones como Ulex minor, Armeria $x$ francoi, Genista falcata, Linaria triornithophora, Silene coutinhoi y Silene acutifolia. Por el contrario, en el distrito extremeño alguno de los taxones representativos son Genista falcata (relictual), Linaria triornithophora (escasa), Adenocarpus argyrophyllus y Echinospartum ibericum.

Referente a la vegetación hay notables diferencias, en este caso debidas en gran medida al uso del territorio (figs. 2 y 3). El melojar domina en las zonas más húmedas y oceánicas (1000-1600 mm), en el piso mesomediterráneo superior y supramediterráneo. Los alcornocales se localizan en zonas con ombroclima subhúmedo o en solanas (600-1000 mm) del mesomediterráneo. En las zonas más secas (350-600 mm), el encinar es el bosque dominante (Ladero, 1987; Rivas-Martínez, 1987; Pinto-Gomes et al. 1994; Antunes, 1996; Costa et al. 1998; Ladero \& Amor, 1999), generalmente en el mesome- diterráneo, y formando comunidades permanentes sobre pedregales en el supramediterráneo.

\section{Metodología}

La metodología empleada se basa en Braun-Blanquet (1964) y Dierschke (1993). Los aspectos sintaxonómicos de este trabajo están basados en las últimas aproximaciones realizadas en la Península Ibérica (RivasMartínez et al. 2001, 2002); seguimos el Código Internacional de Nomenclatura Fitosociológica (Izco \& del Arco, 2003). Para el estudio de la vegetación y sus variantes en función de su uso, en áreas biogeográficamente semejantes, seguimos la metodología sinfitosociológica de Deil (1997) y Deil \& Sundermeier (1992), ya empleada por nosotros en otros trabajos en el territorio (Galán de Mera et al. 2000a; Vicente Orellana \& Galán de Mera, 2003; Vicente Orellana, 2004).

Para el estudio de la flora, aparte de las floras y catálogos europeos (Tutin et al. 1964-1980; Greuter et al. 1984, 1986, 1989), 


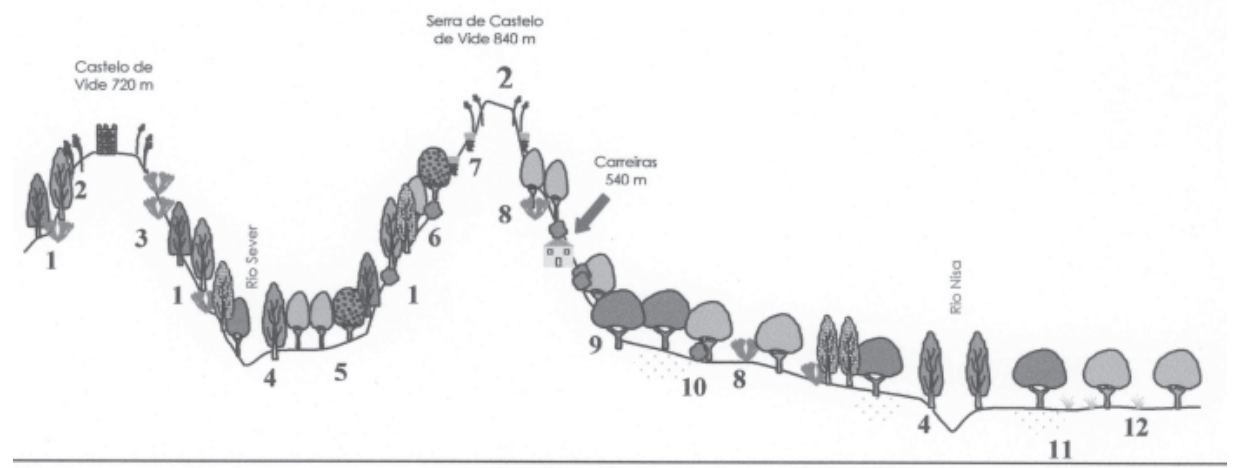

Figura 3. Representación de la vegetación en un transecto N-S en la zona de Alto Alentejo. Representation of a vegetation transect $N$-S in the study area of Alto Alentejo. 1- Reforestación con (crops of) Pinus pinaster, Eucalyptus globulus, Acacia dealbata o Castanea sativa, 2- ArmerioArrhenatheretum sardoi, 3-Cytiso-Sarothamnetum eriocarpi, 4- Scrophulario-Alnetum glutinosae, 5- Arbuto-Quercetum pyrenaicae con reforestaciones (with crops), 6- Genisto-Cistetum ladaniferi, 7- Halimio-Cistetum hirsuti, 8- Arbuto-Quercetum pyrenaicae, 9- Poterio-Quercetum suberis, 10Arbuto-Quercetum quercetosum suberis, 11-Poterio-Quercetum suberis adehesado (estate), 12Arbuto-Quercetum pyrenaicae adehesado (estate).

hemos utilizado otras de carácter nacional y regional (Pereira Coutinho, 1939; Franco, 1971; 1984; Castroviejo, 1986-2008; Valdés et al. 1987; Franco \& Rocha Afonso, 1994, 1999; Devesa Alcaraz, 1995). De especial importancia, para la caracterización fitosociológica de las plantas, han sido las obras de Oberdorfer (1990), Bolòs et al. (1993) y Rothmaler (2000).

\section{RESULTADOS Y DISCUSIÓN}

El uso de distintos regímenes económicos permite observar la diversidad que muestran dos regiones biogeográficamente similares. Los latifundios, donde abundan tanto la ganadería como la agricultura extensiva, presentan en general menor diversidad en comunidades vegetales, pero éstas están mejor conservadas. Esto hace que el paisaje sea más homogéneo. Por el contrario, los minifundios presentan mayor diversidad de comunidades vegetales, en especial arvenses, pero tanto la calidad de los pastos como la conservación de los bosques es menor, resultando un paisaje más heterogéneo.

Aquí presentamos las novedades fitosociológicas encontradas en ambos territorios, con su descripción y discutiendo su originalidad respecto a otras comunidades similares, ordenadas según el esquema sintaxonómico que exponemos al final.

\section{Pulicario uliginosae-Agrostietum salmanticae cynodontetosum dactylionis Vicente Orellana \& Galán de Mera subass. nova}

[Tabla 1, holotypus subass. inv. 15]

Estos vallicares húmedos terofíticos anfibios, que se desarrollan sobre suelos areno-limosos con hidromorfía temporal (Rivas Goday, 1958; Amor et al. 1993), tanto en zonas de vaguadas del encinar (PyroQuercetum rotundifoliae) como en el melojar (Arbuto-Quercetum pyrenaicae), pueden enriquecerse notablemente con la grama (Cynodon dactylon), debido especialmente a un incremento puntual de la humedad 
Tabla 1

Pulicario uliginosae-Agrostietum salmanticae Rivas Goday 1956

12-15: cynodontetosum dactylionis Vicente Orellana \& Galán de Mera subass. nova (Isoeto-Nanujuncetea, Isoetetalia, Agrostion salmanticae)

\begin{tabular}{|c|c|c|c|c|c|c|c|c|c|c|c|c|c|c|c|}
\hline Inventario $n^{\circ}$ & 1 & 2 & 3 & 4 & 5 & 6 & 7 & 8 & 9 & 10 & 11 & 12 & 13 & 14 & 15 \\
\hline Altitud (Dm.) & 50 & 50 & 50 & 76 & 76 & 78 & 77 & 77 & 89 & 50 & 70 & 43 & 40 & 41 & 41 \\
\hline Área $\left(\mathrm{m}^{2}\right)$ & 100 & 100 & 100 & 100 & 100 & 100 & 100 & 100 & 100 & 100 & 50 & 100 & 100 & 100 & 100 \\
\hline \multicolumn{16}{|c|}{ Características de asociación y unidades superiores } \\
\hline Agrostis pourretii & 4 & 4 & 4 & 5 & 5 & 5 & 4 & 2 & 3 & 4 & 4 & 3 & 4 & 3 & 2 \\
\hline Pulicaria paludosa & . & . & . & . & . & . & . & . & & 1 & . & . & 1 & . & 2 \\
\hline Lotus hispidus & . & . & . & . & . & + & . & . & 1 & 2 & . & . & . & . & . \\
\hline Centaurium maritimum & . & . & . & 1 & . & . & . & . & 1 & . & . & . & . & . & . \\
\hline Chaetopogon fasciculatus & . & . & . & . & . & . & . & . & . & . & . & ${ }^{\circ}$ & ${ }^{\circ}$ & 1 & . \\
\hline \multicolumn{16}{|l|}{ Diferenciales de subasociación } \\
\hline Cynodon dactylon & . & . & . & . & . & . & . & . & . & 1 & . & 2 & 3 & 2 & 3 \\
\hline Mentha pulegium & . & . & . & . & . & . & . & . & . & . & . & 2 & 1 & 1 & + \\
\hline Plantago lagopus & . & . & . & . & . & . & . & . & . & . & . & . & 1 & 1 & 1 \\
\hline \multicolumn{16}{|l|}{ Compañeras } \\
\hline Tolpis barbata & 2 & + & 1 & 2 & 2 & 2 & 3 & . & 2 & 1 & 1 & 1 & 1 & 2 & . \\
\hline \multicolumn{16}{|l|}{ Rumex acetosella } \\
\hline subsp. angiocarpus & & & + & + & 1 & + & + & . & + & $\cdot$ & 2 & + & . & . & . \\
\hline Holcus anпuиs & 2 & 1 & 2 & 3 & 3 & 3 & 3 & 3 & 2 & 1 & 3 & . & . & . & . \\
\hline Hypochaeris glabra & + & 1 & 1 & . & 1 & 3 & 1 & 1 & + & 1 & . & . & 1 & + & . \\
\hline Chamaemelum mixtum & 1 & 1 & 1 & 1 & 1 & 1 & . & . & . & 2 & . & 2 & 1 & 1 & 1 \\
\hline Crepis capillaris & . & + & + & + & 2 & 2 & 2 & . & . & & . & . & . & 1 & \\
\hline Gaudinia fragilis & 1 & 1 & 1 & 3 & . & . & . & 1 & . & 2 & + & . & . & 1 & 1 \\
\hline Leontodon longirostris & 1 & 1 & 1 & 1 & + & . & 1 & 1 & + & & . & & & . & . \\
\hline Plantago coronopus & 2 & 1 & 1 & . & + & 1 & . & . & . & 3 & . & 2 & 1 & . & . \\
\hline Bromus hordeaceus & 1 & + & 1 & + & 1 & . & ; & + & . & : & . & + & . & . & . \\
\hline Vulpia ciliata & . & 1 & 3 & 2 & 1 & 1 & 1 & 1 & . & 1 & . & . & . & . & . \\
\hline Xolantha guttata & . & 1 & . & 2 & 1 & 1 & 2 & & 1 & 3 & + & . & . & 1 & . \\
\hline Trifolium arvense & + & . & + & 1 & . & + & 1 & 1 & . & . & + & . & . & . & . \\
\hline Vulpia myuros & 1 & 1 & & & & . & & 1 & 1 & 2 & . & . & 1 & & 1 \\
\hline Trifolium campestre & . & . & 1 & 1 & 1 & . & 2 & 1 & 1 & . & . & . & . & 1 & . \\
\hline Poa bulbosa & 2 & 2 & . & . & . & 1 & . & . & 2 & 1 & 1 & . & . & . & . \\
\hline Scolymus hispanicus & + & + & . & . & . & . & . & . & . & + & . & . & 1 & 1 & 1 \\
\hline Campanula lusitanica & + & . & . & . & + & + & + & 1 & . & . & . & . & . & + & . \\
\hline Echium plantagineum & + & . & . & . & + & . & . & . & . & + & . & 1 & . & 1 & 1 \\
\hline Coleostephus myconis & . & . & . & . & . & . & . & 1 & . & + & . & 1 & 1 & 1 & 1 \\
\hline Andryala integrifolia & . & . & . & + & + & . & 1 & + & . & . & 1 & . & . & . & . \\
\hline Avena barbata subsp. lusitanica & . & . & . & 1 & 1 & + & + & + & & . & . & . & . & . & . \\
\hline Cynosurus effusus & . & . & . & 1 & . & . & 1 & 1 & 1 & . & 1 & . & . & . & . \\
\hline Trifolium glomeratum & 1 & 2 & 1 & . & . & . & 1 & . & . & . & . & . & . & . & . \\
\hline Carlina racemosa & + & . & + & . & . & . & . & . & + & 1 & . & . & . & . & . \\
\hline Rumex bucephalophorus & . & + & . & . & + & . & . & . & . & . & . & + & . & 1 & . \\
\hline Sherardia arvensis & . & . & + & . & . & . & + & + & . & . & . & . & . & . & . \\
\hline Ornithopus compressus & . & . & 1 & . & . & $\dot{+}$ & + & . & . & . & + & . & . & . & . \\
\hline Jasione montana & . & . & . & 1 & 1 & . & 1 & . & . & . & 1 & . & . & . & . \\
\hline Carlina corymbosa & . & . & . & 1 & 1 & . & 1 & $\dot{+}$ & . & . & . & . & . & . & $\dot{.}$ \\
\hline Aegilops geniculata & . & . & . & 1 & . & $\dot{+}$ & 1 & . & 1 & . & . & . & . & . & . \\
\hline Briza maxima & . & . & . & 1 & . & . & + & 1 & 2 & . & . & . & . & . & . \\
\hline Agrostis castellana & . & . & . & + & . & . & . & . & 1 & . & 2 & . & . & . & 1 \\
\hline Holcus lanatus & . & . & . & . & + & . & . & . & . & . & . & . & 1 & 1 & 1 \\
\hline Senecio jacobea & . & . & . & . & + & . & . & . & . & . & + & 1 & . & 1 & . \\
\hline Linaria spartea & . & . & . & . & . & + & + & + & . & + & . & . & . & . & . \\
\hline Hordeum murinum subsp. leporinum & $n 1$ & . & . & . & 1 & . & . & . & . & + & . & . & . & . & i \\
\hline Eryngium campestre & + & + & . & . & . & . & . & . & . & . & . & . & . & . & 1 \\
\hline Spergularia rubra & . & + & + & . & . & . & . & . & . & . & . & 1 & . & . & . \\
\hline Bromus matritensis & . & . & + & . & + & . & 1 & . & 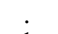 & . & . & . & . & . & . \\
\hline Xolantha macrosepala & . & . & . & 1 & . & + & . & . & 1 & . & . & . & . & . & . \\
\hline Trifolium strictum & . & . & . & + & . & . & . & + & + & . & . & . & . & . & . \\
\hline Petrorhagia dubia & . & . & . & . & 1 & . & . & + & . & . & . & . & . & . & + \\
\hline Anthemis arvensis & . & . & . & . & 1 & . & . & + & + & . & . & . & . & . & . \\
\hline Plantago bellardii & . & . & . & . & . & + & . & 1 & . & 1 & . & . & . & . & . \\
\hline
\end{tabular}


Otras plantas: Carduus pycnocephalus + , Cistus ladanifer,+ Digitalis thapsi,+ Lolium perenne 1 , Quercus rotundifolia pl. + , Raphanus raphanistrum + en 1; Herniaria cinerea 1, Lolium perenne + en 3; Brachypodium distachyon,+ Gastridium ventricosum 1, Logfia gallica 1 en 4; Bellardia trixago + , Campanula rapunculus + , Lolium rigidum + , Sanguisorba verrucosa,+ , Trifolium subterraneum 1 , Verbascum pulverulentum 1 en 5 ; Hymenocarpos lotoides + , Pteridium aquilinum + en 6; Carduus pycnocephalus + , Daucus crinitus + , Geranium molle + , Pteridium aquilinum,+ Rhagadiolus edulis + , Sisymbrium officinale + , Torilis arvensis + , Trifolium stellatum 1, Trifolium subterraneum 1 en 7; Geranium molle + , Logfia gallica + , Ornithopus pinnatus + , Rhagadiolus edulis + , Silene gallica + , Stachys arvensis + , Torilis arvensis + , Urginea maritima + en 8; Anagallis arvensis +, Anthoxanthum aristatum 3, Arrhenatherum elatius subsp. sardoum + , Coronilla repanda subsp. dura,+ Dactylis glomerata subsp. hispanica 1 , Euphorbia exigua,+ Hymenocarpos cornicina ,+ Linum bienne 1, Quercus pyrenaica(pl) 1 en 9; Cistus ladanifer,+ Hymenocarpos lotoides,+ Paronychia argentea + en 10; Anthoxanthum odoratum 2, Asphodelus albus subsp. albus,+ Briza media,+ Festuca ampla subsp. ampla,+ Hypochaeris radicata 1, Orchys cariophora + , Quercus pyrenaica $(\mathrm{pl})+$ en 11; Galactites tomentosa 1, Leontodon taraxacoides 1, Lolium rigidum 1, Lythrum junceum 1, Poa annua 1, Rumex pulcher subsp. woodsii 1, Silene gallica 1 en 12; Aira caryophyllea 1, Anthoxanthum ovatum +, Polycarpon tetraphyllum + , Retama sphaerocarpa 1 en 13; Aira caryophyllea 1, Anthoxanthum ovatum 1, Avena barbata subsp. barbata + , Erodium cicutarium + , Galactites tomentosa 1, Galium parisiense + , Hypericum elodes 1 , Ornithopus pinnatus + , Polycarpon tetraphyllum,+ Rumex pulcher subsp. woodsii + en 14; Daucus crinitus,+ Leontodon taraxacoides 1 , Picnomon acarna,+ Retama sphaerocarpa,+ Trifolium angustifolium 1 , Vulpia geniculata 1 en 15.

Localidades: 1-3, 10: Los Lotes, Cañamero (Cáceres, España) 30STJ9259. 4-8: La Nava, Berzocana (Cáceres, España) 30STJ8664. 9, 11: Collado del Bote, La Nava, Berzocana (Cáceres, España) 30STJ8464. 12: Veloso, Carreiras (Alto Alentejo, Portugal) 29SPD3559. 13-15: Río Cubilar, Logrosán (Cáceres, España) 30STJ8950.

(pequeñas depresiones) unido a una mayor compactación del suelo (zonas muy transitadas por ganadería). Aparece en ambas zonas estudiadas.

Parietarietum judaicae K. Buchwald 1952

Vegetación característica de cantiles, paredes y muros, con carácter nitrófilo y heliófilo (Rivas-Martínez, 1969; RivasMartínez, 1978; Ortiz \& Rodríguez-Oubiña, 1993).

phagnaletosum saxatilis Vicente Orellana \& Galán de Mera subass. nova

[Tabla 2, holotypus subass. inv. 9]

En zonas con mayor sequedad y con mayor influencia antrópica (zonas próximas a las poblaciones o incluso dentro de las mismas), la asociación se enriquece con diversos elementos, especialmente Phagnalon saxatile, constituyendo una nueva subasociación. Hemos encontrado solamente esta comunidad en la zona de Extremadura.

cymbalarietosum muralis Vicente Orellana \& Galán de Mera subass. nova

[Tabla 2, holotypus subass. inv. 13]

Este mismo tipo de vegetación, al incrementarse notablemente la humedad, hasta tal punto que las paredes son rezumantes durante gran parte del año, se enriquece con Cymbalaria muralis, significando el tránsito hacia las comunidades de la clase Adientetea (Galán de Mera et al. 2000b), y constituyendo por tanto una nueva subasociación. Aparece en ambas zonas de estudio.

\section{Sileno acutifoliae-Dianthetum lusitani}

Vicente Orellana \& Galán de Mera ass. nova

[Tabla 3, holotypus ass. inv. 5]

Las comunidades con Silene acutifolia han sido ampliamente estudiadas en el noroeste de la Península Ibérica (RivasMartínez, 1981; Pulgar et al. 1996; Ladero et al. 1999; Rivas-Martínez et al. 2000; Jansen, 2002), siendo éstas del centro de Portugal las más meridionales. A diferencia de las del noroeste y oeste de la Península Ibérica, en esta ocasión nos encontramos con unas comunidades mesomediterráneas netamente rupícolas, sobre cuarcitas, siempre en zonas umbrosas, que se desarrollan en grietas con acumulación de 
Tabla 2

Parietarietum judaicae K. Buchwald 1952

9-10: phagnaletosum saxatilis Vicente Orellana \& Galán de Mera subass. nova 11-14: cymbalarietosum muralis Vicente Orellana \& Galán de Mera subass. nova (Parietarietea, Parietarietalia, Parietario-Galion muralis)

\begin{tabular}{lcccccccccccccc}
\hline Inventario $\mathrm{n}^{\mathrm{o}}$ & 1 & 2 & 3 & 4 & 5 & 6 & 7 & 8 & 9 & 10 & 11 & 12 & 13 & 14 \\
Altitud $(\mathrm{Dm})$. & 59 & 63 & 87 & 85 & 87 & 46 & 46 & 76 & 46 & 46 & 46 & 46 & 63 & 46 \\
Área $\left(\mathrm{m}^{2}\right)$ & 10 & 4 & 2 & 10 & 50 & 4 & 10 & 10 & 10 & 10 & 10 & 10 & 2 & 10
\end{tabular}

Características de asociación y unidades superiores

$\begin{array}{lllllllllllllllll}\text { Parietaria judaica } & 2 & 2 & 4 & 3 & 3 & 2 & 1 & 1 & 1 & 1 & 1 & 2 & 1 & 2\end{array}$

Diferenciales de subasociación

Phagnalon saxatile

Cymbalaria muralis

Compañeras:

Mercurialis ambigua

Sedum album

Campanula erinus

Sonchus oleraceus

Umbilicus rupestris

Lamarckia aurea

Rubus ulmifolius

Fumaria muralis

Coriandrum sativum

Geranium purpureum

Otras plantas: Fraxinus angustifolia + , Fumaria officinalis + , Lactuca serriola,+ Rumex induratus 1 , Tamus communis + en 1; Brachypodium distachyon + , Carduus pycnocephalus + , Dactylis glomerata subsp. hispanica + , Hordeum murinum subsp. leporinum + , Pteridium aquilinum + en 3; Ceterach officinarum 2, Foeniculum vulgare 1, Galium verrucosum + en 4; Carlina corymbosa + , Centaurea ornata + , Centranthus calcitrapae + , Ceterach officinarum + , Convolvulus arvensis,+ Cynosurus effusus + , Dactylis glomerata subsp. hispanica + , Hypochaeris radicata + , Origanum virens 1 , Petrorhagia dubia + , Polypodium cambricum 2, Rumex induratus + , Umbilicus gaditanus + , Vulpia geniculata 1 en 5; Bromus diandrus + en 6; Galium aparine +, Papaver dubium +, Valerianella carinata +, Veronica arvensis 1en 7; Chenopodium murale 1, Chenopodium opulifolium 1, Chenopodium vulvaria 2, Geranium rotundifolium ,+ Heliotropium europaeum + , Lactuca viminea + , Lamium amplexicaule + , Malva sylvestris 1, Polycarpon tetraphyllum +, Silene nocturna + en 8 ; Anthemis arvensis 1, Echium plantagineum +, Fumaria agraria 1, Linaria spartea 1, Raphanus raphanistrum 1, Rumex bucephalophorus 1 en 9; Diplotaxis catholica 1, Fumaria agraria 1, Matricaria chamomilla + en 10; Linaria spartea + , Stellaria media 2 en 11; Freesia sp. 3, Hordeum murinum subsp. leporinum 1, Veronica cymbalaria + en 12; Fumaria officinalis + en 13; Bromus matritensis 2, Desmazeria rigida +, Galium parisiense 1 en 14.

Localidades: 1: Escusa, Marvão, (Alto Alentejo, Portugal) 29SPD3763. 2, 13: Carreiras (Alto Alentejo, Portugal) 29SPD3461. 3-5: Marvão (Alto Alentejo, Portugal) 29SPD3962. 6, 7, 9, 10, 11, 14: Logrosán (Cáceres, España) 30STJ8557. 8: Castelo de Vide (Alto Alentejo, Portugal) 29SPD3364. 12: Jardim, Marvão (Alto Alentejo, Portugal) 29SPD3861. 
Tabla 3

\begin{tabular}{|c|c|c|c|c|c|c|c|c|c|}
\hline \multicolumn{10}{|c|}{$\begin{array}{c}\text { Sileno acutifoliae-Dianthetum lusitani Vicente Orellana \& Galán de Mera ass. nova } \\
\text { (Phagnalo-Rumicetea, Phagnalo-Rumicetalia, Rumici-Dianthion) }\end{array}$} \\
\hline Inventario $\mathrm{n}^{\mathrm{o}}$ & 1 & 2 & 3 & 4 & 5 & 6 & 7 & 8 & 9 \\
\hline Altitud (m.) & 770 & 770 & 770 & 770 & 770 & 770 & 765 & 780 & 755 \\
\hline Área $\left(\mathrm{m}^{2}\right)$ & 10 & 10 & 10 & 10 & 10 & 10 & 4 & 10 & 10 \\
\hline \multicolumn{10}{|c|}{ Características de asociación y unidades superiores } \\
\hline Silene acutifolia & 3 & 2 & 3 & 4 & 3 & 3 & 2 & 2 & 3 \\
\hline Dianthus lusitanus & 1 & 1 & 1 & 1 & 1 & 1 & 1 & 1 & + \\
\hline Conopodium capillifolium & 1 & 1 & 1 & + & + & + & + & . & . \\
\hline Digitalis thapsi & . & . & . & . & . & . & . & 1 & + \\
\hline \multicolumn{10}{|l|}{ Compañeras } \\
\hline Sedum brevifolium & 1 & + & + & + & + & + & 1 & 1 & + \\
\hline Arrhenatherum elatius subsp. sardoum & + & 1 & + & 1 & + & 1 & + & + & 1 \\
\hline Hypochaeris radicata & + & + & 1 & 1 & + & 1 & + & + & . \\
\hline Sedum hirsutum & + & 1 & 2 & 2 & 1 & 2 & + & . & + \\
\hline Umbilicus rupestris & 2 & + & + & 1 & + & 1 & 2 & . & + \\
\hline Armeria $x$ francoi & + & + & + & + & + & + & + & . & . \\
\hline Musgos & 2 & 2 & + & 1 & 2 & 1 & . & . & . \\
\hline Micropyrum patens & 1 & + & + & 2 & + & + & . & . & . \\
\hline Digitalis purpurea & . & . & + & + & . & + & 1 & + & 1 \\
\hline Corrigiola litoralis subsp. perez-larae & . & . & 1 & 1 & . & + & . & . & . \\
\hline
\end{tabular}

Otras plantas: Rumex acetosella subsp. angiocarpus 1 en 1; Polypodium cambricum 1 en 2; Polypodium cambricum + , Pteridium aquilinum 1 en 3; Rumex acetosella subsp. angiocarpus 2 en 4; Quercus pyrenaica $(\mathrm{pl})+$ en 5; Pterid ${ }^{\wedge}$ wm aquilinum,+ Quercus pyrenaica 1 en 6; Agrostis truncatula 1, Calluna vulgaris 1, Micropyrum tenellum + en 8; Asplenium billotii +, Micropyrum tenellum + en 9.

Localidades: 1-6: Srra. de Carreiras (Alto Alentejo, Portugal) 29SPD3362. 7 y 9: Penha dos Corvas, Srra. Carreiras (Alto Alentejo, Portugal) 29SPD3560. 8: Ntra. Sra. da Penha, Castelo de Vide (Alto Alentejo, Portugal) 29SPD3263.

materia orgánica, donde domina Silene acutifolia acompañada de numerosos briófitos, Dianthus lusitanus y otras plantas rupícolas, siendo especialmente significativa la escasa presencia de Digitalis thapsi y la presencia de Digitalis purpurea, lo que la diferenciaría de otras comunidades similares del Sistema Central. Sólo se ha encontrado en la Serra de San Mamede (Portugal).

Feruletum communis Vicente Orellana \& Galán de Mera ass. nova

[Tabla 4, holotypus ass. inv. 8]

Herbazales que se desarrollan a finales de la primavera, dominados por la "cañayerra" -Ferula communis- que va acompañada de otras plantas que requieren humedad edáfica. Se sitúan en cunetas, linderos y fincas con suelos muy nitrogenados por la ganadería bovina, generalmente en contacto con las orlas espinosas (Rubus ulmifolius, Lonicera peryclimenum subsp. hispanica, Aristolochia paucinervis), y con bosques mesosupramediterráneos propios de ombroclima seco-subhúmedo (encinares, alcornocales, melojares); frecuentemente se ve favorecida por los incendios. Debido a su asentamiento en suelos húmedos junto a zarzales y bosques, aparece acompañada de plantas de 
Tabla 4

\begin{tabular}{|c|c|c|c|c|c|c|c|c|c|c|c|c|c|c|c|c|}
\hline \multicolumn{17}{|c|}{$\begin{array}{c}\text { Feruletum communis Vicente Orellana \& Galán de Mera ass. nova } \\
\text { (Artemisietea, Agropyretalia, Hyperico-Ferulion) }\end{array}$} \\
\hline Inventario $\mathrm{n}^{\circ}$ & 1 & 2 & 3 & 4 & 5 & 6 & 7 & 8 & 9 & 10 & 11 & 12 & 13 & 14 & & 16 \\
\hline Altitud (Dm.) & 44 & 44 & 47 & 55 & 55 & 55 & 55 & 43 & 45 & 45 & 45 & 44 & 43 & 44 & 44 & 44 \\
\hline Área $\left(\mathrm{m}^{2}\right)$ & 50 & 50 & 10 & 10 & 10 & 10 & 10 & 50 & 50 & 50 & 50 & 50 & 50 & 50 & 50 & 50 \\
\hline \multicolumn{17}{|c|}{ Características de asociación y alianza } \\
\hline Ferula communis & 1 & 1 & + & 1 & + & + & 2 & 2 & 1 & + & + & + & 1 & + & 1 & \\
\hline Andryala integrifolia & 1 & 2 & 2 & 1 & + & + & + & + & 2 & 2 & 1 & 2 & 1 & 1 & 2 & 1 \\
\hline Hypericum perforatum & + & 2 & 2 & + & 1 & 1 & & 2 & 2 & + & + & 2 & 1 & + & + & 1 \\
\hline Ammi majus & 1 & 3 & 2 & 2 & 3 & 2 & 1 & 2 & & + & . & 2 & 2 & 1 & 2 & + \\
\hline Verbascum pulverulentum & . & + & + & . & . & . & + & 1 & + & . & . & . & & 1 & + & + \\
\hline Scabiosa atropurpurea & + & . & . & . & . & & . & . & + & + & + & 1 & + & & & + \\
\hline Senecio jacobea & . & . & . & . & . & 1 & . & . & + & . & . & . & + & + & + & + \\
\hline Rumex crispus & . & . & $\dot{+}$ & . & & . & & . & . & . & . & $\dot{+}$ & & . & . & . \\
\hline Malva althaeoides & & & . & . & 1 & 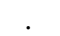 & 1 & . & . & . & . & . & & . & . & . \\
\hline \multicolumn{17}{|c|}{ Características de unidades superiores } \\
\hline Daucus carota & + & + & . & . & . & + & + & 1 & 1 & + & + & 1 & & + & + & . \\
\hline Galium aparine & + & . & . & . & . & . & . & . & . & + & . & 1 & & . & . & . \\
\hline Compañeras: & & & & & & & & & & & & & & & & \\
\hline Coleostephus myconis & 2 & 2 & 2 & 1 & 2 & 1 & 2 & 2 & + & 1 & 1 & 2 & 2 & 1 & 1 & + \\
\hline Avena sterilis & 1 & 1 & 2 & 3 & 1 & 2 & 2 & + & 2 & + & 1 & 1 & 3 & 3 & 2 & 2 \\
\hline Rubus ulmifolius & + & 2 & . & 2 & 1 & 2 & + & + & 1 & 1 & . & 2 & & 1 & 2 & 2 \\
\hline Hordeum leporinum & + & 1 & . & 1 & 1 & + & + & + & . & + & + & 2 & 1 & 2 & 2 & 2 \\
\hline Campanula rapunculus & & + & $\dot{+}$ & + & 1 & 1 & . & . & $\dot{+}$ & + & + & + & 2 & 1 & + & 1 \\
\hline Galactites tomentosa & 2 & . & + & . & + & + & . & . & 1 & 1 & + & 2 & 1 & + & . & + \\
\hline Convolvulus arvensis & + & 1 & . & . & 1 & + & . & & & + & + & + & 1 & + & + & 1 \\
\hline Holcus lanatus & + & 1 & . & . & . & . & . & + & 3 & 1 & 4 & 3 & 3 & 3 & 2 & 3 \\
\hline Cynosurus elegans & & + & + & . & . & . & + & & 1 & + & + & + & + & + & . & + \\
\hline Tolpis barbata & 1 & . & 2 & + & + & . & + & + & 1 & 1 & 1 & 1 & & & & . \\
\hline Aegilops ovata & + & + & . & . & . & & & & 1 & 1 & 2 & 2 & 1 & 1 & 2 & + \\
\hline Medicago polymorpha & & 2 & . & $\dot{+}$ & $\dot{+}$ & & 2 & 1 & . & . & & & 2 & 2 & 2 & + \\
\hline Lolium rigidum & 2 & + & . & . & . & & . & & . & + & 3 & 1 & 2 & 1 & 2 & 1 \\
\hline Origanum virens & . & + & + & + & . & + & . & + & . & . & . & . & + & + & + & 1 \\
\hline Bromus diandrus & & . & & & & & . & & . & . & & & + & + & + & + \\
\hline Dactylis hispanica & + & . & 1 & + & + & + & . & & . & . & + & 1 & & . & . & . \\
\hline Trifolium angustifolium & + & . & . & 1 & . & . & . & + & + & + & 1 & + & & . & . & . \\
\hline Torilis nodosa & + & . & + & & . & & + & + & . & + & + & + & & . & . & . \\
\hline Rumex bucephalophorus & & . & 1 & 1 & 1 & + & . & & + & . & . & + & & . & . & . \\
\hline Cynara humilis & 2 & . & . & + & . & 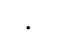 & & & 1 & + & . & + & & . & . & . \\
\hline Trifolium campestre & . & . & & . & . & & 2 & + & + & & & & 1 & . & . & . \\
\hline Briza maxima & . & . & 1 & & . & 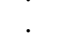 & 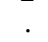 & & . & 2 & 1 & 1 & & . & . & . \\
\hline Trifolium arvense & . & . & . & 1 & & & + & + & + & . & . & . & & . & . & . \\
\hline Echium plantagineum & . & . & . & + & 1 & + & + & & . & . & . & . & & . & . & . \\
\hline Vicia villosa & & . & & . & . & . & 2 & 2 & . & . & . & . & & . & . & . \\
\hline Tordylium maximum & + & . & + & . & . & & . & 1 & . & . & . & & & . & . & . \\
\hline Melica magnolii & 1 & . & . & & & & . & & . & + & . & 1 & & . & . & \\
\hline Vicia benghalensis & . & . & . & 1 & + & + & . & & & & & . & & . & . & . \\
\hline Agrostis castellana & . & . & . & . & . & . & . & . & 3 & 3 & 2 & . & . & . & . & . \\
\hline Crataegus monogyna & . & . & + & + & . & & . & & . & + & . & . & . & . & . & . \\
\hline
\end{tabular}

Otras plantas: Crepis capillaris,+ Crepis vesicaria,+ Linaria spartea,+ Quercus pyrenaica $(\mathrm{pl})+$ Rumex pulcher + , Silene latifolia + en 3; Avena barbata s.str. +, Hypochaeris glabra + , Parentucellia viscosa + en 4; Avena barbata s.str. + en 5; Asparagus acutifolius + en 7; Anchusa azurea +, Crepis capillaris 1 en 8; Parentucellia viscosa + en 9; Ononis spinosa + , Quercus pyrenaica + en 10; Bromus hordeaceus + , Mentha suaveolens + en 11; Bromus hordeaceus 1 , Plantago lanceolata + , Rumex pulcher + , Sonchus oleraceus + en 12; Rumex induratus + en 13.

Localidades: 1, 2, 8, 12-16: Los Cercones, Logrosán (Cáceres, España) 30STJ8658. 3: Cabeça, Carreiras (Alto Alentejo, Portugal) 29SPD3359. 4-7: Srra. de Urra, Castelo de Vide (Alto Alentejo, Portugal) 29SPD3563. 9-11: Estación Ferrocarril, Logrosán (Cáceres, España) 30STJ8657. 
pastizales (Holcus lanatus, Dactylis glomerata subsp. hispanica, Crepis capillaris, Avena sterilis, Parentucellia viscosa) y de herbazales de orlas boscosas (Origanum virens, Campanula rapunculus, Lamium bifidum, Silene latifolia, Tordylium maximum).

De momento conocemos su areal de las provincias Carpetano-Ibérico-Leonesa y Luso-Extremadurense.

La ecología tan especial y la composición florística de esta asociación mediterránea occidental ibérica, nos permite incluirla en la alianza Hyperico perforatiFerulion communis Vicente Orellana \& Galán de Mera all. nova (Tabla 4, holotypus: Feruletum communis Vicente Orellana \& Galán de Mera ass. nova)[características: Ammi majus, Andryala integrifolia, Hypericum perforatum, Ferula communis, Verbascum pulverulentum, Daucus carota, Scabiosa atropurpurea, Senecio jacobea, Malva althaeoides, Rumex crispus], geovicaria del Dauco-Melilotion Görs ex Oberdorfer et al. 1967 eurosiberiano con la que comparte plantas como Picris echioides y Daucus carota.

Raphano raphanistri-Diplotaxietum catholicae Vicente Orellana \& Galán de Mera ass. nova

[Tabla 5, holotypus ass. inv. 1]

Estos herbazales nitrófilos que se desarrollan desde mediados de invierno a principios de primavera, sobre suelos arenolimosos, son bastante comunes en la provincia Luso-Extremadurense, alcanzando también los términos occidentales de la provincia Carpetano-Ibérico-Leonesa. Están caracterizados sobre todo por la fuerte presencia de Diplotaxis catholica, de temprana aparición (desde noviembre hasta abril), a la que posteriormente se les van uniendo otras plantas como Raphanus raphanistrum y Calendula arvensis (desde febrero-finales de abril). Este nuevo pastizal que hemos encontrado en ambas zonas de estudio, se desarrolla habitualmente en áreas de vegetación potencial del encinar, especialmente en cultivos abandonados, siendo sustituido sinfenológicamente por otros pastizales nitrófilos (desde mediados a finales de la primavera) bien distintos, especialmente aquellos dominados por Coleostephus myconis, Chrysanthemum segetum o Galactites tomentosa.

\section{Rumici angiocarpi-Coleostephetum} myconis Vicente Orellana \& Galán de Mera ass. nova

[Tabla 6, holotypus ass. inv. 4]

El abandono de los cultivos en zonas de encinares (Pyro-Quercetum rotundifoliae) y melojares (Arbuto-Quercetum pyrenaicae) permite la instalación de este pastizal subnitrófilo, con muchas gramíneas (Aegilops geniculata, Avena sterilis, Bromus diandrus, B. hordeaceus, Lolium rigidum, Vulpia ciliata) y donde Coleostephus myconis se hace dominante. Además aparece caracterizada por Daucus crinitus, Jasione montana subsp. echinata y Rumex acetosella subsp. angiocarpus. Coleostephus myconis es una Asterácea que se distribuye en toda la Cuenca Mediterránea (Heywood, 1984), aunque parece más frecuente en el oeste (Grierson, 1975), lo que nos puede dar una idea de su importancia en el paisaje derivado de la influencia humana. Rumex acetosella subsp. angiocarpus, ampliamente distribuido por el SO de Europa y N de Africa (López González, 1990), muestra una gran fidelidad por los suelos areno-limosos asociándose a C. myconis. Este conjunto de características que diferencian a esta comunidad nos permiten describir esta nueva asociación, típicamente luso-extremadurense mesomediterránea, que está presente en ambos territorios estudiados. En la tabla 7 recogemos las comparación con otras 
Tabla 5

Raphano raphanistri-Diplotaxietum catholicae Vicente Orellana \& Galán de Mera ass. nova (Stellarietea, Aperetalia spicae-venti, Scleranthion annui)

$\begin{array}{lccccccccc}\text { Inventario } \mathrm{n}^{\mathrm{o}} & 1 & 2 & 3 & 4 & 5 & 6 & 7 & 8 & 9 \\ \text { Altitud }(\mathrm{m} .) & 500 & 470 & 470 & 470 & 480 & 460 & 465 & 475 & 480 \\ \text { Área }\left(\mathrm{m}^{2}\right) & 50 & 100 & 50 & 50 & 50 & 50 & 50 & 50 & 50\end{array}$

Características de asociación y unidades superiores

\begin{tabular}{|c|c|c|c|c|c|c|c|c|}
\hline Diplotaxis catholica & 4 & 2 & 2 & 3 & 4 & 5 & 2 & 4 \\
\hline Raphanus raphanistrum & 2 & 1 & 1 & 1 & 1 & 1 & & 1 \\
\hline Calendula arvensis & 1 & 1 & 1 & 1 & + & 1 & & 1 \\
\hline Chamaemelum fuscatum & 3 & 4 & 3 & 3 & 1 & 1 & & 1 \\
\hline Coleostephus myconis & . & + & 1 & 3 & . & . & & . \\
\hline Erodium moschatum & 2 & . & + & . & . & 2 & & . \\
\hline Senecio vulgaris & 2 & . & . & + & + & 1 & & + \\
\hline Echium plantagineum & + & . & . & 1 & . & . & & 1 \\
\hline Chrysanthemum segetum & . & 1 & . & 1 & . & . & & . \\
\hline Sonchus oleraceus & 1 & . & . & . & . & . & & . \\
\hline Rumex acetosella subsp. angiocarpus & & . & . & . & . & . & & . \\
\hline Vicia sativa & . & 3 & . & . & . & . & & . \\
\hline Erodium cicutarium & . & . & . & 1 & . & . & & . \\
\hline \multicolumn{9}{|l|}{ Compañeras } \\
\hline Spergula arvensis & 1 & 1 & . & 1 & . & . & & . \\
\hline Trifolium repens & 1 & + & . & 1 & . & 2 & & . \\
\hline Medicago arabica & . & 1 & 1 & 2 & . & . & & . \\
\hline Geranium molle & 2 & . & + & . & . & . & & . \\
\hline Galactites tomentosa & + & . & + & . & . & . & & . \\
\hline Stachys arvensis & + & . & . & + & . & . & & . \\
\hline Poa infirma & . & 2 & + & . & . & . & & . \\
\hline
\end{tabular}

Otras plantas: Anthriscus caucalis 1, Capsella bursa-pastoris + , Cardamine hirsuta + , Lamium bifidum + , Plantago coronopus + , Solanum nigrum + , Stellaria media 1 en 1 ; Rumex crispus + en 3; Hypochaeris radicata + , Leontodon longirostris 2 , Lotus conimbricensis,+ , Plantago lagopus 1 , Tolpis barbata + , Trifolium subterraneum 1 en 4; Dactylis glomerata 1, Malva sylvestris 1, Vicia lutea + en 5; Crepis vesicaria + en 6; Carlina racemosa + , Crepis vesicaria + , Leontodon longirostris 1 en 7; Capsella bursa-pastoris + , Lamium amplexicaule + , Malva sylvestris 1, Rumex pulcher 1 en 8; Lamium amplexicaule 1, Lupinus angustifolius +, Malva sylvestris +, Poa annua +, Stellaria media 1 en 9.

Localidades: 1: Cabeça, Carreiras (Alto Alentejo, Portugal) 29SPD3359. 2-4: Zorita (Cáceres, España) 30STJ6853. 5: Herguijuela (Cáceres, España) 30STJ6261. 6: Ermita de Fuensanta, Zorita (Cáceres, España) 30STJ6655. 7: Zorita (Cáceres, España) 30STJ6652. 8: Logrosán (Cáceres, España) 30STJ8557. 9: Los Lotes, Cañamero (Cáceres, España) 30STJ9259. 
comunidades donde interviene Coleostephus myconis. Se diferencia del Anthoxantho ovati-Vulpietum geniculatae Cantó 2002 (Rivas-Martínez et al., 2002), también lusoextremadurense, por estar ésta mucho más empobrecida en plantas de Echio-Galactition y presentar elementos característicos de inundación periódica, como Anthoxanthum ovatum, Trifolium resupinatum, Geranium dissectum y Hordeum geniculatum. Por otro lado, la comunidad que cita Amor et al. (1993) como Galactito-Vulpietum geniculatae en Extremadura (tabla 7, comunidad 2), presenta especies como Rumex acetosella subsp. angiocarpus, Coleostephus myconis, Lupinus hispanicus, Brassica barrelieri, que no aparecen en la descripción originaria de Bolòs et al. (1970) en Baleares, careciendo de otras especies como Trifolium nigrescens, Medicago murex, Reichardia picroides, Lotus ornithopodioides, Urospermum dalechampii, Phalaris minor y Rostraria cristata (tabla 7, comunidad 11). Por lo que los inventarios de la comunidad de Amor et al. (1993) corresponderían a esta nueva asociación.

brassicetosum barrelieri Vicente Orellana \&

Galán de Mera subass. nova

[Tabla 6, holotypus subass. inv. 13]

Cuando estos pastizales subnitrófilos se asientan en suelos donde el horizonte superficial es arenoso, aparecen otros elementos típicos sabulícolas como Brassica barrelieri y Chaetonychia cymosa, constituyendo una subasociación, que es especialmente frecuente en zonas con vegetación potencial del encinar (PyroQuercetum rotundifoliae) portugués. No obstante y tomando los inventarios de Amor et al. (1993), creemos que está presente en toda la provincia Luso-Extremadurense.

\section{Holco setiglumis-Anthoxanthetum aristati}

Rivas Goday 1958

Pastizales que se desarrollan en suelos poco profundos o pedregosos en el dominio de encinares (Pyro-Quercetum rotundifoliae) y melojares (Arbuto-Quercetum pyrenaicae), cercanos a roquedos cuarcíticos o incluso formando praderas (Belmonte, 1986), que en nuestro territorio pueden presentar una subasociación y una variante:

sisymbrietosum officinalis Vicente Orellana

\& Galán de Mera subass. nova

[Tabla 8, holotypus subass. inv. 9]

Subasociación que se desarrolla en las dehesas de melojos (Arbuto-Quercetum pyrenaicae), en zonas de sombra o sesteo del ganado, generalmente bajo la zona de influencia de la copa de los árboles, con un notable incremento de la nitrificación, abundando determinadas especies que gustan de estas condiciones como Sisymbrium officinale, Malva nicaeensis, M. sylvestris, Carduus pycnocephalus o Erodium moschatum. Hemos encontrado esta subasociación solamente en los melojares de Las Villuercas.

Variante con Digitalis thapsi

[Tabla 8]

Variante que se desarrolla en suelos poco profundos, decapitados, formando grandes extensiones dominadas por Digitalis thapsi. Se ha constatado su presencia en ambas zonas estudiadas.

\section{Gaudinio fragilis-Agrostietum castellanae}

Rivas-Martínez \& Belmonte 1986

Vallicares y pastos de siega con gran cantidad de elementos anuales, que se desarrollan en claros de encinares (PyroQuercetum rotundifoliae) y melojares (Arbuto-Quercetum pyrenaicae), sobre suelos arenosos silíceos, empobrecidos, y con un ligero encharcamiento temporal (Rivas-Martínez \& Belmonte, 1986; Amor et al. 1993; Ladero et al. 1998). Este pastizal está dominado por Agrostis castellana, generalmente acompañada por otras gramíneas de talla media, como Gaudinia 
Tabla 6

Rumici angiocarpi-Coleostephetum myconis Vicente Orellana \& Galán de Mera ass. nova 12-14: brassicetosum barrelieri Vicente Orellana \& Galán de Mera subass. nova (Stellarietea, Thero-Brometalia, Echio-Galactition)

$\begin{array}{lcccccccccccccc}\text { Inventario } \mathrm{n}^{\mathrm{o}} & 1 & 2 & 3 & 4 & 5 & 6 & 7 & 8 & 9 & 10 & 11 & 12 & 13 & 14 \\ \text { Altitud }(\mathrm{m} .) & 610 & 610 & 405 & 650 & 400 & 500 & 410 & 650 & 610 & 610 & 480 & 490 & 490 & 485 \\ \text { Área }\left(\mathrm{m}^{2}\right) & 100 & 20 & 50 & 100 & 100 & 100 & 100 & 100 & 50 & 20 & 100 & 20 & 100 & 100 \\ \text { Características de asociación } & & & & & & & & & & & \end{array}$

Coleostephus myconis

Echium plantagineum

Rumex acetosella subsp. angiocarpus

Silene gallica

Galactites tomentosa

Avena sterilis

Trifolium angustifolium

Anagallis arvensis

Avena barbata subsp. barbata

Aegilops geniculata

Cynosurus echinatus

Vulpia ciliata

Erodium moschatum

Linaria spartea

Crepis vesicaria

Petrorhagia dubia

Trifolium stellatum

Gastridium ventricosum

Lupinus hispanicus

Diferenciales de subasociación

Brassica barrelieri

Cerastium glomeratum

Spergula arvensis

Aphanes microcarpa

Crassula tillaea

Compañeras de unidades superiores

Chamaemelum mixtum

Rumex bucephalophorus

Lolium rigidum

Raphanus raphanistrum

Malva cretica subsp. althaeoides

Calendula arvensis

Chrysanthemum segetum

Bromus diandrus

Sonchus oleraceus

Misopates orontium

Viola arvensis

Convolvulus arvensis

Bromus matritensis

Hordeum murinum subsp. leporinum

Vicia villosa

Anthemis arvensis

Chamaemelum fuscatum

Bromus hordeaceus

Sisymbrium officinale

Fumaria officinalis

Bromus sterilis

Vicia sativa

Medicago polymorpha

Papaver rhoeas

Erodium cicutarium 


\section{Compañeras}

Tolpis barbata

Leontodon taraxacoides

Ornithopus compressus

Andryala integrifolia

Vulpia myuros

Agrostis castellana

Spergularia rubra

Cistus ladanifer

Jasione montana

Hypochaeris glabra

Trifolium arvense

Dactylis glomerata

subsp. hispanica

Hypochaeris radicata

Logfia gallica

Holcus lanatus

Plantago lagopus

Brachypodium distachyon

Briza maxima

Stachys arvensis

Ornithopus pinnatus

Crepis capillaris

Campanula lusitanica

\begin{tabular}{|c|c|c|c|c|c|c|c|c|c|c|c|c|}
\hline 2 & 1 & . & 1 & 3 & 2 & 4 & 1 & . & . & . & . & . \\
\hline . & . & 1 & . & 1 & 1 & . & . & 1 & + & . & . & 1 \\
\hline . & . & . & 1 & 1 & . & 1 & . & . & + & . & 2 & 1 \\
\hline+ & . & + & . & . & + & 1 & 1 & 1 & . & . & . & . \\
\hline 3 & 2 & 1 & . & 1 & . & . & . & 3 & 3 & . & . & . \\
\hline+ & . & 1 & + & . & . & . & 1 & . & + & . & . & . \\
\hline+ & 1 & . & . & 1 & 1 & . & . & + & . & . & . & . \\
\hline 1 & + & . & . & . & . & . & 1 & + & . & . & . & . \\
\hline 1 & . & . & . & 1 & 1 & . & 1 & . & . & . & . & . \\
\hline+ & . & . & . & + & . & . & . & 1 & . & . & 1 & . \\
\hline 1 & . & . & . & . & . & 1 & . & + & . & + & . & . \\
\hline . & 2 & . & 1 & . & . & . & 2 & . & 1 & . & . & . \\
\hline . & . & 1 & . & + & . & . & . & . & . & . & . & + \\
\hline . & . & . & . & 1 & . & 1 & 1 & . & . & . & . & 1 \\
\hline+ & . & . & 1 & . & . & . & 1 & . & . & . & . & . \\
\hline . & 1 & 1 & . & . & 1 & . & . & . & . & . & . & . \\
\hline . & + & . & . & . & . & . & . & 1 & + & . & . & . \\
\hline . & . & . & 1 & . & 1 & . & 1 & . & . & . & . & . \\
\hline . & . & . & + & . & . & . & . & . & . & . & 2 & 2 \\
\hline . & . & . & . & + & . & . & . & . & . & . & 1 & 1 \\
\hline . & . & . & . & 1 & + & - & . & . & + & . & . & . \\
\hline . & . & . & . & . & . & . & + & 1 & . & 2 & . & . \\
\hline
\end{tabular}

Otras plantas: Centaurium erythraea subsp. majus 1, Daucus carota 1 , Diplotaxis virgata + , Ononis spinosa + , Reseda luteola + , Trifolium scabrum 1 en 1; Cynosurus effusus + , Daucus carota + en 2 ; Gaudinia fragilis 1, Hypericum humifusum +, Lythrum junceum 1, Mentha pulegium 1, Pulicaria paludosa 1, Senecio jacobea + , Tolpis umbellata 2, Trifolium repens 1 en 3; Briza media 1, Carlina corymbosa 1, Daucus crinitus 1, Hypericum perforatum + , Linum bienne,+ Plantago lanceolata 1 , Sherardia arvensis 1, Urginea maritima + , Verbascum pulverulentum + en 4; Agrostis pourretii + , Cistus psilosepalus + , Hymenocarpos lotoides + , Hypericum humifusum + , Plantago coronopus 1 , Sesamoides purpurascens +, Tuberaria guttata 1 en 5; Coincya monensis subsp. cheiranthos + , Hordeum vulgare 2, Rubus ulmifolius + en 6; Avena sativa 1, Galium divaricatum + , Herniaria lusitanica + , Phalaris minor + , Polycarpon tetraphyllum 1, Triticum aestivum 1 en 7; Cistus salviifolius + , Desmazeria rigida 1, Hymenocarpos lotoides + , Olea europaea 1, Polycarpon tetraphyllum + , Quercus pyrenaica + , Quercus rotundifolia + , Sesamoides purpurascens + , Tuberaria macrosepala 1 en 8; Avena sativa 2, Daphne gnidium +, Galium parisiense + , Hordeum vulgare + , Jasione montana var. montana 1 en 9; Cynosurus effusus 1, Daucus crinitus +, Galium parisiense + en 10; Carduus bourgeanus + , Lathyrus clymenum + , Olea europaea + , Rumex pulcher subsp. woodsii 1, Tordylium maximum 1, Trifolium campestre 1 en 11; Aira caryophyllea 1, Asterolinon linum-stellatum 1, Erodium botrys 1, Geranium rotundifolium + , Leontodon longirostris 3, Lotus conimbricensis + , Mibora minima 1, Plantago coronopus 1, Teesdalia coronopifolia 1, Thapsia villosa + en 12; Corrigiola litoralis subsp. perez-larae + , Juncus pygmaeus 1, Lotus conimbricensis + , Moenchia erecta subsp. erecta 1, Montia fontana + , Poa bulbosa 1, Polygonum aviculare 1, Sagina apetala 1 en 13; Allium naepolitanum +, Eruca sativa 1, Polygonum aviculare 1, Silene latifolia +, Stellaria media + en 14.

Localidades: 1, 2, 9, 10: Pto. de los Endrinares, Berzocana (Cáceres, España) 30STJ8761. 3, 6, 11: Veloso, Carreiras (Alto Alentejo, Portugal) 29SPD3559. 4, 7: Minas Srra. de San Cristóbal, Logrosán (Cáceres, España) 30STJ8556. 5: Penha dos Corvas, Srra. Carreiras (Alto Alentejo, Portugal) 29SPD3560. 8: Berzocana (Cáceres, España) 30STJ8968. 11: Estación Ferrocarril, Logrosán (Cáceres, España) 30STJ8657. 12-14: Cabeça, Carreiras (Alto Alentejo, Portugal) 29SPD3359. 


\begin{tabular}{|c|c|c|c|c|c|c|c|c|c|c|c|c|c|c|}
\hline $\mathrm{N}^{\circ}$ Comunidad & & & & & & & & & & 1 & & 1 & 1 & \\
\hline \multirow[b]{2}{*}{ Inventarios por comunidad } & 1 & 2 & 3 & 4 & 5 & 6 & 7 & 8 & 9 & 0 & 1 & 2 & 3 & 4 \\
\hline & 2 & & & & & & & & 1 & & 1 & & & 3 \\
\hline \multirow[t]{3}{*}{ Región } & $\mathrm{C}$ & 0 & 9 & 8 & 3 & 2 & t & 2 & 0 & 4 & 2 & 1 & 5 & 5 \\
\hline & $\mathrm{C}$ & $\mathrm{C}$ & $\mathrm{C}$ & $\mathrm{C}$ & B & B & $\mathrm{T}$ & $\mathrm{J}$ & $\mathrm{C}$ & B & B & B & $\mathrm{C}$ & G \\
\hline & $\mathrm{P}$ & $\mathrm{C}$ & $\mathrm{C}$ & $\mathrm{C}$ & A & A & $\mathrm{O}$ & A & A & $\mathrm{L}$ & $\mathrm{L}$ & $\mathrm{L}$ & $\mathrm{T}$ & A \\
\hline
\end{tabular}

\section{Rumici angiocarpi-Coleostephetum myconis}

Rumex acetosella subsp. angiocarpus

Jasione montana var. montana

Daucus crinitus

Centaurea paniculata subsp. castellana

Lupinus hispanicus

Brassica barrelieri

$\begin{array}{ccccc}\text { V } & \text { III } & \cdot & \cdot & \text { IV } \\ \text { II } & \text { I } & \cdot & . & \text { II } \\ \text { I } & \cdot & \cdot & \text { II } & \text { IV } \\ . & . & \cdot & \cdot & \text { V } \\ + & \text { I } & \cdot & \cdot & \cdot\end{array}$

Trifolio cherleri-Taeniatheretum gastridietosum ventricosi

Gastridium ventricosum

Ctenopsis delicatula

I II V

Coleostepho myconis-Galactitetum tomentosae

Coleostephus myconis

Medicago arabica

Bromus sterilis

Lolium multiflorum

Trifolio pallidi-Vulpietum geniculatae

Trifolium pallidum

Silene scabriflora

subsp. tuberculata

Galactito-Vulpietum geniculatae

Trifolium nigrescens

Medicago murex

Convolvulus humilis

Reichardio picroidis-Stipetum capensis

Stipa capensis

Reichardia picroides

Anthoxantho ovati-Vulpietum geniculatae

Anthoxanthum ovatum

Phalaris paradoxa

Hordeum geniculatum

Echio-Galactition

Galactites tomentosa

Echium plantagineum

Vulpia geniculata

Lotus ornithopodioides

Urospermum picroides

Phalaris minor

Urospermum dalechampii

Reichardia intermedia

$\begin{array}{rccccccccccccr}\text { IV } & \text { V } & \text { IV } & \text { II } & . & . & \text { II } & . & . & . & . & . & . & \text { IV } \\ \text { I } & . & \text { II } & \text { I } & . & . & \text { III } & . & . & . & . & . & & \text { II } \\ + & . & . & . & . & . & . & . & . & . & . & . & . & \text { II } \\ . & . & . & . & . & . & . & . & . & . & . & . & . & \text { III }\end{array}$

Referencias de las comunidades: 1 - Rumici angiocarpi-Coleostephetum myconis (Vicente Orellana, 2004); 2- Galactito-Vulpietum geniculatae (Amor et al. 1993); 3- Rumici divaricati-Galactitetum tomentosae (Belmonte, 1986); 4- Galactito-Vulpietum geniculatae (Santos et al. 1989); 5- GastridetoTrifolietum scabri (Rivas Goday, 1964); 6- Vulpio geniculatae-Trisetetum paniceae (Rivas Goday, 1964); 7- Anthoxantho ovati-Vulpietum geniculatae (Rivas-Martínez et al. 2002); 8- Galactito tomentosae-Vulpietum geniculatae (García Fuentes \& Cano Carmona, 1995); 9- Trifolio pallidiVulpietum geniculatae (Galán de Mera, 1995); 10- Reichardo picroidis-Stipetum capensis (RivasMartínez et al. 1992); 11- Galactito-Vulpietum geniculatae (Bolòs et al. 1970); 12-Galactito tomentosae-Echietum lycopsis (Bolòs \& Moliner, 1969); 13-Bromo-Galactitetum tomentosae (Bolòs et al. 1970); 14-Coleostepho myconis-Galactitetum tomentosae (Izco \& Collado, 1983).

Tabla 7. Tabla sintética comparativa de las distintas comunidades de Echio-Galactition. Abreviaturas: Badajoz (BA), Baleares (BL), Cáceres (CC), Cádiz (CA), Cataluña (CT), Galicia (GA), Jaén (JA), Portugal (P), Toledo (TO). 
fragilis, y se desarrolla sobre todo en las dehesas que se dedican a ganado bovino. agrostietosum pourretii Vicente Orellana \&

Galán de Mera subass. nova

[Tabla 9, holotypus subass. inv. 11]

Subasociación que se origina en aquellas vaguadas donde el encharcamiento es más prolongado, siendo especialmente frecuentes Agrostis pourretii y A. castellana, formando una comunidad muy característica de las dehesas extremeñas.

Armerio francoi-Arrhenatheretum sardoi Vicente Orellana \& Galán de Mera ass. nova

[Tabla 10, holotypus ass. inv. 1]

Pastizal de talla media dominado por Arrhenatherum elatius subsp. sardoum, al que acompañan otras plantas de la clase, como Agrostis castellana, Festuca ampla, y algunas occidentales como Avena barbata subsp. lusitanica, Armeria x francoi y Centaurea aristata subsp. langeana. Armeria $x$ francoi es un híbrido (Armeria beirana $\mathrm{x}$ A. transmontana) característico de la Serra da Estrela y Serra de S. Mamede (Nieto Feliner, 1990; Costa et al. 1998); Centaurea aristata subsp. langeana y Avena barbata subsp. lusitanica tienen una distribución occidental más amplia (Devesa Alcaraz, 1995; Romero Zarco, 1990). Esta comunidad, subserial del melojar (ArbutoQuercetum pyrenaicae), es muy común en los alrededores de las grandes fortalezas del territorio. Se asienta sobre suelos poco profundos y pedregosos, tal vez relacionados con la ganadería equina (Montserrat Recoder, 1975) y con una explotación originaria de la Edad Media (Lamim Vieira, 1997). Otro pastizal de características semejantes fue descrito por Teles (1970) en el sector Orensano-Sanabriense.

Festuco multispiculatae-Arrhenatheretum sardoi Vicente Orellana \& Galán de

\section{Mera ass. nova}

[Tabla 11, holotypus ass. inv. 6]

Pastizal toledano-tagano, supramediterráneo, de talla alta, que se desarrolla a principios del verano (junio-julio) en las repisas con algo de sustrato, de los afloramientos cuarcíticos venteados del Macizo de Las Villuercas y elevaciones adyacentes, donde Festuca paniculata subsp. multispiculata y Arrhenatherum elatius subsp. sardoum se hacen especialmente abundantes junto con otras gramíneas como Holcus gayanus, Agrostis castellana, Deschampsia flexuosa y Corynephorus canescens. Suelen acompañar elementos que se desarrollan en sustratos poco profundos, como Hypochaeris radicata, Jasione mariana, Conopodium capillifolium y Rumex acetosella subsp. angiocarpus. En el territorio estudiado contacta con los melojares de Arbuto-Quercetum pyrenaicae (Quercus pyrenaica, Erica arborea, Pterospartum tridentatum, Halimium ocymoides), y otras comunidades rupícolas silicícolas como Digitali-Dianthetum. La presencia de Agrostis castellana y Arrhenatherum elatius subsp. sardoum, hace que la incluyamos en la alianza AgrostioStipion, si bien es una comunidad más continental de zonas más elevadas que la descrita en Portugal con Armeria x francoi. También en la zona portuguesa encontramos una comunidad con Festuca paniculada subsp. multispiculata descrita a continuación, aunque su composición floristica y su ecología nos hace llevarla a una alianza diferente.

\section{Festuco multispiculatae-Agrostietum} curtisii Vicente Orellana \& Galán de Mera ass. nova

[Tabla 12, holotypus ass. inv. 3]

Agrostis curtisii es una gramínea ligada a las comunidades de brezales de Ericion umbellatae (Loidi et al. 2007), aunque en 
Tabla 8

\begin{tabular}{|c|c|c|c|c|c|c|c|c|c|c|}
\hline \multicolumn{11}{|c|}{$\begin{array}{l}\text { Holco setiglumis-Anthoxanthetum aristati Rivas Goday } 1958 \\
4-7: \text { var. con Digitalis thapsi } \\
\text { isymbrietosum officinalis Vicente Orellana \& Galán de Mera subass. nova } \\
\text { (Helianthemetea, Helianthemetalia, Helianthemion) }\end{array}$} \\
\hline Inventario $\mathrm{n}^{\mathrm{o}}$ & 1 & 2 & 3 & 4 & 5 & 6 & 7 & 8 & 9 & 10 \\
\hline Altitud (m.) & 645 & 500 & 780 & 500 & 500 & 500 & 750 & 782 & 783 & 950 \\
\hline Área $\left(\mathrm{m}^{2}\right)$ & 10 & 20 & 100 & 100 & 200 & 200 & 50 & 100 & 100 & 50 \\
\hline \multicolumn{11}{|c|}{ Características de asociación y unidades superiores } \\
\hline Holcus annuus & 1 & 4 & 3 & + & 1 & 1 & & 3 & 1 & 2 \\
\hline Tolpis barbata & 1 & 2 & 2 & 2 & 2 & 2 & + & 2 & + & \\
\hline Anthoxanthum aristatum & 1 & 2 & 1 & 1 & + & & . & 1 & 1 & 1 \\
\hline Vulpia myuros & & 2 & & 2 & 1 & 1 & & 1 & + & + \\
\hline Briza maxima & 1 & 2 & 1 & + & . & & 2 & 1 & . & . \\
\hline Jasione montana & 1 & 2 & 1 & 2 & & 1 & . & & . & \\
\hline Trifolium campestre & 1 & 2 & . & 1 & 1 & & & 2 & . & . \\
\hline Xolantha guttata & . & & . & 2 & 1 & 1 & + & + & . & . \\
\hline Trifolium arvense & . & 1 & & 1 & + & + & . & & . & \\
\hline Leontodon longirostris & . & 1 & 2 & & & 1 & . & 1 & . & \\
\hline Hypochaeris glabra & . & & 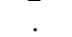 & 1 & 2 & 1 & . & . & . & + \\
\hline Rumex bucephalophorus & . & 1 & . & + & & + & . & . & . & . \\
\hline Plantago bellardii & . & . & & 3 & 2 & 3 & . & . & . & \\
\hline Campanula lusitanica & . & . & + & & 1 & + & . & . & . & . \\
\hline Ornithopus pinnatus & . & & . & 1 & . & + & . & . & . & . \\
\hline Daucus carota & . & + & . & . & . & . & . & . & . & . \\
\hline Ornithopus compressus & . & + & & . & . & . & . & . & . & . \\
\hline Linum trigynum & . & . & 1 & . & & . & . & . & . & . \\
\hline Hymenocarpos lotoides & . & . & . & . & + & & . & . & . & \\
\hline Filago pyramidata & . & . & . & . & . & 1 & . & . & . & . \\
\hline \multicolumn{11}{|l|}{ Diferenciales de subasociación } \\
\hline Sisymbrium officinale & . & . & . & . & . & . & . & 1 & 3 & 3 \\
\hline Hordeum murinum subsp. leporinum & $n$. & . & . & . & . & . & . & 1 & 3 & 4 \\
\hline Urtica urens & . & . & . & . & . & . & . & . & 2 & 2 \\
\hline Rumex pulcher subsp. woodsii & . & . & . & . & . & . & . & . & 2 & 1 \\
\hline Malva nicaeensis & . & . & . & . & . & . & . & . & 1 & 1 \\
\hline \multicolumn{11}{|l|}{ Diferenciales de variante } \\
\hline Digitalis thapsi & . & . & & 3 & 3 & 3 & 2 & & & \\
\hline Agrostis pourretii & . & . & 1 & 4 & 4 & 4 & . & 2 & . & . \\
\hline \multicolumn{11}{|l|}{ Compañeras } \\
\hline Lolium rigidum & 1 & 2 & 1 & + & & . & + & 1 & . & + \\
\hline Cynosurus effusus & 1 & 3 & 2 & . & + & & . & 2 & . & . \\
\hline Crepis capillaris & 1 & & & & + & + & + & 2 & . & . \\
\hline Vulpia ciliata & . & 1 & 2 & 1 & . & 1 & & 2 & . & \\
\hline Anthemis arvensis & & & 1 & + & . & & + & 2 & . & + \\
\hline Agrostis castellana & $\dot{2}$ & 1 & + & . & : & $\dot{+}$ & . & & . & . \\
\hline Carlina corymbosa & 1 & 1 & 1 & . & . & . & $\cdot$ & $i$ & . & . \\
\hline Andryala integrifolia & . & 1 & 1 & + & & & 1 & . & . & . \\
\hline Cistus ladanifer & . & + & & 1 & 1 & 1 & . & & . & . \\
\hline \multicolumn{3}{|l|}{ Rumex acetosella subsp. angiocarpus. } & 1 & 1 & . & + & . & 1 & . & . \\
\hline Campanula rapunculus & + & 1 & + & . & . & . & & . & . & . \\
\hline Holcus lanatus & 1 & + & . & . & . & . & 1 & . & . & . \\
\hline Dactylis glomerata subsp. hispanica & $a+$ & + & ${ }^{\circ}$ & . & . & . & + & . & . & . \\
\hline Petrorhagia dubia & 1 & . & $\dot{+}$ & $\cdot$ & & $\dot{.}$ & . & $\dot{+}$ & . & . \\
\hline Chamaemelum mixtum & 1 & & & 1 & 1 & . & . & . & . & . \\
\hline Gaudinia fragilis & . & 2 & 2 & . & 1 & . & . & $\theta_{0}$ & . & . \\
\hline Bromus matritensis & . & 1 & 1 & . & . & . & . & 3 & . & . \\
\hline Aegilops geniculata & . & 1 & 1 & & & & . & 1 & . & . \\
\hline Scolymus hispanicus & . & . & . & 1 & 1 & 1 & . & . & . & . \\
\hline Poa bulbosa & . & . & . & 1 & 1 & 2 & . & . & . & . \\
\hline Quercus rotundifolia & . & . & . & + & 1 & 1 & . & . & . & . \\
\hline Lotus hispidus & . & . & . & 1 & 1 & 1 & . & . & . & . \\
\hline Spergularia rubra & . & . & . & + & 1 & 1 & . & . & . & . \\
\hline Plantago coronopus & . & . & . & 4 & 3 & . & . & . & . & . \\
\hline
\end{tabular}


Otras plantas: Aegilops triuncialis 1, Avena sterilis + , Cistus salviifolius 2, Hypochaeris radicata + , Silene gallica + , Taeniatherum caput-medusae + , Verbascum pulverulentum + en 1; Adenocarpus complicatus +, Avena barbata subsp. barbata +, Brachypodium distachyon +, Bromus diandrus + , Chrysanthemum segetum + , Cichorium intybus + , Crepis vesicaria subsp. haenseleri + , Cytisus scoparius + , Echium plantagineum 1, Galactites tomentosa + , Galium parisiense + , Hypericum perforatum + , Lathyrus angulatus + , Linum bienne + , Parentucellia viscosa 1 , Raphanus raphanistrum + , Sanguisorba verrucosa 1, Scabiosa atropurpurea + , Taeniatherum caput-medusae + , Torilis arvensis 1, Trifolium angustifolium 1, Trifolium cherleri + , Trifolium glomeratum 2, Trifolium strictum 1 en 2; Avena barbata subsp. lusitanica 1, Bromus hordeaceus + , Bromus lanceolatus 1, Cistus salviifolius 2, Daphne gnidium 1, Gastridium ventricosum 1, Pteridium aquilinum 3, Quercus pyrenaica (pl) 2 , Quercus pyrenaica 1, Rubus ulmifolius +, Trifolium stellatum 1, Verbascum pulverulentum + en 3; Brachypodium distachyon +, Daphne gnidium +, Eryngium campestre +, Herniaria cinerea +, Leontodon taraxacoides 1, Trifolium subterraneum + en 4; Carlina racemosa 1, Eryngium campestre 1, Polycarpon tetraphyllum + , Urginea maritima 1 en 5; Carlina racemosa 1, Chrysanthemum segetum +, Herniaria cinerea 1, Trifolium glomeratum 1 en 6; Arrhenatherum elatius subsp. sardoum + , Centaurea aristata subsp. langeana 2 , Hypochaeris radicata + , Linaria triornothophora 1 , Plantago lagopus + , Plantago lanceolata + , Rubus ulmifolius + , Sesamoides purpurascens + en 7; Bromus hordeaceus + , Cerastium glomeratum 1 , Geranium molle + , Linum bienne + , Pteridium aquilinum + , Quercus pyrenaica 1, Sherardia arvensis + , Trifolium stellatum 1 en 8 ; Anacyclus clavatus 1, Bromus lanceolatus + , Capsella bursa-pastoris 1, Carduus tenuiflorus 3, Chenopodium murale 1, Erodium moschatum 1, Geranium molle 1, Malva sylvestris 1, Medicago polymorpha 1, Quercus pyrenaica joven 1 en 9; Anthriscus caucalis 2, Carduus pycnocephalus 2, Quercus pyrenaica 1 en 10.

Localidades: 1, 3, 8, 9: La Nava, Berzocana (Cáceres, España) 30STJ8664. 2, 4-6: Los Lotes, Cañamero (Cáceres, España) 30STJ9259. 7: Ntra. Sra. da Penha, Castelo de Vide (Alto Alentejo, Portugal) 29SPD3263. 10: Collado del Bote, La Nava, Berzocana (Cáceres, España) 30STJ8464.

ocasiones llega a formar pastizales, sobre todo en áreas culminícolas (Galán de Mera, 1993). Festuco multispiculatae-Agrostietum curtisii se desarrolla entre los pisos meso- y supramediterráneo inferior, con ombroclima húmedo, sobre suelos arenosos lixiviados procedentes de granitos. Son pastizales altos y laxos que están dominados por Festuca paniculata subsp. multispiculata y Agrostis curtisii, generalmente acompañados de Avenula sulcata subsp. occidentalis (endemismo occidental ibérico), y elementos de los brezales adyacentes como Halimium ocymoides, Cistus psilosepalus y Pterospartum tridentatum. Se encuentran en la Serra de San Mamede (Serra de Carreiras, Castelo de Vide y Marvão), bajo los pinares y claros de brezal, especialmente en aquellos enclaves que han sufrido numerosos incendios y rozas. Es una asociación geovicaria del Deschampsio strictaeAgrostietum curtisii aljíbico y monchiquense (Galán de Mera, 1993; Galán de Mera et al. 1997). En la tabla 13 recogemos de manera sintética los inventarios de nuestra asociación y los de otras comunidades similares conocidas en el oeste de la Península. No obstante, hay otras del norte de la Península Ibérica que por su gran diferencia florística no incluimos aquí (Honrado et al. 2004).

\section{Adenocarpion argyrophylli Vicente Orellana} \& Galán de Mera all. nova

[holotypus: Adenocarpetum argyrophylli Rivas-Martínez Cantó, Sánchez Mata \& Belmonte 2002]

Codesales luso-extemadurenses que se desarrollan sobre afloramientos rocosos de carácter ácido, pobres en flora y dominados habitualmente por Adenocarpus argyrophyllus. Precisamente es este carácter rupícola lo que nos hace pensar en una nueva alianza, diferenciándola del Genistion floridae (Belmonte, 1986; Rivas-Martínez \& Belmonte, 1987; Rivas-Martínez et al. 2002). Por tanto, en el territorio encontramos una asociación mesomediterránea 
Tabla 9

Gaudinio fragilis-Agrostietum castellanae Rivas-Martínez \& Belmonte 1986 9-12: agrostietosum pourretii Vicente Orellana \& Galán de Mera subass. nova (Stipo-Agrostietea, Agrostietalia, Agrostion castellanae)

Inventario $\mathrm{n}^{\circ}$

Altitud (m.)

$\begin{array}{llllllllllll}1 & 2 & 3 & 4 & 5 & 6 & 7 & 8 & 9 & 10 & 11 & 12\end{array}$

Área $\left(\mathrm{m}^{2}\right)$

$\begin{array}{llllllllllll}750 & 750 & 750 & 490 & 490 & 750 & 750 & 750 & 640 & 490 & 490 & 490\end{array}$

Características de asociación y unidades superiores

Agrostis castellana

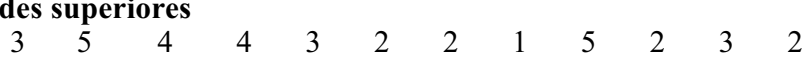

Arrhenatherum elatius subsp. sardoum

Festuca paniculata

subsp. multispiculata

Avenula sulcata subsp. occidentalis

Avena barbata subsp. lusitanica

Diferenciales de subasociación

Agrostis pourretii

Anthoxanthum aristatum

Compañeras

Hypochaeris radicata

Tolpis barbata

Andryala integrifolia

Jasione montana

Briza maxima

Vulpia geniculata

Dactylis glomerata subsp. hispanica

Aegilops geniculata

Carlina corymbosa

Xolantha guttata

Avena sterilis

Rumex acetosella subsp. angiocarpus

Lotus corniculatus

Trifolium angustifolium

Anthemis arvensis

Echium plantagineum

Rumex bucephalophorus

Daucus carota

Lolium rigidum

Galactites tomentosa

Lavandula stoechas subsp. sampaiana Anacyclus clavatus

Hypericum perforatum

Senecio jacobea

Centaurea aristata subsp. langeana

Helichrysum stoechas

Hordeum murinum subsp. leporinum

Bromus hordeaceus

Taeniatherum caput-medusae

Melica magnolii

Avena barbata subsp. barbata

Campanula rapunculus

Sesamoides purpurascens

Retama sphaerocarpa

Crepis capillaris

Thapsia villosa

Centaurium erythraea subsp. majus 
Otras plantas: Anthoxanthum odoratum 1, Campanula lusitanica + , Chamaemelum mixtum,+ Conopodium pyrenaeum + , Coronilla repanda subsp. dura 1, Crucianella angustifolia 1, Cynosurus effusus 2, Filago lutescens + , Lepidium heterophyllum 1, Linum bienne + , Logfia gallica + , Ornithopus compressus 2, Scabiosa atropurpurea +, Vicia sativa +, Vulpia myuros 1 en 1; Anthoxanthum odoratum 1, Aristolochia paucinervis 1, Bromus lanceolatus 1, Cynosurus echinatus 1, Holcus lanatus + , Quercus pyrenaica +, Trifolium campestre + en 2; Coleostephus myconis 1, Plantago lanceolata,+ Trifolium arvense + en 3 ; Scolymus hispanicus + en 4; Cytisus striatus +, Cynodon dactylon + en 5; Linaria triornothophora 1, Pteridium aquilinum + , Ulex minor + en 7; Ulex minor + en 8; Aegilops triuncialis 1, Conopodium capillifolium 1, Crucianella angustifolia + , Cynosurus echinatus 1, Chamaemelum mixtum 1, Ononis spinosa +, Trifolium campestre 2, Verbascum pulverulentum + en 9; Cytisus striatus +, Daphne gnidium +, Scolymus hispanicus + en 10; Cynodon dactylon 2 en 12.

Localidades: 1, 2: Collado del Bote, La Nava, Berzocana (Cáceres, España) 30STJ8464. 3, 6, 7, 8: Ntra. Sra. da Penha, Castelo de Vide (Alto Alentejo, Portugal) 29SPD3263. 4, 5, 10, 11, 12: Dehesa Boyal, Logrosán (Cáceres, España) 30STJ8655. 9: La Nava, Berzocana (Cáceres, España) 30STJ8664.

(Adenocarpetum argyrophylli), típica de afloramientos cuarcíticos y graníticos, que contacta con el encinar (Quercus rotundifolia, Cistus ladanifer, Cytisus multiflorus, Lavandula sampaiana), y otra nueva supramediterránea de los enclaves más altos de Montes de Toledo (GenistoAdenocarpetum argyrophylli), que altitudinalmente contacta con encinares permanentes sobre rocas y con escobonales (Erica arborea, Genista cinerascens, Cytisus scoparius) y sus pastizales subseriales (Festuca paniculada subsp. multispiculata). Ambas asociaciones, por su carácter rupícola van acompañadas por otros elementos de asociaciones que comparten una ecología similar, como Dianthus lusitanus, Digitalis thapsi, Sedum hirsutum, Sedum brevifolium. Son especies características de la alianza: Adenocarpus argyrophyllus y Genista cinerascens.

\section{Genisto cinerascentis-Adenocarpetum} argyrophylli (Rivas-Martínez, Cantó, Sánchez-Mata \& Belmonte) Vicente Orellana \& Galán de Mera stat. nov.

[Bas.: Adenocarpetum argyrophylli genistetosum cinerascentis Rivas-Martínez, Cantó, Sánchez Mata \& Belmonte in Itinera Geobot. 15(1): 30 (2002)]

Codesales supramediterráneos toledano-taganos, que se desarrollan sobre afloramientos cuarcíticos por encima de los $1300 \mathrm{~m}$, dominados por Adenocarpus argyrophyllus. Suelen estar acompañados por elementos típicos de estas zonas altas, como Genista cinerascens, y elementos del pastizal culminícola, como Arrhenatherum elatius subsp. sardoum, Festuca paniculata subsp. multispiculata y Holcus gayanus, o especies típicamente rupícolas como Dianthus lusitanus y Sedum brevifolium. Es por ello que pensamos que esta comunidad tiene entidad suficiente como para ser considerada una nueva asociación de carácter supramediterráneo y enclaves culminícolas, en vez de otros rangos como indican otros autores (Ladero, 1970b; Rivas-Martínez et al. 2002). Además, en puntos muy localizados aparece con Echinospartum ibericum, elemento muy escaso en los Montes de Toledo y que crece siempre en zonas muy altas y venteadas, constituyendo una nueva subasociación.

echinospartetosum iberici Vicente Orellana

\& Galán de Mera subass. nova

[Tabla 14, holotypus subass. inv. 13]

Comunidades supramediterráneas toledano-taganas de Adenocarpus argyrophyllus que puntualmente van acompañadas por Echinospartum ibericum, en fisuras de cresteríos cuarcíticos de las 
Tabla 10

Armerio francoi-Arrhenatheretum sardoi Vicente Orellana \& Galán de Mera ass. nova (Stipo-Agrostietea, Agrostietalia, Agrostio-Stipion)

$\begin{array}{lccccccc}\text { Inventario } \mathrm{n}^{\mathrm{o}} & 1 & 2 & 3 & 4 & 5 & 6 & 7 \\ \text { Altitud }(\mathrm{m} .) & 835 & 785 & 840 & 835 & 868 & 833 & 710 \\ \text { Área }\left(\mathrm{m}^{2}\right) & 100 & 50 & 100 & 50 & 200 & 20 & 25\end{array}$

Características de asociación y unidades superiores Arrhenatherum elatius subsp. sardoum Armeria $x$ francoi Agrostis castellana Festuca ampla subsp. ampla Avena barbata subsp. lusitanica Andryala integrifolia

Festuca paniculata subsp. multispiculata Agrostis truncatula Agrostis curtisii

\section{Compañeras}

Crucianella angustifolia

Dactylis glomerata subsp. hispanica

Cynosurus effusus

Carlina corymbosa

Bromus diandrus

Torilis arvensis

Rumex acetosella subsp. angiocarpus

Tolpis barbata

Campanula lusitanica

Crepis capillaris

Leontodon taraxacoides

Centranthus calcitrapae

Hypochaeris radicata

Briza maxima

Vulpia geniculata

Pteridium aquilinum

Convolvulus arvensis

$\begin{array}{lllllll}3 & 4 & 3 & 2 & 4 & 3 & 4 \\ 1 & 2 & 2 & 2 & 3 & 1 & 2 \\ 1 & 1 & 3 & 3 & 2 & 2 & . \\ 2 & 2 & 2 & 2 & 2 & . & . \\ 4 & 3 & 4 & 2 & . & 3 & . \\ . & + & + & + & 1 & . & . \\ . & . & . & . & . & + & . \\ . & . & . & . & . & . & 1 \\ . & . & . & . & . & . & +\end{array}$

Otras plantas: Chamaemelum mixtum + , Trifolium stellatum 1 en 1 ; Allium pallens + , Anthoxanthum aristatum 2, Aristolochia paucinervis 1, Centaurea aristata subsp. langeana 1, Daucus carota + , Fraxinus angustifolia (p1.) +, Vulpia myuros 1 en 2; Chamaemelum mixtum +, Cytisus striatus +, Dianthus lusitanus + , Digitalis thaps + , Vicia villosa + en 3; Allium sphaerocephalon + , Rosmarinus officinalis 1 en 4; Aristolochia paucinervis 1, Carex divisa + , Holcus annuus + , Holcus lanatus 1, Hypericum perforatum 1, Melica magnolii + , Origanum virens 1 , Plantago lanceolata + , Rumex bucephalophorus + , Stachys germanica 1, Vicia benghalensis + , Vicia peregrina + en 5; Centaurea ornata + , Chamaemelum fuscatum + , Cytisus multiflorus , Daucus carota 1, Lolium rigidum 1, Paronychia argentea + , Sedum album + , Silene colorata + , Trifolium stellatum + , Trifolium strictum + en 6; Anthemis arvensis +, Cistus ladanifer + , Digitalis purpurea 1, Narcissus bulbocodium + en 7.

Localidades: 1-6: Marvão (Alto Alentejo, Portugal) 29SPD3962. 7: Srra. de Carreiras (Alto Alentejo, Portugal) 29SPD3362. 
Tabla 11

Festuco multispiculatae -Arrhenatheretum sardoi Vicente Orellana \& Galán de Mera ass. nova (Stipo-Agrostietea, Agrostietalia, Agrostio-Stipion)

\begin{tabular}{lrrrrrrrr}
\hline Inventario $\mathrm{n}^{\mathrm{o}}$ & 1 & 2 & 3 & 4 & 5 & 6 & 7 & 8 \\
Altitud (Dm.) & 158 & 158 & 153 & 130 & 129 & 131 & 153 & 158 \\
Área $\left(\mathrm{m}^{2}\right)$ & 25 & 25 & 10 & 20 & 50 & 20 & 25 & 20
\end{tabular}

Características de asociación y unidades superiores Festuca paniculata subsp. multispiculata Arrhenatherum elatius subsp. sardoum Corynephorus canescens Agrostis catellana Deschampsia flexuosa

Holcus gayanus

Anthoxanthum ovatum

\section{Compañeras}

Rumex acetosella subsp. angiocarpus

Jasione mariana

Dianthus lusitanus

Hypochaeris radicata

Conopodium capillifolium

Poa bulbosa

Erica arborea

$\begin{array}{cccccccc}2 & 3 & 2 & 3 & 1 & 3 & + & + \\ 1 & 2 & 4 & 4 & 3 & 2 & 4 & 3 \\ 1 & 2 & 1 & . & . & 1 & 1 & + \\ 1 & 1 & 1 & . & 4 & 1 & 2 & . \\ + & . & + & . & . & . & 1 & 1 \\ . & . & . & . & . & 2 & . & 1 \\ . & . & + & . & . & . & 1 & .\end{array}$

Otras plantas: Sedum brevifolium + en 1; Quercus pyrenaica + en 2; Umbilicus rupestris + en 3; Andryala integrifolia,+ Briza maxima + , Coincya monensis subsp. cheiranthos 2, Digitalis purpurea +, Koeleria crassipes 1, Micropyrum tenellum + en 4; Asphodelus albus +, Avenula sulcata subsp. sulcata 1, Briza maxima 1, Cynosurus effusus 1 , Pterospartum tridentatum,+ Halimium ocymoides + , Petrorrhagia dubia +, Quercus pyrenaica + en 5; Vulpia myuros + en 7.

Localidades: 1, 2, 3, 7: Pico de Las Villuercas, Guadalupe (Cáceres, España) 30STJ9371. 4-5: Cancho Redondo, Navalvillar de Ibor (Cáceres, España) 30STJ9683. 6, 8: Collado del Turuñuelo, La Calera (Cáceres, España) 30SUJ0379.

Sierras de Las Villuercas muy expuestas al viento. Su fisionomía y la composición florística son muy diferentes a las comunidades que encontramos en zonas altas del Sistema Central (Sánchez-Mata, 1989; Rivas-Martínez et al. 2000; Jansen, 2002), o los enebrales del centro de la Península (Cano et al. 2007), por lo que pensamos más apropiado tratarla como subasociación.

Rubetum ulmifolio-vigoi Vicente Orellana \& Galán de Mera ass. nova

[Tabla 15, holotypus ass. inv. 8]

Asociación de zonas montanas que se desarrolla sobre suelos muy arcillosos, que forma la orla de los claros de melojar (Arbuto-Quercetum pyrenaicae). Rubus vigoi R. Roselló, Peris \& Stübing $(=R$. weberanus Monasterio-Huelin) es una especie descrita recientemente, que se distribuye por la mitad norte de la Península Ibérica (MonasterioHuelin in Castroviejo, 1998). Se diferencia claramente de Rubus ulmifolius por sus flores con pétalos blancos, turiones rojos, glabros y arqueados, aguijones rectos, y es caducifolio. Florece a finales de julio y fructifica a finales de septiembre y principios de octubre, presentando una polidrupa menos numerosa pero casi el doble de grande que la de Rubus ulmifolius. En la provincia Luso- 
Extremadurense conocemos citas tanto de Extremadura (Devesa Alcaraz, 1995; Rivas Goday, 1964 como Rubus rhombifolius), como de Portugal (Monasterio-Huelin, 1.c.) correspondientes al macizo de Las Villuercas y la Beira Baixa respectivamente; sin embargo no conocíamos datos fitosociológicos. También tenemos constancia de que por el sur llega hasta el Valle de Alcudia. Esta comunidad, casi monoespecífica, está dominada por Rubus vigoi, al que suele acompañar Rubus ulmifolius, y alguna otra espinosa, aunque con presencia mucho más baja (Rosa canina, Rosa corymbifera, Crataegus monogyna, Prunus spinosa). Como compañeras pueden aparecer diferentes especies del melojar adyacente y de sus pastos (Quercus pyrenaica, Castanea sativa, Cytisus scoparius, Cytisus striatus, Cistus psilosepalus, Arrhenatherum elatius subsp. bulbosum, Arrhenatherum elatius subsp sardoum, Satureja vulgaris subsp. arundana, Bromus sterilis, Bromus diandrus, Origanum virens).

Rubetum ulmifolio-caesii Vicente Orellana \& Galán de Mera ass. nova

[Tabla 16, holotypus ass. inv. 3]

Comunidad de zarzales mesosupramediterránea, que se desarrolla bajo las alisedas montanas del territorio (ScrophularioAlnetum glutinosae), en gargantas estrechas con un ambiente muy umbrío, dominada por Rubus caesius, al que acompañan Rubus ulmifolius y Rosa corymbifera, enredaderas (Tamus communis, Lonicera peryclimenum subsp. hispanica, Hedera helix), plantas nemorales (Anthryscus sylvestris, Teucrium scorodonia, Geranium robertianum subsp. purpureum, Geum urbanum, Lapsana communis, Senecio sylvaticus) y nitrófilas (Urtica dioica, Sonchus oleraceus). Al constituir orla de la aliseda, también aparecen elementos característicos de la misma, como Alnus glutinosa, otras especies arbóreas típicas de estos bosques de ribera (Populus alba, Populus nigra, Salix alba) y de bosques cercanos (Quercus broteroi, Pyrus bourgaeana, Castanea sativa). Su fenología es muy tardía, típicamente estival, comenzando su floración a mediados de julio. En el momento en que estas alisedas son aclaradas, este zarzal es sustituido por otro tipo de comunidades con mayor carácter heliófilo, siendo lo más frecuente el zarzal de Lonicero-Rubetum. De momento hemos contrastado su areal toledano-tagano, aunque no descartamos su presencia en otros territorios occidentales.

\section{Pyro bourgeanae-Securinegetum tinctoriae,} variante con Quercus rotundifolia

[Tabla 17]

Son los tamujares luso-extremadurenses que se desarrollan en los márgenes y en los propios cauces de los ríos con curso irregular. Estos ríos y arroyos sufren grandes avenidas en las épocas de lluvias y prolongadas sequías en los meses calurosos (Rivas Goday, 1964; Pérez Chiscano, 1994; López Sáez \& Velasco Negueruela, 1995). En las zonas de relieve plano donde las inundaciones son periódicas (al menos una vez cada año), se acumulan limos, lo que permite que algunas especies del encinar penetren en el tamujar, especialmente la propia encina, constituyendo una variante del tamujar (Vicente Orellana \& Galán de Mera, 2003).

\section{Poterio agrimonioidis-Quercetum suberis quercetosum pyrenaicae Vicente} Orellana, Pérez Latorre, Cabezudo \& Galán de Mera subass. nova

[Tabla 18, holotypus subass. inv. 10]

En las zonas más altas del alcornocal $(700 \mathrm{~m})$, donde el suelo es menos arcilloso, más profundo y se registran temperaturas más suaves por aumento de nieblas o mayores precipitaciones, Quercus pyrenaica empieza a hacerse presente, constituyendo una subasociación del alcornocal luso- 
Tabla 12

Festuco multispiculatae-Agrostietum curtisii Vicente Orellana \& Galán de Mera ass. nova (Stipo-Agrostietea, Agrostietalia, Festucion elegantis)

\begin{tabular}{lcccccccc}
\hline Inventario $\mathrm{n}^{\mathrm{o}}$ & 1 & 2 & 3 & 4 & 5 & 6 & 7 & 8 \\
Altitud $(\mathrm{m})$. & 545 & 650 & 595 & 605 & 625 & 525 & 600 & 750 \\
Área $\left(\mathrm{m}^{2}\right)$ & 10 & 25 & 20 & 20 & 100 & 50 & 100 & 50
\end{tabular}

Características de asociación y unidades superiores

Agrostis curtisii

Festuca paniculata

subsp. multispiculata

Avenula sulcata subsp. occidentalis

Arrhenatherum elatius subsp. sardoum

Agrostis castellana

Stipa gigantea

Armeria $x$ francoi

\section{Compañeras}

Cistus psilosepalus

Rumex acetosella subsp. angiocarpus

Hypochaeris radicata

Ulex minor

Andryala integrifolia

Briza maxima

Pteridium aquilinum

Thapsia villosa

Pterospartum tridentatum

$\begin{array}{llllllll}3 & 3 & 2 & 4 & 3 & 3 & 1 & . \\ 2 & 1 & 2 & . & . & . & . & 1 \\ . & . & 1 & 2 & + & . & . & 1 \\ . & . & . & . & 4 & + & 4 & + \\ + & . & . & . & . & 2 & . & 1 \\ . & . & . & . & 1 & . & . & . \\ . & . & . & . & + & . & . & .\end{array}$

Otras plantas: Cynosurus echinatus + , Holcus lanatus 2, Rubus ulmifolius + , Senecio vulgaris 1, Senecio vulgaris 1 en 1; Erica australis + , Halimium ocymoides + , Pedicularis sylvatica subsp. lusitanica +, Quercus pyrenaica (pl.) + en 2; Anarrhinum bellidifolium +, Lepidophorum repandum 1, Lithodora prostrata subsp. lusitanica 1, Pinus pinaster + en 3; Cistus crispus 1, Cistus ladanifer +, Cytisus striatus + , Daucus carota + , Plantago lagopus + , Tolpis barbata + en 4; Asphodelus albus subsp. albus +, Cistus crispus 1, Dianthus lusitanus 1, Halimium ocymoides 1, Holcus lanatus +, Jasione montana 1, Lavandula stoechas subsp. sampaiana + , Pinus radiata + , Quercus rotundifolia + en 5; Chamaemelum mixtum +, Molinia caerulea subsp. caerulea 1, Pedicularis sylvatica subsp. lusitanica + , Polygala microphylla + , Rubus ulmifolius + , Senecio vulgaris 1 , Spergularia rubra + en 6; Castanea sativa + , Cistus salviifolius + , Digitalis purpurea + , Erica australis,,+ Helichrysum stoechas + , Leontodon taraxacoides 1, Quercus suber + en 7; Centaurea aristata subsp. langeana + , Linaria triornothophora + , Tolpis barbata + en 8.

Localidades: 1, 2, 4-7: Srra. de Carreiras (Alto Alentejo, Portugal) 29SPD3362. 3: Srra. de Urra, Castelo de Vide (Alto Alentejo, Portugal) 29SPD3563. 8: Ntra. Sra. da Penha, Castelo de Vide (Alto Alentejo, Portugal) 29SPD3263. 
Tabla 13

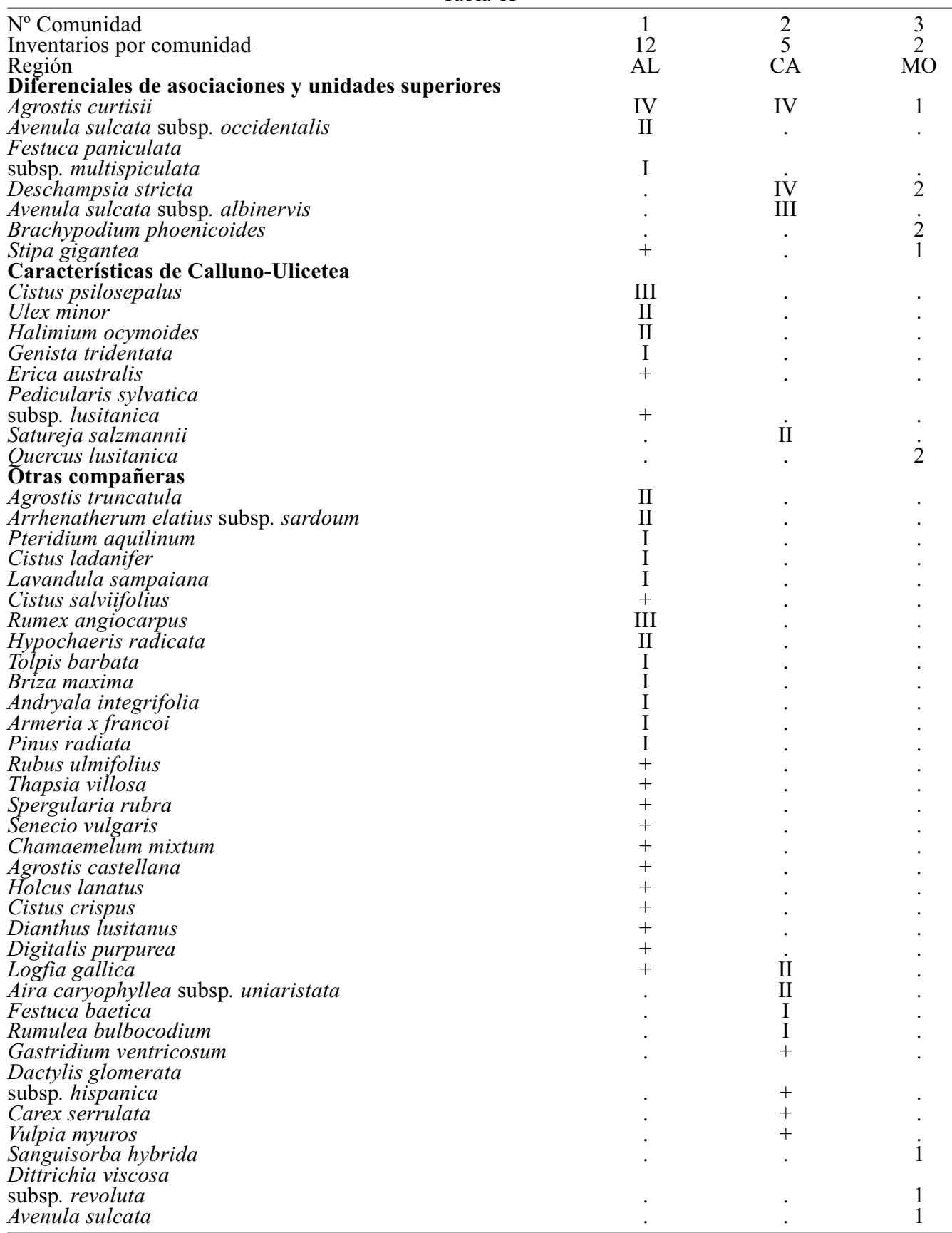

Referencias de las comunidades: 1-Festuco multispiculatae-Agrostietum curtisii (tab. 12); 2-Deschampsio strictae-Agrostietum curtisii (Galán de Mera, 1993); 3- Com. Deschampsia stricta y Brachypodium phoenicoides (Galán de Mera, 1993).

Tabla 13. Tabla sintética con comunidades de Agrostis curtisii del O de la Península Ibérica. Abreviaturas: Alto Alentejo (AL), Cádiz (CA), Monchique (MO). 
Tabla 14

1-4: Adenocarpetum argyrophyllii Rivas-Martínez, Cantó, Sánchez-Mata \& Belmonte 2002 5-13: Genisto cinerascentis-Adenocarpetum argyrophyllii (Rivas-Martínez, Cantó, Sánchez-Mata \& Belmonte) Vicente Orellana \& Galán de Mera stat. nov.

10-13: echinospartetosum iberici Vicente Orellana \& Galán de Mera subass. nova (Cytisetea, Cytisetalia, Adenocarpion argyrophylli)

\begin{tabular}{lccccccccccccc}
\hline Inventario $\mathrm{n}^{\mathrm{o}}$ & 1 & 2 & 3 & 4 & 5 & 6 & 7 & 8 & 9 & 10 & 11 & 12 & 13 \\
Altitud $(\mathrm{Dm})$. & 67 & 68 & 59 & 60 & 160 & 160 & 130 & 130 & 130 & 159 & 159 & 130 & 129 \\
Área $\left(\mathrm{m}^{2}\right)$ & 20 & 20 & 20 & 20 & 10 & 25 & 10 & 10 & 40 & 20 & 20 & 20 & 20
\end{tabular}

Características de asociación y unidades superiores

$\begin{array}{llllllllllllllll}\text { Adenocarpus argyrophyllus } & 5 & 5 & \mathrm{~V} & \mathrm{~V} & 3 & 4 & 4 & 3 & 5 & 2 & 1 & 1 & 1\end{array}$
$\begin{array}{lllll}\text { Cytisus striatus } & 2 & 3 & \text { III } & \text { III }\end{array}$ Cytisus multiflorus $\quad 2 \quad 2$ III IV

Genista cinerascens

Adenocarpus complicatus

Cytisus scoparius

Diferenciales de subasociación

Echinospartum ibericum

\section{Compañeras}

Arrhenatherum elatius

Dianthus lusitanus

Sedum brevifolium

Quercus rotundifolia

Jasione montana

Deschampsia flexuosa

Conopodium capillifolium

Micropyrum tenellum

Festuca paniculata

subsp. multispiculata

Digitalis thapsi

Juniperus oxycedrus

$\begin{array}{ccccccccccccc}. & . & \text { IV } & \text { V } & 1 & 1 & + & + & 3 & 1 & + & 1 & 1 \\ 1 & + & \text { IV } & \text { IV } & 1 & 1 & 1 & 1 & . & + & + & + & + \\ . & . & . & . & 2 & 1 & 1 & + & . & + & 1 & + & 1 \\ . & . & \text { III } & \text { III } & . & . & . & 1 & 3 & . & . & + & + \\ . & . & . & . & . & . & + & + & . & . & + & + & + \\ . & . & . & . & + & + & . & . & . & + & 1 & . & . \\ . & . & . & . & + & + & . & . & . & + & . & . & 1 \\ . & . & . & . & 3 & . & . & . & . & . & 1 & + & 1 \\ & & & & & & & & & & & & \\ . & . & . & . & . & + & + & . & . & . & . & + & + \\ + & . & \text { III } & \text { IV } & . & . & . & . & . & . & . & . & . \\ . & . & \text { III } & \text { IV } & . & . & . & . & 5 & . & . & . & .\end{array}$

Otras plantas: Rubus ulmifolius 1 en 1; Cistus ladanifer III, Conopodium majus I, Lavandula sampaiana III en 3; Cistus ladanifer II, Lavandula sampaiana III en 4; Sedum hirsutum 1 en 5; Sedum hirsutum 1 en 6; Pteridium aquilinum 5 en 9; Erica arborea + en 11; Andryala integrifolia + , Digitalis purpurea 1, Halimium ocymoides 1 en 12.

Localidades: 1, 2: Sierra de San Cristóbal, Logrosán (Cáceres, España) 30STJ8456. 3: Adenocarpetum argyrophylli (Belmonte, 1986). 4: Adenocarpetum argyrophylli (Rivas-Martínez et al. 2002). 5, 6: Pico de las Villuercas, Guadalupe (Cáceres, España) 30STJ7193. 7, 8: Collado del Turuñuelo, La Calera (Cáceres, España) 30SUJ0379. 9: Adenocarpetum argyrophylli genistetosum cinerascentis (Rivas-Martínez et al. 2002). 10, 11: Pico de las Villuercas, Guadalupe (Cáceres, España) 30STJ7193. 12, 13: Cancho Redondo, Navalvillar de Ibor (Cáceres, España) 30STJ9683. 
extremadurense. Se suele desarrollar bajo ombroclima subhúmedo-húmedo, sobre tierras pardas meridionales y suelos rojos silíceos asentados sobre sustratos paleozoicos (cuarcitas y pizarras).

Esta subasociación ya fue citada por Pérez Latorre et al. (1993) en distintas localidades andaluzas, refiriéndose a un nombre inválido de Rivas-Martínez (1975)[1974], por lo que la describimos en esta ocasión.

\section{Pyro bourgeanae-Quercetum rotundifoliae}

\section{Rivas-Martínez 1987}

Es la asociación que representa al encinar silicícola mesomediterráneo lusoextremadurense, que se desarrolla en ombroclima seco-subhúmedo sobre tierras pardas meridionales asentadas sobre sustratos paleozoicos (pizarras y cuarcitas), sedimentos miocenos (arcosas y subarcosas) y rañas pliocuaternarias, tanto en laderas de solana, colinas suaves y penillanuras (Ladero et al. 1990). Es un bosque en el que predominan las encinas (Quercus rotundifolia) y el peral silvestre o peralillo (Pyrus bourgaeana). El sotobosque es mucho menos denso que en el alcornocal, con menos elementos esclerófilos y perennifolios. Algunos de ellos son Daphne gnidium, Asparagus acutifolius o Rubia peregrina (Rivas-Martínez et al. 1988). En las zonas de estudio se pueden encontrar varias versiones de este encinar, que consideramos como subasociaciones.

quercetosum pyrenaicae Vicente Orellana \&

Galán de Mera subass. nova

[Tabla 19, holotypus subass. inv. 16]

Significa el contacto del melojar con el encinar en determinados enclaves muy húmedos por inversión térmica o compensación edáfica, encontrándonos un encinar con sus matorrales seriales, salpicado con algunos melojos. Se diferencia del Poterio-Quercetum quercetosum pyrenaicae por su preferencia por suelos poco arcillosos. jasminetosum fruticantis Vicente Orellana

\section{\& Galán de Mera subass. nova}

[Tabla 20, holotypus subass. inv. 4]

Subasociación que se desarrolla de manera muy localizada en los afloramientos calizos de Montes de Toledo. Se caracteriza por la presencia de varias plantas calcícolas, en especial Jasminus fruticans.

juniperetosum badiae Vicente Orellana \& Galán de Mera subass. nova

[Tabla 20, holotypus subass. inv. 8]

Comunidad permanente del encinar silicícola, muy pobre en elementos, con carácter continental, que aparece en afloramientos cuarcíticos muy expuestos y frecuentemente incendiados, lo que favorece la presencia de Juniperus oxycedrus subsp. badia (Ladero et al. 1994). En la actualidad se han descrito nuevos sintaxones referentes a enebrales en el centro y sur de la Península Ibérica basados en Juniperus oxycedrus subsp. lagunae (Cano et al. 2007). Respecto a esta subespecie, los caracteres que aportan estos autores son los mismos que los que indica Amaral Franco (1986) para separar $J$. oxycedrus subsp. badia de J. oxycedrus s.str., por lo que no podemos atender la reivindicación de Rivas-Martínez et al. (2002) de la subespecie laguniana para el centro de la Península, de acuerdo con Flora iberica (www.floraiberica.org). Por otra parte, Cano et al. (2007) señalan cómo estos enebrales en realidad son encinares que han sido alterados; tal vez, la asociación más cercana por composición florística a las comunidades de las Villuercas sea Echinosparto iberici-Juniperetum lagunae, asociación en la que Echinospartum ibericum sólo aparece en 4 inventarios de los 14 de la tabla. Por todo ello, pensamos que nuestra comunidad no es un enebral, sino una variante del encinar.

Arbuto unedonis-Quercetum pyrenaicae quercetosum suberis Vicente Orellana \& Galán de Mera subass. nova 
Tabla 15

\begin{tabular}{|c|c|c|c|c|c|c|c|c|c|c|c|c|c|c|}
\hline \multicolumn{15}{|c|}{$\begin{array}{c}\text { Rubetum ulmifolio-vigoi Vicente Orellana \& Galán de Mera ass. nova } \\
\text { (Rhamno-Prunetea, Prunetalia spinosae, Pruno-Rubion ulmifolii) }\end{array}$} \\
\hline Inventario $\mathrm{n}^{\mathrm{o}}$ & 1 & 2 & 3 & 4 & 5 & 6 & 7 & 8 & 9 & 10 & 11 & 12 & 13 & 14 \\
\hline Altitud (m.) & 460 & 700 & 1031 & 550 & 550 & 856 & 920 & 862 & 965 & 460 & 800 & 460 & 460 & 460 \\
\hline Área $\left(\mathrm{m}^{2}\right)$ & 50 & 50 & 50 & 50 & 50 & 25 & 50 & 50 & 10 & 50 & 50 & 50 & 50 & 50 \\
\hline \multicolumn{15}{|c|}{ Características de asociación y unidades superiores } \\
\hline Rubus vigoi & 3 & 3 & 5 & 4 & 5 & 4 & 4 & 4 & 3 & 3 & 3 & 3 & 4 & 4 \\
\hline Rubus ulmifolius & 1 & 1 & 1 & 1 & 1 & 1 & 1 & 2 & . & 1 & 1 & 1 & + & + \\
\hline Pteridium aquilinum & 3 & 4 & 1 & 2 & 1 & . & 1 & . & . & . & 1 & . & . & 1 \\
\hline Lonicera peryclimenum & & & & & & & & & & & & & & \\
\hline subsp. hispanica & . & . & . & . & . & & . & 1 & . & . & + & . & . & . \\
\hline Rubus caesius & . & & & & . & + & . & + & . & . & . & . & . & \\
\hline Rosa canina & . & . & 1 & . & . & . & . & & . & . & . & . & . & . \\
\hline Rosa corymbifera & . & . & . & . & . & . & . & 2 & . & . & . & . & . & \\
\hline Crataegus monogyna & . & . & . & . & . & . & . & 1 & . & . & . & . & . & . \\
\hline Prunus spinosa & . & . & . & . & . & . & . & 1 & . & . & . & . & . & . \\
\hline Compañ̃eras & & & & & & & & & & & & & & \\
\hline Agrostis castellana & 1 & . & . & . & 1 & + & & & + & 1 & . & + & 2 & 1 \\
\hline Briza maxima & 1 & . & . & . & + & . & 1 & & . & 1 & & + & 1 & 1 \\
\hline Holcus lanatus & 1 & & . & . & . & . & & . & . & + & 1 & 1 & 2 & 1 \\
\hline Daucus carota & + & + & & & & & + & & . & + & . & . & + & + \\
\hline Cytisus scoparius & . & . & 1 & . & + & 1 & 1 & + & . & . & . & . & . & . \\
\hline Satureja vulgaris & & & & & & & & & & & & & & \\
\hline subsp. arundana & + & 1 & & & & + & & & . & . & . & & 1 & 1 \\
\hline Hypericum perforatum & + & + & + & . & . & 1 & + & & . & . & . & & & $\cdot$ \\
\hline Vicia villosa & + & r. & & & & & 1 & + & . & . & 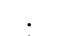 & 1 & + & . \\
\hline Avena barbata subsp. barbata & + & . & . & . & 1 & . & 1 & . & . & . & + & + & . & . \\
\hline $\begin{array}{l}\text { Arrhenatherum elatius } \\
\text { subsp. bulbosum }\end{array}$ & 1 & & . & + & & & & & . & + & 1 & . & . & . \\
\hline Castanea sativa & & + & & . & + & . & + & & . & . & . & . & . & . \\
\hline Bromus sterilis & + & . & + & . & . & . & + & & . & . & & & & \\
\hline Bromus diandrus & . & . & . & . & . & . & 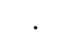 & & . & . & 1 & 1 & + & \\
\hline Plantago lanceolata & . & . & . & . & . & . & & & . & + & . & + & & + \\
\hline Daphne gnidium & & & . & & . & . & & & . & . & 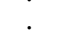 & + & 1 & 1 \\
\hline
\end{tabular}

Otras plantas: Andryala integrifolia 1, Dactylis glomerata subsp. hispanica 1, Malva tournefortiana ,+ Galactites tomentosa + , Digitalis purpurea var. tomentosa,+ Campanula rapunculus,+ Raphanus raphanistrum +, Crepis capillaris + en 1; Andryala integrifolia + , Teucrium scorodonia 1, Rumex acetosella subsp. angiocarpus + , Silene latifolia + , Silene vulgaris + , Sanguisorba hybrida 2 , Origanum virens 1, Tamus communis +, Tolpis barbata +, Lathyrus latifolius +, Agrimonia eupatoria +, Bituminaria bituminosa + en 2; Teucrium scorodonia 1, Lapsana communis + , Quercus pyrenaica 1, Anthriscus sylvestris + , Jasione sessiliflora + , Cichorium intybus + , Piptatherum milliaceum + en 3 ; Pinus pinaster,+ Physospermum cornubiense + , Carduus platypus + en 4; Arbutus unedo,+ Tordylium maximum + , Anthemis arvensis + , Cytisus striatus + , Fumaria muralis + , Leucanthemum pallens + , Lolium rigidum + en 5; Arbutus unedo +, Lactuca viminea,+ Populus nigra,+ Erica arborea +, Halimium umbellatum + , Hypochaeris radicata + en 6; Galactites tomentosa + , Lapsana communis + , Cistus ladanifer 1 , Torilis arvensis + , Rumex acetosella subsp. angiocarpus + , Malva tournefortiana +, Echium flavum +, Sonchus oleraceus + en 7; Silene latifolia +, Quercus pyrenaica +, Tordylium maximum,+ Lactuca viminea + , Crepis vesicaria + , Geranium columbinum,+ Anthemis triumfettii + en 8; Cistus ladanifer 1, Cistus psilosepalus 1, Helichrysum stoechas + , Arrhenatherum elatius subsp. sardoum + en 9; Pinus pinaster +, Cistus psilosepalus 1, Centranthus calcitrapae +, Ulex minor 1 , Cistus crispus + en 10; Silene vulgaris + , Torilis arvensis + , Scrophularia scorodonia 1, Galium aparine + en 11; Centranthus calcitrapae 1, Geranium robertianum subsp. purpureum 1, Mentha suaveolens + , Aristolochia paucinervis + , Bromus matritensis + en 12; Digitalis purpurea var. tomentosa +, Dactylis glomerata subsp. hispanica 1, Helichrysum stoechas + , Pterospartum tridentatum + , Centaurea aristata subsp. langeana + , Avena barbata subsp. lusitanica 1, Carlina corymbosa 1, Aegilops triuncialis 1, Lavandula stoechas subsp. sampaiana,+ Cynosurus echinatus +, Cynara humilis + en 13; Arrhenatherum elatius subsp. sardoum +, Pterospartum tridentatum +, Centaurea aristata subsp. langeana + , Carlina racemosa + en 14.

Localidades: 1, 8, 13: Alcorneo, Valencia de Alcántara (Cáceres, España) 29SPD5253. 2: Río Guadalupejo, Guadalupe (Cáceres, España) 30STJ8768. 3: Subida a la Base Militar, Los Albercones, Guadalupe (Cáceres, España) 30STJ9672. 4, 5: Salado-Oscuro, Portalegre (Alto Alentejo, Portugal) 29SPD3652. 6: Ermita del Humilladero, Guadalupe (Cáceres, España) 30STJ9871. 7: Pto. Espada, Marvão (Alto Alentejo, Portugal) 29SPD4153. 9, 10: Arroyo Viborejo, Guadalupe (Cáceres, España) 30STJ9872. 11, 12: Frontera España-Portugal, Valencia de Alcántara (Cáceres, España) 29SPD4558. 14: Navezuelas (Cáceres, España) 30STJ9173. 
Tabla 16

Rubetum ulmifolio-caesii Vicente Orellana \& Galán de Mera ass. nova (Rhamno-Prunetea, Prunetalia spinosae, Pruno-Rubion ulmifolii)

$\begin{array}{lcccccccc}\text { Inventario } \mathrm{n}^{\mathrm{o}} & 1 & 2 & 3 & 4 & 5 & 6 & 7 & 8 \\ \text { Altitud }(\mathrm{m} .) & 770 & 716 & 849 & 770 & 520 & 520 & 712 & 520 \\ \text { Área }\left(\mathrm{m}^{2}\right) & 25 & 25 & 25 & 25 & 25 & 25 & 25 & 25\end{array}$

\section{Características de asociación y unidades superiores}

Rubus caesius

Rubus ulmifolius

Lonicera peryclimenum subsp. hispanica

Tamus communis

Rosa corymbifera

$\begin{array}{cccccccc}4 & 4 & 4 & 4 & 4 & 4 & 4 & 4 \\ 2 & 1 & 1 & 2 & + & 3 & . & . \\ + & . & . & 1 & . & . & 1 & . \\ + & . & . & 1 & . & . & 1 & . \\ . & . & 1 & . & . & . & 1 & +\end{array}$

\section{Compañeras}

Brachypodium sylvaticum

Alnus glutinosa

Urtica dioica

Teucrium scorodonia

Geranium robertianum subsp. purpureum

Hedera helix

Anthriscus sylvestris

$\begin{array}{cccccccc}1 & 1 & 1 & + & 1 & 1 & 1 & 1 \\ \cdot & + & 1 & . & + & + & 1 & + \\ . & . & . & 1 & 1 & 1 & + & + \\ . & . & 1 & + & 2 & . & . & 2 \\ 1 & 1 & . & . & . & . & + & . \\ . & + & . & + & . & . & + & . \\ . & . & . & . & 1 & + & . & 1\end{array}$

Otras plantas: Agrimonia eupatoria + , Carex echinata + , Geum urbanum 1, Myrrhoides nodosa 1 , Populus alba,+ Rhagadiolus edulis + , Silene vulgaris + , Sonchus oleraceus + , Tordylium maximum 1, Torilis arvensis 1, Trifolium pratense + en 1; Carex echinata 1, Castanea sativa 1, Fragaria vesca 1, Lapsana communis + , Plantago major + , Prunella vulgaris + , Senecio sylvaticus + , Trifolium pratense 1 en 2; Cytisus striatus + , Hypericum perforatum + , Lapsana communis + , Oenanthe crocata + , Pyrus bourgaeana 1, Salix alba +, Stellaria media + en 3; Agrimonia eupatoria + , Carex pendula

1, Corylus avellana + , Geum urbanum + , Populus nigra + , Pteridium aquilinum 2, Quercus broteroi + en 4; Rubia peregrina + en 6; Carex pendula 2, Oenanthe crocata + , Pteridium aquilinum 1, Tanacetum corymbosum + en 7; Avena sterilis + en 8.

Localidades: 1, 2, 4, 7: Río Guadalupejo, Guadalupe (Cáceres, España) 30STJ9768. 3: Río Ibor, Guadalupe (Cáceres, España) 30STJ9874. 5, 6, 8: Río Almonte, Cabañas del Castillo (Cáceres, España) 30STJ8482.

[Tabla 21, holotypus subass. inv. 11]

Melojares mesomediterráneos que se desarrollan sobre cambisoles y regosoles dístricos, bajo ombroclima húmedo (Navarro Andrés et al. 1987; Amor et al. 1993; Ladero et al. 1994; Antunes, 1996). Esta asociación se enriquece con la presencia del alcornoque en las zonas bajas más húmedas y arcillosas, vaguadas y pequeñas laderas húmedas con relieve suave, constituyendo una subasociación del melojar.

\section{ESQUEMA SINTAXONÓMICO}

Aunque en el trabajo hemos descrito solamente los nuevos sintáxones, damos a conocer el esquema sintaxonómico de la vegetación de los territorios estudiados.

LEMNETEA Tüxen ex O. Bolòs \& Masclans 1955

+ Lemnetalia minoris Tüxen ex O. Bolòs \& Masclans 1955

* Lemnion minoris Tüxen ex O. Bolòs \& 
Tabla 17

Pyro bourgeanae-Securinegetum tinctoriae (Rivas Goday 1964) Rivas-Martínez \& Rivas Goday 1975 7-9: var. con Quercus rotundifolia

(Salici purpureae-Populetea nigrae, Salicetalia purpureae, Securinegion buxifoliae)

\begin{tabular}{|c|c|c|c|c|c|c|c|c|c|}
\hline Inventario $\mathrm{n}^{\mathrm{o}}$ & 1 & 2 & 3 & 4 & 5 & 6 & 7 & 8 & 9 \\
\hline Altitud (m.n.m.) & 405 & 405 & 410 & 410 & 405 & 435 & 430 & 450 & 450 \\
\hline Área $\left(\mathrm{m}^{2}\right)$ & 50 & 50 & 50 & 50 & 50 & 100 & 120 & 10 & 10 \\
\hline \multicolumn{10}{|c|}{ Características de asociación y unidades superiores } \\
\hline Flueggea tinctoria & 5 & 5 & 5 & 5 & 5 & 4 & 4 & 4 & 4 \\
\hline \multicolumn{10}{|c|}{ Diferenciales de variante } \\
\hline $\begin{array}{l}\text { Quercus rotundifolia } \\
\text { Danhne gnidium }\end{array}$ & $\cdot$ & $\cdot$ & . & $\cdot$ & . & . & 1 & 1 & 2 \\
\hline
\end{tabular}

\section{Compañeras}

Mentha pulegium

Holcus lanatus

Hypericum perforatum

Melica magnolii

Oenanthe crocata

Rumex conglomeratus

Coleostephus myconis

Phalaris aquatica

Plantago lanceolata

Crataegus monogyna

Lavandula sampaiana

\begin{tabular}{|c|c|c|c|c|c|c|c|}
\hline 1 & + & 1 & 1 & 1 & & . & . \\
\hline 1 & 1 & 1 & 1 & 2 & 1 & & \\
\hline . & - & . & + & . & . & 1 & 1 \\
\hline . & . & . & . & 1 & . & + & 1 \\
\hline 2 & . & . & . & 1 & . & . & . \\
\hline & + & & & 1 & . & . & . \\
\hline+ & $\cdot$ & + & 1 & . & . & . & . \\
\hline 1 & 1 & . & . & . & . & . & . \\
\hline+ & . & . & + & + & . & . & . \\
\hline . & . & . & + & . & 1 & + & . \\
\hline . & . & . & . & . & 1 & 1 & . \\
\hline
\end{tabular}

Otras plantas: Ammi majus 1, Senecio jacobea + en 1; Retama sphaerocarpa + en 2; Rumex pulcher subsp. woodsii + en 3; Aristolochia paucinervis + en 4; Aristolochia paucinervis 1, Galium aparine 1 en 5; Asparagus acutifolius 1, Daucus carota 1, Rubus ulmifolius 1, Rumex induratus + , Urginea maritima + en 6; Agrostis castellana + en 7; Agrostis castellana 1, Andryala arenaria,+ Avena barbata subsp. barbata +, Avena barbata subsp. lusitanica +, Campanula rapunculus + , Dactylis glomerata subsp. hispanica 1, Holcus annuus 2, Silene portensis + , Thymus mastichina + en 8; Campanula rapunculus 1, Crepis capillaris + , Dactylis glomerata subsp. hispanica 1, Holcus annuus 2, Rubus ulmifolius 2, Thalictrum speciosissimum + , Tolpis barbata 1 en 9.

Localidades: 1-5, Los Cerros, Río Cubilar, Logrosán (Cáceres, España) 30STJ8950. 6-9: La Lanchuela, Río Ruecas, Logrosán (Cáceres, España) 30STJ8955.

Masclans 1955

1. Lemnetum gibbae Miyawaki \& J. Tüxen 1960 [Pleustófitos de aguas remansadas, contaminadas y eutrofizadas].

POTAMETEA Klika in Klika \& Novák 1941

+ Potametalia Koch 1926

* Potamion (Koch 1926) Libbert 1931

2. Potamogetonetum nodosi Soó (1928) 1960

[Hidrófitos de aguas profundas enraizados en arcillas].

* Ranunculion aquatilis Passarge 1964
3. Callitricho stagnalis-Ranunculetum saniculifolii Galán de Mera in Pérez Latorre, Galán de Mera, P. Navas, D. Navas, Y. Gil \& Cabezudo 1999 [Vegetación mediterránea occidental de batráquidos de aguas someras].

* Ranunculion fluitantis Neuhäus1 1959

4. Com. Ranunculus trichophyllus [Comunidad de aguas rápidas someras, europea occidental].

BIDENTETEA TRIPARTITAE Tüxen, Lohmeyer \& Preising ex von Rochow 1951 
Tabla 18

Poterio agrimonioidis-Quercetum suberis Rivas Goday in Rivas Goday, Borja, Esteve, Galiano, Rigual \& Rivas-Martínez 1960

10-11: quercetosum pyrenaicae Vicente Orellana, Pérez Latorre, Cabezudo \& Galán de Mera subass. nova (Quercetea, Quercetalia, Quercion broteroi)

\begin{tabular}{|c|c|c|c|c|c|c|c|c|c|c|c|}
\hline Inventario $\mathrm{n}^{\mathbf{0}}$ & 1 & 2 & 3 & 4 & 5 & 6 & 7 & 8 & 9 & 10 & 11 \\
\hline Altitud (m.) & 565 & 470 & 762 & 780 & 705 & 581 & 584 & 520 & 430 & 585 & 700 \\
\hline Área $\left(\mathrm{m}^{2}\right)$ & 100 & 50 & 200 & 100 & 50 & 200 & 50 & 100 & 100 & 100 & 50 \\
\hline \multicolumn{12}{|c|}{ Características de asociación y unidades superiores } \\
\hline Quercus suber & 3 & 2 & 2 & 2 & 3 & 2 & 2 & 2 & 2 & 3 & 3 \\
\hline Daphne gnidium & 1 & . & + & + & + & 1 & 1 & . & . & + & 1 \\
\hline Adenocarpus complicatus & . & . & . & . & . & 3 & 3 & . & . & . & . \\
\hline Arbutus unedo & . & . & . & . & . & 1 & 2 & . & . & . & . \\
\hline Quercus rotundifolia & . & . & . & . & . & . & . & . & 1 & + & . \\
\hline Urginea maritima & . & . & . & . & . & . & . & . & . & + & 1 \\
\hline Aristolochia paucinervis & . & . & 1 & . & . & . & . & . & . & . & . \\
\hline Erica arborea & . & . & . & . & . & 1 & . & . & . & . & . \\
\hline Asparagus acutifolius & . & . & . & . & . & . & . & . & + & . & . \\
\hline \multicolumn{12}{|l|}{ Diferenciales de subasociación } \\
\hline $\begin{array}{l}\text { Quercus pyrenaica } \\
\text { Compañeras }\end{array}$ & + & + & . & 1 & 1 & 1 & 1 & 1 & 1 & 2 & 3 \\
\hline Cytisus striatus & 2 & 1 & 2 & + & . & 2 & 1 & . & 2 & . & 1 \\
\hline Cistus salviifolius & . & + & . & 2 & + & 2 & 2 & 1 & 2 & . & 2 \\
\hline Rubus ulmifolius & 1 & 2 & . & 1 & . & 3 & . & 1 & 2 & . & . \\
\hline Cistus psilosepalus & 2 & . & . & 1 & 3 & . & . & 2 & . & . & 4 \\
\hline Castanea sativa & 2 & . & . & 1 & . & 1 & + & . & . & 2 & . \\
\hline Pteridium aquilinum & 4 & . & . & . & 5 & . & . & 1 & . & 2 & 2 \\
\hline Pinus pinaster & 2 & . & . & 4 & + & . & . & . & . & 1 & . \\
\hline \multicolumn{12}{|l|}{ Satureja vulgaris } \\
\hline subsp. arundana & 1 & . & . & + & . & . & + & . & . & . & . \\
\hline Genista falcata & . & 1 & . & . & 1 & . & . & 1 & . & . & . \\
\hline \multicolumn{12}{|l|}{ Lavandula stoechas } \\
\hline subsp. sampaiana & . & . & 1 & . & 2 & . & . & . & . & $\cdot$ & 4 \\
\hline Cistus crispus & . & . & . & 1 & + & . & . & 1 & . & . & . \\
\hline Asphodelus albus subsp. albus & $s$. & . & . & . & . & . & . & + & . & 1 & 1 \\
\hline
\end{tabular}

Otras plantas: Acacia dealbata + , Digitalis purpurea 1, Fraxinus angustifolia,+ Lonicera peryclimenum subsp. hispanica 1, Olea europaea 1 en 1; Adenocarpus anisochilus + , Tamus communis + , Teucrium scorodonia + en 2; Adenocarpus anisochilus 2, Arrhenatherum elatius subsp. bulbosum 3, Origanum virens + , Sedum forsterianum 1 en 3; Asphodelus ramosus + , Festuca paniculata subsp. multispiculata + , Hypericum perforatum + en 4; Halimium ocymoides 1 en 5; Centaurea cordubensis + , Centaurium erythraea subsp. majus 1, Cistus ladanifer 1, Conopodium capillifolium,+ Cytisus scoparius 1 , Holcus lanatus + , Malva tournefortiana + , Olea europaea + , Vitis vinifera var. sylvestris + en 6; Agrostis castellana +, Brachypodium sylvaticum +, Bupleurum rigidum +, Cistus ladanifer 1 , Crataegus monogyna 1, Origanum virens 1, Teucrium scorodonia 1 en 7; Mentha suaveolens + , Scrophularia scorodonia + , Senecio lividus + , Tamus communis + , Ulex minor 2 en 8; Cistus ladanifer + , Ferula communis 1, Phagnalon saxatile 1, Thapsia villosa + en 9; Agrostis curtisii 1, Simethis planifolia 1 en 10; Digitalis thapsi + , Genista triacanthos + , Halimium ocymoides 2 en 11.

Localidades: 1: Srra. de Carreiras (Alto Alentejo, Portugal) 29SPD3362. 2, 9: Veloso, Carreiras (Alto Alentejo, Portugal) 29SPD3559. 3: Marvão (Alto Alentejo, Portugal) 29SPD3962. 4: Ntra. Sra. da Penha, Castelo de Vide (Alto Alentejo, Portugal) 29SPD3263. 5, 11: Carreiras (Alto Alentejo, Portugal) 29SPD3461. 6, 7: Valle de la Majada del Venero, Cañamero (Cáceres, España) 30STJ9263. 8: Ribeira de Nisa, Portalegre (Alto Alentejo, Portugal) 29SPD3456. 10: Srra. de Urra, Castelo de Vide (Alto Alentejo, Portugal) 29SPD3563. 
+ Bidentetalia tripartitae Br.-B1. \& Tüxen ex Klika \& Hadac 1944

* Bidention tripartitae Nordhagen 1940 em. Tüxen in Poli \& J. Tüxen 1960

5. Bidenti tripartitae-Polygonetum lapathifolii Rivas-Martínez, Belmonte, Fernández-González \& Sánchez-Mata in Sánchez-Mata 1989 [Vegetación nitrófila estivo-autumnal de orillas nitrificadas con lodos].

ISOETO-NANOJUNCETEA Br.-B1. \& Tüxen ex Westhoff, Dijk \& Passchier 1946

+ Isoetetalia Br.-Bl. 1936

* Agrostion salmanticae Rivas Goday 1958 6. Pulicario uliginosae-Agrostietum salmanticae Rivas Goday 1956 [Vegetación anfibia terofítica de suelos areno-limosos con hidromorfía temporal].

cynodontetosum dactylionis Vicente Orellana \& Galán de Mera subass. nova [de suelos más húmedos y compactados].

PHRAGMITO-MAGNOCARICETEA Klika in Klika \& Novák 1941

+ Phragmitetalia Koch 1926

* Phragmition communis Koch 1926

** Phragmitenion communis

7. Typho angustifoliae-Phragmitetum australis (Tüxen \& Preising 1942) RivasMartínez, Báscones, Díaz, FernándezGonzález \& Loidi 1991 [Espadañales en aguas permanentes remansadas].

+ Nasturtio-Glycerietalia Pignatti 1954

* Glycerio-Sparganion Br.-Bl. \& Sissingh in Boer 1942

** Glycerio-Sparganienion

8. Rorippo microphyllae-Sparganietum erecti Molina Abril 1996 [Vegetación centro occidental ibérica del lecho menor de los ríos con aguas eutrofizadas].

** Glycerienion fluitantis (Géhu \& Géhu-Franck 1987) J.A. Molina 1996

9. Glycerio declinatae-Eleocharitetum palustris Rivas-Martínez \& Costa in RivasMartínez, Costa, Castroviejo \& Valdés 1980 [Comunidades helofíticas de aguas someras, remansadas, con fuerte sequía estival].

** Phalaridenion arundinaceae (Kopecky 1961)

J.A. Molina 1996
10. Glycerio declinatae-Oenanthetum crocatae Rivas-Martínez, Belmonte, Fernández-González \& Sánchez-Mata in Sánchez Mata 1989 [Herbazales silicícolas de aguas corrientes].

* Nasturtion officinalis Géhu \& Géhu-Franck 1987

11. Glycerio declinatae-Apietum nodiflori Molina Abril 1996 [Herbazal helofítico termófilo].

var. con Myosotis welwitschii [variante termófila].

+Magnocaricetalia Pignatti 1954

* Caricion broterianae (Rivas-Martínez, Fernández-González \& Sánchez-Mata 1986) J.A Molina 1996

12. Galio palustris-Caricetum lusitanicae Rivas-Martínez, Belmonte \& Sánchez-Mata in Sánchez-Mata 1989 [Asociación ibérica occidental de cárices de remansos y aguas lentas].

scirpetosum holoschoeni Belmonte \& Sánchez-Mata in Sánchez Mata 1989 [variante mesomediterránea de suelos nitrificados].

ASPLENIETEA TRICHOMANIS (Br.-B1. in Meier \& Br.-B1. 1934) Oberdorfer 1977

+ Androsacetalia vandellii Br.-B1. in Meier \& Br.B1. 1934 nom. corr. Rivas-Martínez, Fernámdez González, Loidi, Lousã \& Penas 2001

* Cheilanthion hispanicae Rivas Goday 1956

13. Asplenio billotii-Cheilanthetum hispanicae Rivas Goday in Sáenz \& RivasMartínez 1979 [Asociación mesomediterránea de fisuras verticales, silicícola].

14. Comunidad de Sedum hirsutum y Sedum brevifolium [Comunidades de pequeñas fisuras horizontales y cornisas soleadas]. var. con Dianthus lusitanus [de fisuras más profundas con una incipiente acumulación de suelo].

PARIETARIETEA Rivas-Martínez in Rivas Goday 1964

+ Parietarietalia Rivas-Martínez in Rivas Goday 1964

* Parietario-Galion muralis Rivas-Martínez in Rivas Goday 1964

15. Parietarietum judaicae K. Buchwald 1952 
Tabla 19

\begin{tabular}{|c|c|c|c|c|c|c|c|c|c|c|c|c|c|c|c|c|c|c|}
\hline \multicolumn{19}{|c|}{$\begin{array}{l}\text { Pyro bourgeanae-Quercetum rotundifoliae Rivas-Martínez } 1987 \\
\text { 11-13: quercetosum suberis Rivas Goday } 1964 \\
\text { 18: quercetosum pyrenaicae Vicente Orellana \& Galán de Mera subass. nova } \\
\text { (Quercetea ilicis, Quercetalia ilicis, Quercion broteroi) }\end{array}$} \\
\hline Inventario $\mathrm{n}^{\mathrm{o}}$ & 1 & 2 & 3 & 4 & 5 & 6 & 7 & 8 & 9 & 10 & 11 & 12 & 13 & 14 & 15 & 16 & & 18 \\
\hline & 535 & 453 & & 520 & & 498 & & 556 & 549 & 509 & 575 & 540 & 795 & 593 & 600 & & 5515 & 541 \\
\hline Area $\left(\mathrm{m}^{2}\right)$ & 100 & 100 & 100 & 100 & 100 & 100 & 100 & 100 & 100 & 100 & 50 & 100 & 100 & 100 & 100 & 0 & 100 & 100 \\
\hline \multicolumn{19}{|c|}{ Características de asociación y unidades superiores } \\
\hline Quercus rotundifolia & 2 & 3 & 3 & 1 & 1 & 2 & 2 & 1 & 1 & 2 & 2 & 2 & 1 & 2 & 2 & 1 & 1 & \\
\hline Urgi & + & 1 & + & + & + & + & + & + & 1 & + & & + & . & + & + & + & + & \\
\hline Daphne & + & + & + & + & + & + & + & + & 1 & + & & . & . & 1 & 1 & + & + & \\
\hline Pyrus bourgeana & 2 & 1 & 1 & 1 & + & . & . & . & . & . & . & . & . & . & . & . & . & \\
\hline \multicolumn{19}{|c|}{ Diferenciales de subasociaciones } \\
\hline Quercus suber & . & . & & . & + & . & . & . & & & 1 & 1 & 2 & + & . & & . & + \\
\hline Querch & . & . & . & . & . & . & . & + & & . & + & . & . & 2 & 2 & 1 & 1 & 1 \\
\hline \multicolumn{19}{|l|}{ Compañeras } \\
\hline Cistus ladanifer & 2 & 3 & 3 & 1 & 2 & 2 & 3 & 3 & 3 & 3 & 2 & 3 & 3 & 5 & 5 & 3 & 4 & 4 \\
\hline $\begin{array}{l}\text { Lavandula stoechas } \\
\text { subsp. sampaiana }\end{array}$ & & & & & & & & & & & & & & & & & & \\
\hline Cytisu & 1 & + & 2 & 1 & + & & $\begin{array}{l}1 \\
+\end{array}$ & 1 & $\begin{array}{l}2 \\
+\end{array}$ & 1 & 2 & 1 & . & 2 & 1 & 1 & $\begin{array}{l}1 \\
1\end{array}$ & \\
\hline Reta & $a 1$ & + & + & 1 & + & i & 1 & 1 & 1 & + & 2 & . & $\dot{1}$ & . & . & 1 & . & \\
\hline Asphodelus & + & + & + & . & 3 & . & . & + & + & + & . & . & . & + & + & + & . & \\
\hline onogyna & + & . & . & . & + & & . & + & r & . & & . & . & 1 & + & . & & $\dot{+}$ \\
\hline Rubus ulmifolius & . & . & . & . & . & $i$ & $\dot{+}$ & . & & $\cdot$ & $\dot{+}$ & . & . & + & . & . & & + \\
\hline
\end{tabular}

Otras plantas: Cistus salviifolius + , Lavandula stoechas subsp. luisieri + en 6; Adenocarpus anisochilus + , Cistus crispus + , Hypochaeris radicata + , Origanum virens 1 , Pteridium aquilinum 1 , Tolpis umbellata 1 en 11; Cistus psilosepalus 1, Cistus salviifolius 2, Lavandula stoechas subsp. luisieri + , Pteridium aquilinum 2 en 12; Ballota hirsuta 2, Cytisus grandiflorus 1, Cytisus multiflorus + , Dianthus lusitanus + , Umbilicus rupestris + en 13.

Localidades: 1-3, 6-9, 13: Valle de Los Venaos, Srra. de los Poyales, Logrosán (Cáceres, España) 30STJ8659. 4, 5, 10: Valle del Búho, Pto. de Berzocana, Logrosán (Cáceres, España) 30STJ8660. 11: Monte Paleiros, Ribeira de Nisa, Portalegre (Alto Alentejo, Portugal) 29SPD3554. 12: Ribeira de Nisa, Portalegre (Alto Alentejo, Portugal) 29SPD3456. 14-18: Casa Zahudejo, Cerro del Cabrero, Pto. de Berzocana, Logrosán (Cáceres, España) 30STJ8759.

[Vegetación heliófila nitrófila de cantiles y muros].

phagnaletosum saxatilis Vicente Orellana \& Galán de Mera subass. nova [de lugares soleados y xéricos].

cymbalarietosum muralis Vicente Orellana \& Galán de Mera subass. nova [de paredes con agua rezumante].

ANOMODONTO-POLYPODIETEA RivasMartínez 1975
+ Anomodonto-Polypodietalia O. Bolòs \& Vives in O. Bolòs 1957

* Bartramio-Polypodion serrati O. Bolòs \& Vives in O. Bolòs 1957

16. Anogrammo leptophyllae-Umbilicetum rupestris Amor, Ladero \& Valle 1993 [Fisuras terrosas umbrías con briófitos y helechos].

PHAGNALO-RUMICETEA INDURATI (Rivas Goday \& Esteve 1972) Rivas-Martínez, Izco \& Costa 1973 
+ Phagnalo saxatilis-Rumicetalia indurati Rivas Goday \& Esteve 1972

* Rumici indurati-Dianthion lusitani RivasMartínez, Izco \& Costa ex V. Fuente 1986

17. Digitali thapsi-Dianthetum lusitani Rivas-Martínez ex V. Fuente 1986 [Grietas anchas con escaso acúmulo de materia orgánica, ibérica occidental].

18. Sileno acutifoliae-Dianthetum lusitani Vicente Orellana \& Galán de Mera ass. nova [Comunidad altoalentejana de grietas anchas sombrías].

19. Phagnalo saxatilis-Rumicetum indurati Rivas-Martínez ex Navarro \& Valle 1984 in Ruiz 1986 [Caméfitos y hemicriptófitos de grietas y taludes, con influencia antrópica, iberoatlántica].

var. con Crambe hispanica y Coriandrum sativum [variante de murallas con materiales calizos].

ARTEMISIETEA VULGARIS Lohmeyer, Preising \& Tüxen ex von Rochow 1951

Artemisienea vulgaris

+ Agropyretalia repentis Oberdorfer, Müller \& Görs in Oberdorfer, Görs, Korneck, Lohmeyer, Müller, Philippi \& Seibert 1967

* Hyperico perforati-Ferulion communis Vicente Orellana \& Galán de Mera all. nova

20. Feruletum communis Vicente Orellana \& Galán de Mera ass. nova [Herbazales carpetano-ibérico-leoneses y lusoextremadurenses sobre suelos profundos ácidos, con humedad edáfica].

Onopordenea acanthii Rivas-Martínez, Báscones, T.E. Díaz, Fernández-González, Izco, Loidi, Lousã \& Penas 2002

+ Carthametalia lanati Brullo in Brullo \& Marcenò 1985

* Onopordion castellani Br.-B1. \& O. Bolòs 1958 corr. Rivas-Martínez, T.E. Díaz, FernándezGonzález, Izco, Loidi, Lousã \& Penas 2002

21. Comunidad de Verbascum pulverulentum y Onopordum illyricum [Vegetación de suelos arenosos removidos y escombreras].

22. Bourgaeo humilis-Galactitetum tomentosae Rivas Goday 1964 [Cardonales de talla media sobre suelos silíceos arenosos].

* Silybo-Urticion Sissingh ex Br.-B1. \& O. Bolòs 1958
23. Carduo bourgeani-Silybetum mariani Rivas-Martínez ex Rivas-Martínez, Costa \& Loidi 1992 [Cardonales de talla elevada sobre suelos fuertemente nitrificados y removidos, muy húmedos a principios de la primavera].

POLYGONO-POETEA ANNUAE RivasMartínez 1975

+ Polygono arenastri-Poetalia annuae Tüxen in Géhu, Richard \& Tüxen 1972 corr. RivasMartínez, Báscones, Díaz, Fernández-González \& Loidi 1991

* Polycarpion tetraphylli Rivas-Martínez 1975

24. Crassulo tillaeae-Saginetum apetalae Rivas-Martínez 1975 [Vegetación de suelos arenosos compactados por el pisoteo].

trifolietosum suffocati Rivas-Martínez 1975 [subasociación con tréboles por aumento de la nitrofilia por pastoreo].

25. Solivetum stoloniferae Rivas-Martínez 1975 [Vegetación terofítica nitrófila urbana adaptada al pisoteo].

var. con Campanula erinus [variante de los intersticios carbonatados del pavimento].

* Euphorbion prostratae Rivas-Martínez 1976 26. Euphorbio chamaesyces-Oxalidetum corniculatae Lorenzoni 1964 [Vegetación nitrófila urbanícola de los canales de vertidos domésticos de las ciudades medievales].

STELLARIETEA MEDIAE Tüxen, Lohmeyer \& Preising ex von Rochow 1951

Stellarienea mediae

+ Aperetalia spicae-venti J. Tüxen \& Tüxen in Malato-Beliz, J. Tüxen \& Tüxen 1960

* Scleranthion annui (Kruseman \& Vlieger 1939)

Sissingh in Westhoff, Dijk \& Passchier 1946

** Spergulo pentandrae- Arabidopsienion thalianae Rivas Goday 1964

27. Chrysanthemo myconis-Anthemidetum fuscatae Rivas Goday 1964 [Comunidades mesegueras subnitrófilas primaverales, sobre sustratos silíceos].

var. con Rumex bucephalophorus [enriquecimiento por la entrada masiva de ganado ovino a los campos de cultivo]. var. con Raphanus raphanistrum [enriquecimiento por el ahuecado del suelo por el arado].

28. Raphano raphanistri-Diplotaxietum 
catholicae Vicente Orellana \& Galán de Mera ass. nova [Vegetación ruderal, nitrófila, vernal, sobre suelos areno-limosos, bajo bioclima mesomediterráneo seco-subhúmedo].

Chenopodio-Stellarienea Rivas Goday 1956

+ Chenopodietalia muralis Br.-B1. in Br.-B1., Gajewski, Wraber \& Walas 1936 em. RivasMartínez 1977

* Chenopodion muralis Br.-Bl. in Br.-Bl., Gajewski, Wraber \& Walas 1936

** Chenopodienion muralis

29. Chenopodietum muralis $\mathrm{Br}$ - $\mathrm{B} 1$. in $\mathrm{Br}$-- $\mathrm{B} 1$., Gajewski, Wraber \& Walas 1936 [Herbazal estival urbanícola fuertemente nitrófilo, de estercoleros y suelos muy removidos].

** Malvenion parviflorae Rivas-Martínez 1978 30. Sisymbrio irionis-Malvetum parviflorae Rivas-Martínez 1978 [Herbazal primaveral muy nitrófilo de ambientes urbanos y rurales]. sisymbrietosum officinalis Ruiz \& Valdés 1987 [de acostaderos de ganado vacuno].

+ Thero-Brometalia (Rivas Goday \& RivasMartínez ex Esteve 1973) O. Bolòs 1975

* Echio plantaginei-Galactition tomentosae O. Bolòs \& Molinier 1969

31. Rumici angiocarpi-Coleostephetum myconis Vicente Orellana \& Galán de Mera ass. nova [Pastizal subnitrófilo lusoextremadurense mesomediterráneo, de suelos antiguamente removidos y ya asentados, compactos].

brassicetosum barrelieri Vicente Orellana \& Galán de Mera subass. nova [aumento de arena en las capas superiores del suelo]. var. con Lupinus hispanicus [enriquecimiento por mayor humedad y ahuecado del suelo].

* Alysso granatensis-Brassicion barrelieri RivasMartínez \& Izco 1977

32. Chamaemeletum mixti Ruiz \& A. Valdés 1987 [Herbazales subnitrófilos de barbechos antiguos sobre suelos silíceos].

+ Sisymbrietalia officinalis J. Tüxen in Lohmeyer et al. 1962 em. Rivas-Martínez, Báscones, T.E. Díaz, Fernández-González \& Loidi 1991

* Hordeion leporini Br.-Bl. in Br.-Bl., Gajewski, Wraber \& Walas 1936 corr. O. Bolòs 1962 33. Bromo scopari-Hordeetum leporini Rivas-Martínez 1978 [Herbazales subnitrófilos viarios de suelos areno-limosos].

GALIO-URTICETEA Passarge ex Kopecky 1969 + Galio aparines-Alliarietalia petiolatae Görs \& Müller 1969

* Galio-Alliarion petiolatae Oberdorfer \& Lohmeyer in Oberdorfer, Görs, Korneck, Lohmeyer, Müller, Philippi \& Seibert 1967

** Alliarienion petiolatae

34. Myrrhoidi nodosae-Alliarietum petiolatae Rivas-Martínez \& Mayor ex V. Fuente 1986 [Hemicriptófitos escionitrófilos de bosques caducifolios en suelos profundos con elevada humedad].

chaerophylletosum temuli FernándezGonzález \& Sánchez Mata in Sánchez Mata 1989 [de suelos húmedos con una fuerte presión antropozoógena, y elementos de carácter atlántico].

smyrnietosum perfoliati Sánchez Mata 1989 [de claros de melojares y castañares].

** Smyrnienion olusatri Rivas Goday ex RivasMartínez, Fernández-González \& Loidi 1999

35. Urtico membranaceae-Smyrnietum olusatri A. \& O. Bolòs in O. Bolòs \& Molinier 1958 [Herbazales vivaces de suelos profundos fuertemente nitrificados, urbanícola].

* Balloto-Conion maculati Brullo in Brullo \& Marcenò 1985

36. Galio aparines-Conietum maculati RivasMartínez ex G. López 1978 [Herbazales vivaces heliófilos de suelos muy nitrificados, ahuecados y con una cierta humedad].

37. Urtico dioicae-Sambucetum ebuli (Br.-B1. in Br.-Bl., Gajewski, Wraber \& Walas 1936) Br.-B1. in Br.-B1., Roussine \& Nègre 1952 [Vegetación vivaz de porte alto, nitrófila, de suelos no removidos con humedad constante].

+ Convolvuletalia sepium Tüxen ex Mucina 1993

* Convolvulion sepium Tüxen ex Oberdorfer 1957

38. Arundini donacis-Convolvuletum sepium Tüxen \& Oberdorfer ex O. Bolòs 1962 [Cañaverales].

GERANIO PURPUREI-CARDAMINETEA HIRSUTAE Rivas-Martínez, FernándezGonzález \& Loidi 1999 (2002)

+ Geranio purpurei-Cardaminetalia hirsutae Brullo in Brullo \& Marcenò 1985 
Tabla 20

Pyro bourgeanae-Quercetum rotundifoliae Rivas-Martínez 1987

1-5: jasminetosum fruticantis Vicente Orellana \& Galán de Mera subass. nova 6-11: juniperetosum badiae Vicente Orellana \& Galán de Mera subass. nova (Quercetea ilicis, Quercetalia ilicis, Quercion broteroi)

\begin{tabular}{lccccccccccc}
\hline Inventario $\mathrm{n}^{\mathrm{o}}$ & 1 & 2 & 3 & 4 & 5 & 6 & 7 & 8 & 9 & 10 & 11 \\
Altitud (m.n.m.) & 666 & 666 & 430 & 430 & 430 & 702 & 600 & 614 & 580 & 580 & 807 \\
Area $\left(\mathrm{m}^{2}\right)$ & 100 & 100 & 100 & 100 & 100 & 100 & 100 & 100 & 100 & 100 & 20
\end{tabular}

Características de asociación y unidades superiores

Quercus rotundifolia

Phillyrea angustifolia

Asparagus acutifolius

Viburnum tinus

Arbutus unedo

Urginea maritima

Quercus broteroi

Ruscus aculeatus

Daphne gnidium

Quercus suber

Diferenciales de subasociaciones

Jasminus fruticans

Pistacia terebinthus

Rubia peregrina

Coronilla juncea

Cistus albidus

Ruta montana

Juniperus oxycedrus subsp. badia

\begin{tabular}{|c|c|c|c|c|c|c|c|c|c|}
\hline \multicolumn{10}{|c|}{ es superiores } \\
\hline 4 & 4 & 2 & 3 & 3 & 1 & + & 1 & 1 & 3 \\
\hline 1 & 1 & . & . & & 1 & . & 1 & . & 1 \\
\hline 1 & + & + & 1 & 1 & . & . & . & . & . \\
\hline+ & 1 & . & . & . & . & . & . & . & . \\
\hline . & + & . & 1 & & . & . & . & . & . \\
\hline . & . & + & . & 1 & . & . & . & . & . \\
\hline+ & . & . & . & . & . & . & . & . & . \\
\hline . & + & . & . & . & . & . & . & . & . \\
\hline . & - & . & 1 & . & . & . & . & . & . \\
\hline . & . & . & . & . & + & 1 & . & . & . \\
\hline
\end{tabular}

\section{Compañeras}

Cistus ladanifer

Cytisus striatus

Olea europaea

var. sylvestris

Lavandula stoechas subsp. sampaiana

Lonicera periclimenum

subsp. hispanica

Cytisus scoparius

\begin{tabular}{|c|c|c|c|c|c|c|c|c|c|}
\hline 1 & 1 & 3 & 2 & 1 & . & . & . & $\cdot$ & . \\
\hline 1 & 1 & 1 & 1 & + & . & . & . & . & . \\
\hline 1 & 1 & . & + & . & . & . & . & . & . \\
\hline+ & 2 & + & 1 & - & . & . & . & . & . \\
\hline+ & 1 & 2 & 2 & 2 & . & . & . & . & . \\
\hline+ & + & . & . & . & 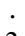 & i & & & \\
\hline . & $\cdot$ & + & . & . & 3 & 3 & 2 & 2 & 3 \\
\hline . & . & . & + & . & 1 & 2 & 1 & 1 & 2 \\
\hline+ & . & $\cdot$ & . & . & 1 & + & . & . & . \\
\hline+ & 1 & 1 & 1 & 1 & . & . & . & . & . \\
\hline$\cdot$ & $\cdot$ & $\cdot$ & $\cdot$ & $\cdot$ & . & . & + & 1 & 1 \\
\hline+ & + & & 1 & . & · & • & · & . & . \\
\hline . & + & 1 & 1 & . & . & . & . & . & . \\
\hline
\end{tabular}

Otras plantas: Bituminaria bituminosa,+ Melica magnolii + , Origanum virens 1 , Torilis arvensis 1 en 1; Bituminaria bituminosa 1, Cistus salviifolius 1, Dactylis glomerata subsp. hispanica 1, Helichrysum stoechas + , Origanum virens 1 en 2; Bryonia dioica + , Crataegus monogyna + , Retama sphaerocarpa + , Rhamnus lycioides 1 , Rosmarinus officinalis 1 en $3 ;$ Rosa $\mathrm{sp} .+$ en $4 ;$ Rhamnus lycioides 1, Rosmarinus officinalis 2, Thapsia villosa + en 5; Genista florida 2, Quercus pyrenaica + en 6; Genista florida 2 en 7; Asphodelus ramosus + , Dactylis glomerata + , Olea europaea + en 8; Arrhenatherum elatius subsp. sardoum 1, Dianthus lusitanus + , Stipa gigantea 1 en 9; Arrhenatherum elatius subsp. sardoum + , Asphodelus ramosus 1, Dactylis glomerata subsp. hispanica + en 10; Erica australis + , Pinus pinaster + en 11 .

Localidades: 1, 2: Proximidades Cueva Castañar de Ibor (Cáceres, España) 30STJ9290. 3-5: El Vergel, Peraleda de San Román (Cáceres, España) 30STK9100. 6: La Encrucijada, Castañar de Ibor (Cáceres, España) 30STJ8995. 7: El Frontón, Castañar de Ibor (Cáceres, España) 30STJ8887. 8: El Portezuelo, Cabañas del Castillo (Cáceres, España) 30STJ8382. 9, 10: Estrecho de la Peña, Sierra Palomera, Alía (Cáceres, España) 30SUJ1471. 11: Puerto de San Vicente (Toledo, España) 30SUJ1875. 
* Geranio pusilli-Anthriscion caucalidis RivasMartínez 1978

39. Galio aparinellae-Anthriscetum caucalidis Rivas-Martínez 1978 [Vegetación terofítica primaveral escionitrófila y humícola de linderos, paredes umbrosas, bajo encinares y alcornocales umbríos o de sus orlas espinosas].

geranietosum lucidi Ladero, Navarro \& Valle 1983 [de suelos más húmedos, con muy poca luz].

40. Lamio bifidi-Anthriscetum caucalidis Ladero, Fuertes \& Pérez Chiscano 1980 [Vegetación terofítica humícola, vernal, de melojares y alisedas].

TRIFOLIO-GERANIETEA Müller 1962

+ Melampyro-Holcetalia Passarge 1979

* Origanion virentis Rivas-Martínez \& O. Bolòs in Rivas-Martínez, T.E. Díaz, F. Prieto, Loidi \& Penas 1984

** Origanenion virentis

41. Clinopodio villosae-Origanetum virentis Rivas-Martínez in Rivas-Martínez, T.E. Díaz, F. Prieto, Loidi \& Penas 1984 [Herbazales vivaces de lindero y claros de encinares y alcornocales].

42. Vincetoxico nigri-Origanetum virentis Ladero, Navarro, Valle, Pérez, Santos, Ruiz, Fernández, Valdés \& González 1985 [Herbazales vivaces de lindero y claros de melojares].

HELIANTHEMETEA GUTTATI (Br.-Bl. in Br.B1., Roussine \& Nègre 1952) Rivas Goday \& Rivas-Martínez 1963 em. Rivas-Martínez 1978

+ Helianthemetalia guttati Br.-B1. in Br.-B1., Molinier \& Wagner 1940

* Helianthemion guttati Br.-Bl. in Br.-Bl., Molinier \& Wagner 1940

** Helianthemenion guttati 43. Anthoxantho aristati-Micropyretum patentis Belmonte \& Sánchez Mata in Sánchez Mata 1989 [Pastizal pionero silicícola de los litosuelos de los berrocales graníticos y afloramientos cuarcíticos].

44. Holco setiglumis-Anthoxanthetum aristati Rivas Goday 1958 [Pastizal graminoide de praderas cercanas a roquedos, con suelo pedregoso y carácter umbroso]. sisymbrietosum officinalis Vicente Orellana \& Galán de Mera subass. nova [de suelos nitrificados por el ganado bajo melojos].

var. con Digitalis thapsi [de suelos decapitados y pedregosos].

45. Trifolio cherleri-Plantaginetum bellardii Rivas Goday 1958 [Pastizal de suelos esqueléticos, silíceos, oligótrofos].

var. con Chamaemelum mixtum [Transición hacia los herbazales subnitrófilos].

** Sedenion caespitosi Rivas-Martínez 1978

46. Sedo caespitosi-Tillaeetum muscosae Rivas Goday 1958 [Vegetación pionera sobre suelos arenosos silíceos compactos que retienen poco agua].

sedetosum andegavensis Sánchez Mata, 1989 [de suelos areno-limosos que retienen más humedad].

* Sedion pedicellato-andegavensis RivasMartínez, Fernández-González \& Sánchez Mata 1986

47. Sedetum caespitoso-arenarii RivasMartínez ex V. Fuente 1986 [Vegetación terofítica de suelos ácidos esqueléticos, con textura arenosa gruesa, no compactados, con encharcamiento temporal breve].

POETEA BULBOSAE Rivas Goday \& RivasMartínez in Rivas-Martínez 1978

+ Poetalia bulbosae Rivas Goday \& RivasMartínez in Rivas Goday \& Ladero 1970

* Trifolio subterranei-Periballion Rivas Goday 1964

48. Poo bulbosae-Trifolietum subterranei Rivas Goday 1964 [Majadales silicícolas cespitosos, mesomediterráneos, lusoextremadurenses].

trifolietosum campestris (Rivas Goday \& Ladero 1970) Ladero, Amigo \& Romero 1994 [de áreas con redileo infrecuente]. isoetetosum histricis Rivas Goday 1964 [de áreas con encharcamiento temporal].

LYGEO-STYPETEA Rivas-Martínez 1978

+ Hyparrhenietalia hirtae Rivas-Martínez 1978

* Hyparrhenion hirtae Br.-B1., P. Silva \& Rozeira 1956

49. Dauco criniti-Hyparrhenietum sinaicae 
Tabla 21

Arbuto unedonis-Quercetum pyrenaicae (Rivas Goday in Rivas Goday, Esteve, Galiano, Rigual \& Rivas-Martínez 1960) Rivas-Martínez 1987

6-11: quercetosum suberis Vicente Orellana \& Galán de Mera subass. nova (Querco-Fagetea, Quercetalia roboris, Quercion pyrenaicae)

\begin{tabular}{|c|c|c|c|c|c|c|c|c|c|c|c|}
\hline Inventario $\mathrm{n}^{\mathrm{o}}$ & 1 & 2 & 3 & 4 & 5 & 6 & 7 & 8 & 9 & 10 & 11 \\
\hline Altitud (m.) & 450 & 895 & 410 & 531 & 550 & 534 & 560 & 573 & 585 & 692 & 526 \\
\hline Área $\left(\mathrm{m}^{2}\right)$ & 100 & 100 & 100 & 100 & 100 & 100 & 100 & 50 & 100 & 100 & 100 \\
\hline \multicolumn{12}{|c|}{ Características de asociación y unidades superiores } \\
\hline Quercus pyrenaica & 3 & 4 & 4 & 4 & 4 & 3 & 4 & 2 & 3 & 4 & 3 \\
\hline Tamus communis & 1 & . & . & . & . & 1 & + & . & . & + & 1 \\
\hline Arenaria montana & . & . & . & . & . & 1 & . & . & . & . & . \\
\hline Hedera helix & . & . & . & . & . & . & . & . & . & . & 2 \\
\hline Polygonatum odoratum & . & . & . & . & . & . & . & . & . & . & 1 \\
\hline \multicolumn{12}{|l|}{ Diferenciales de subasociación } \\
\hline Quercus suber & . & . & . & . & . & + & + & 1 & 1 & 1 & 1 \\
\hline Daphne gnidium & . & . & 1 & . & . & + & . & 2 & + & & + \\
\hline Ruscus aculeatus & . & . & . & . & . & . & . & . & + & 1 & 1 \\
\hline \multicolumn{12}{|l|}{ Compañeras } \\
\hline Cytisus striatus & 3 & . & 1 & + & + & . & 1 & 1 & . & + & . \\
\hline Pteridium aquilinum & . & . & 3 & 3 & 3 & 1 & 2 & . & 4 & 2 & . \\
\hline Cistus psilosepalus & . & . & 1 & . & + & 2 & 1 & . & 1 & 1 & + \\
\hline Cistus ladanifer & . & 1 & 1 & 2 & 2 & + & 1 & . & . & . & . \\
\hline Rubus ulmifolius & 2 & . & . & . & . & 4 & 1 & 1 & 1 & . & 2 \\
\hline Cistus salviifolius & 3 & . & . & . & . & 1 & . & 3 & + & . & 1 \\
\hline Lavandula stoechas subsp. sampaiana & . & . & + & 1 & 1 & . & + & . & . & . & . \\
\hline Crataegus monogyna & . & . & . & . & 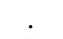 & 1 & + & 1 & . & . & + \\
\hline Lavandula stoechas subsp. luisieri & . & . & . & 1 & 1 & . & + & . & . & . & . \\
\hline Asplenium onopteris & . & 1 & . & . & . & 1 & . & . & . & · & + \\
\hline Castanea sativa & . & . & . & . & . & + & . & . & 1 & 2 & . \\
\hline Cytisus grandiflorus & . & . & . & . & . & 1 & . & . & . & 1 & 2 \\
\hline Lonicera peryclimenum & & & & & & & & & & & \\
\hline subsp. hispanica & . & . & . & . & . & . & . & . & + & 1 & 1 \\
\hline
\end{tabular}

Otras plantas: Asparagus acutifolius + , Digitalis thapsi + , Galium parisiense 1, Mentha suaveolens 1 , Olea europaea,+ Phagnalon saxatile,+ Rumex induratus 1 , Silene latifolia 1 , Thapsia villosa 1 , Umbilicus rupestris + , Verbascum pulverulentum + en 1; Carex depressa 1, Cynosurus echinatus 1, Dactylis glomerata subsp. hispanica +, Dianthus lusitanus +, Erica arborea 1, Erica umbellata 1, Geranium lucidum +, Geranium robertianum subsp. purpureum 1, Halimium umbellatum subsp. viscosum + , Holcus lanatus 1, Hypochaeris radicata 1 , Leucanthemopsis pallida subsp. flaveola 1, Linaria nivea + , Quercus rotundifolia 2, Sedum brevifolium,+ Sedum forsterianum 1, Stellaria media +, Umbilicus rupestris + en 2; Andryala integrifolia + , Avenula sulcata subsp. occidentalis +, Carlina corymbosa 1, Digitalis purpurea 1, Jasione montana + en 3; Urginea maritima + en 4 ; Senecio lividus 1, Lithodora prostrata subsp. lusitanica 1 en 5; Adenocarpus anisochilus + , Andryala integrifolia ,+ Arbutus unedo 1, Centranthus calcitrapae,+ Laurus nobilis 1, Lonicera implexa 1, Osyris alba 1, Scrophularia scorodonia + , Ulex minor + , Vicia disperma + en $6 ;$ Helichrysum stoechas + en 7 ; Adenocarpus complicatus 1 , Arbutus unedo 1, Galium mollugo 3, Helichrysum stoechas,+ Holcus annuus,+ Hypericum perforatum,+ Malva tournefortiana + , Origanum virens + , Pyrus bourgeana 1, Rumex induratus + , Silene vulgaris 1 en 8; Asparagus acutifolius + , Asphodelus albus subsp. albus 1, Bromus diandrus 1, Erica australis + , Euphorbia monchiquensis 1, Hypochaeris radicata + , Pinus pinaster + , Rumex acetosella subsp. angiocarpus 1, Simethis planifolia 1 , Teucrium scorodonia +, Urginea maritima + en 9; Adenocarpus anisochilus 1, Arisarum simorrhinum + Aristolochia paucinervis 1, Arum italicum +, Asphodelus albus subsp. albus 1, Brachypodium sylvaticum 1 , Cynosurus echinatus + , Dactylis glomerata subsp. hispanica 1, Geranium lucidum + , Linaria triornothophora 1 , Pinus pinaster 2, Polypodium cambricum + , Rhagadiolus edulis + , Satureja vulgaris subsp. arundana + , Senecio lividus,+ Vicia benghalensis + , Vicia sativa 1, Viola arvensis + en 10; Avena sterilis,+ Briza maxima,+ Bryonia dioica + , Coleostephus myconis 1, Fumaria officinalis + , Lathyrus clymenum 1, Lathyrus latifolius + , Osyris alba 1, Rosa andegavensis 1, Rumex papillaris + , Silene vulgaris,+ , Thapsia villosa,+ Torilis arvensis + , Vicia benghalensis +, Vicia lutea +, Vicia sativa + en 11.

Localidades: 1: Estación Ferrocarril, Logrosán (Cáceres, España) 30STJ8657. 2: Collado del Boquete de los Meladillos, Cañamero (Cáceres, España) 30STJ9169. 3: Veloso, Carreiras (Alto Alentejo, Portugal) 29SPD3559. 4, 5, 7: Ribeira de Nisa, Portalegre (Alto Alentejo, Portugal) 29SPD3456.6, 11: Monte Paleiros, Ribeira de Nisa, Portalegre (Alto Alentejo, Portugal) 29SPD3554. 8: Valle de la Majada del Venero, Cañamero (Cáceres, España) 30STJ9263. 9: Srra. de Urra, Castelo de Vide (Alto Alentejo, Portugal) 29SPD3563. 10: Srra. de Marvão, Marvão (Alto Alentejo, Portugal) 29SPD3863. 
Rivas-Martínez in Rivas-Martínez, FernándezGonzález \& Sánchez Mata 1986 corr. DíezGarretas \& Asensi 1999 [Pastizal graminoide en pequeñas repisas de zonas escarpadas y taludes pedregosos termófilos].

\section{STIPO GIGANTEAE-AGROSTIETEA} CASTELLANAE Rivas-Martínez, Fernández González \& Loidi 1999

+ Agrostietalia castellanae Rivas-Martínez in Rivas-Martínez, Costa, Castroviejo \& E. Valdés 1980

* Agrostion castellanae Rivas Goday 1958 corr. Rivas Goday \& Rivas-Martínez 1963

50. Gaudinio fragilis-Agrostietum castellanae Rivas-Martínez \& Belmonte 1986 [Vallicares sobre suelos arenosos silíceos, empobrecidos, con ligero encharcamiento temporal].

agrostietosum pourretii Vicente Orellana \& Galán de Mera subass. nova [de suelos con mayor encharcamiento].

* Agrostio castellanae-Stipion giganteae Rivas Goday ex Rivas-Martínez \& Fernández González 1991

51. Melico magnolii-Stipetum giganteae Rivas-Martínez ex Peinado \& Martínez Parras 1985 [Berceal silicícola luso-extremadurense, en claros de melojar o en roquedos cuarcíticos, siempre sobre suelos profundos].

52. Armerio francoi-Arrhenatheretum sardoi Vicente Orellana \& Galán de Mera ass. nova [Pastizal de talla media, sobre suelos poco profundos y pedregosos].

\section{Festuco multispiculatae -} Arrhenatheretum sardoi Vicente Orellana \& Galán de Mera ass. nova [Pastizal subrupícola, supramediterráneo superior, que se desarrolla en las repisas de crestones cuarcíticos].

* Festucion elegantis Rivas-Martínez \& Sánchez Mata in Rivas-Martínez, Fernández González \& Sánchez Mata 1986

54. Festuco multispiculatae-Agrostietum curtisii Vicente Orellana \& Galán de Mera ass. nova [Pastizal vivaz sobre suelos arenosos y lixiviados procedentes de granitos].

var. con Agrostis truncatula [variante de áreas erosionadas con sustrato arenoso y suelos poco profundos].

MOLINIO-ARRHENATHERETEA Tüxen 1937
+ Molinietalia caeruleae Koch 1926

* Juncion acutiflori Br.-Bl. in Br.-Bl. \& Tüxen 1952

55. Hyperico undulati-Juncetum acutiflori Teles 1970 [Juncales occidentales ibéricos sobre suelos silíceos y gleyzados con nivel freático superficial].

+ Holoschoenetalia vulgaris Br.-Bl. ex Tchou 1948

* Molinio-Holoschoenion vulgaris Br.-B1. ex Tchou 1948

56. Trifolio resupinati-Holoschoenetum Rivas Goday 1964 [Juncal de zonas con encharcamiento temporal prolongado, sobre sustrato silíceo arenoso].

+ Paspalo-Heleochloetalia Br.-Bl. in Br.-Bl., Roussine \& Nègre 1952

* Paspalo-Agrostion verticillati Br.-B1. in Br.-B1., Roussine \& Nègre 1952

57. Ranunculo scelerati-Paspaletum paspalodis Rivas Goday 1964 corr. Peinado, Bartolomé, Martínez-Parras \& Ollala 1988 [Céspedes densos, muy resistentes al pisoteo, en las graveras que dejan los ríos al descubierto a finales del verano].

+ Plantaginetalia majoris Tüxen \& Preising in Tüxen 1950

* Trifolio fragiferi-Cynodontion Br.-B1. \& O. Bolòs 1958

58. Trifolio resupinati-Caricetum chaetophyllae Rivas-Martínez \& Costa in Rivas-Martínez, Costa, Castroviejo \& E. Valdés 1980 [Gramadales densos sobre suelos arenosos muy húmedos, originados por nitrificación de juncales debido a un intenso pastoreo].

* Mentho-Juncion inflexi De Foucault 1984 59. Mentho suaveolentis-Juncetum inflexi Rivas-Martínez in Sánchez-Mata 1989 [Juncal hidrófilo termófilo, con encharcamiento temporal y una fuerte acción antrópica].

CALLUNO-ULICETEA Br.-B1. \& Tüxen ex Klika \& Hadac 1944

+ Ulicetalia minoris Quantin 1935

* Ericion umbellatae Br.-B1., P. Silva, Rozeira \&

Fontes 1952

** Ericenion umbellatae Rivas-Martínez 1979 60. Halimio ocymoidis-Ericetum umbellatae Rivas Goday 1964 [Brezal de talla baja que 
se desarrolla sobre suelos poco profundos y desnudos, muy ácidos, xéricos y sometidos a intensa exposición solar].

61. Halimio ocymoidis-Cistetum hirsuti Br.B1., P. Silva \& Rozeira 1965 [Jaral-brezal de pequeña talla, con acusado carácter oceánico, sobre suelos que no han sufrido una degradación extrema, y que conservan sus horizontes superficiales].

62. Halimio umbellati-Ulicetum minoris Antunes 1996 [Matorral bajo, en pendientes con afloramientos de granitos y cuarcitas, sobre todo en exposición norte].

CISTO-LAVANDULETEA Br.-B1. in Br.-B1., Molinier \& Wagner 1940

+ Lavanduletalia stoechadis Br.-Bl. in Br.-Bl., Molinier \& Wagner 1940 em. Rivas-Martínez 1968

* Ulici argentei-Cistion ladaniferi Br.-B1., P. Silva

\& Rozeira 1965

63. Genisto hirsutae-Cistetum ladaniferi Rivas Goday 1956 [Jarales silicícolas lusoextremadurenses sobre tierras pardas meridionales y suelos rojos que se asientan sobre pizarras y cuarcitas, con ombroclima seco]

ericetosum australis Rivas Goday 1956 [de zonas más elevadas y húmedas].

CYTISETEA SCOPARIO-STRIATI RivasMartínez 1975

+ Cytisetalia scopario-striati Rivas-Martínez 1975

* Adenocarpion argyrophylli Vicente Orellana \& Galán de Mera all. nova

64. Adenocarpetum argyrophylli RivasMartínez, Cantó, Sánchez-Mata \& Belmonte 2002 [Codesal fisurícola mesomediterráneo]. 65. Genisto cinerascentis-Adenocarpetum argyrophylli (Rivas-Martínez, Cantó, SánchezMata \& Belmonte) Vicente Orellana \& Galán de Mera stat. nov. [Codesal fisurícola supramediterráneo].

echinospartetosum iberici Vicente Orellana \& Galán de Mera subass. nova [de zonas cacuminales muy venteadas y expuestas].

* Genistion floridae Rivas-Martínez 1974 66. Cytiso multiflori-Sarothamnetum eriocarpi Rivas Goday 1964 [Escobonal sobre suelos profundos, silíceos, con ombroclima subhúmedo-húmedo].

* Retamion sphaerocarpae Rivas-Martínez 1981 67. Cytiso multiflori-Retametum sphaerocarpae Rivas-Martínez ex Navarro, Sánchez, González, Gallego, Elena \& Valle 1987 [Retamar toledanotagano, sobre sustrato silíceo y con ombroclima seco o subhúmedo].

var. con Asphodelus ramosus [de suelos más húmedos y encharcamiento estacional].

* Ulici europaei-Cytision striati Rivas-Martínez, Báscones, T.E. Díaz, Fernández-González \& Loidi 1991

68. Genisto falcatae-Adenocarpetum anisochili Antunes, Capelo, Costa \& Lousã in Costa, Capelo, Lousã, Antunes, Aguiar, Izco \& Ladero 2000 [Codesal oretano sobre suelos profundos graníticos, mesomediterráneo húmedo].

RHAMNO-PRUNETEA Rivas Goday \& Borja ex Tüxen 1962

+ Prunetalia spinosae Tüxen 1952

* Pruno-Rubion ulmifolii O. Bolòs 1954

** Rosenion carioti-pouzinii Arnaiz ex Loidi 1989

69. Lonicero hispanicae-Rubetum ulmifolii Rivas-Martínez, Costa, Castroviejo \& Valdés 1980 [Zarzales con lianas sobre suelos profundos, arenosos, meso-oligótrofos y húmedos].

70. Rubetum ulmifolio-vigoi Vicente Orellana \& Galán de Mera ass. nova [Zarzales lusoextremadurenses sobre suelos muy arcillosos]. 71. Rubetum ulmifolio-caesii Vicente Orellana \& Galán de Mera ass. nova [Zarzales luso-extremadurenses nemorales, bajo alisedas].

SALICI PURPUREAE-POPULETEA NIGRAE (Rivas-Martínez \& Cantó ex Rivas-Martínez, Báscones, T.E. Díaz, Fernández-González \& Loidi 1991) Rivas-Martínez, T.E. Díaz, Fernández-González, Izco, Loidi, Lousã \& Penas 2002

+ Populetalia albae Br.-Bl. ex Tchou 1948

* Fraxino angustifoliae-Ulmenion minoris RivasMartínez 1975

72. Ficario ranunculoidis-Fraxinetum angustifoliae Rivas-Martínez \& Costa in Rivas-Martínez, Costa, Castroviejo \& Valdés 
1980 [Fresnedas sobre suelos arenosos mesooligótrofos gleyzados, termomesomediterráneas occidentales].

* Osmundo-Alnion (Br.-B1., P. Silva \& Rozeira 1956) Dierschke \& Rivas-Martínez in RivasMartínez 1975

73. Scrophulario scorodoniae-Alnetum glutinosae Br.-B1., P. Silva \& Rozeira 1956 [Alisedas riparias con influencia atlántica, termo-mesomediterráneas, sobre suelos arenoso-silíceos permanentemente encharcados, gleyzados, sin sequía estival].

74. Viti viniferae-Salicetum atrocinereae Rivas-Martínez \& Costa in Rivas-Martínez, Costa, Castroviejo \& Valdés 1980 [Sauceda no riparia sobre suelos temporalmente inundados, gleymorfos].

+ Salicetalia purpureae Moor 1958

* Securinegion buxifoliae Rivas Goday 1964 75. Pyro bourgeanae-Securinegetum tinctoriae (Rivas Goday 1964) Rivas-Martínez \& Rivas Goday 1975 [Tamujar lusoextremadurense, en cauces de curso irregular]. var. con Quercus rotundifolia [tamujar con encinas en zonas limosas].

* Salicion salviifoliae Rivas-Martínez, T.E. Díaz,

F. Prieto, Loidi \& Penas 1984

76. Salicetum salviifoliae Oberdorfer \& Tüxen in Tüxen \& Oberdorfer 1958 [Saucedas con fuerte sequía estival, sobre suelos algo arenosos de ríos y arroyos].

QUERCETEA ILICIS Br.-Bl. ex A. \& O. Bolòs 1950

+Quercetalia ilicis Br.-B1. ex Molinier 1934 em. Rivas-Martínez 1975

* Quercion broteroi Br.-Bl., P. Silva \& Rozeira 1956 em. Rivas-Martínez 1975 corr. Ladero 1974

** Quercenion broteroi

77. Poterio agrimonioidis-Quercetum suberis Rivas Goday in Rivas Goday, Borja, Esteve, Galiano, Rigual \& Rivas-Martínez 1960 [Alcornocales mesomediterráneos lusoextremadurenses subhúmedos].

quercetosum pyrenaicae Vicente Orellana, Pérez Latorre, Cabezudo \& Galán de Mera subass. nova [de zonas más altas y umbrosas, representando el contacto con los melojares].
** Paeonio broteroi-Quercenion rotundifoliae Rivas-Martínez in Rivas-Martínez, Costa \& Izco 1986

78. Pyro bourgeanae-Quercetum rotundifoliae Rivas-Martínez 1987 [Encinar silicícola mesomediterráneo luso-extremadurense secosubhúmedo].

quercetosum suberis Rivas Goday 1964 [con alcornoques en suelos arcillosos]. quercetosum pyrenaicae Vicente Orellana \& Galán de Mera subass. nova [con melojos en enclaves más húmedos por inversión térmica o compensación edáfica]. juniperetosum badiae Vicente Orellana \& Galán de Mera subass. nova [con enebros sobre afloramientos cuarcíticos muy expuestos].

jasminetosum fruticantis Vicente Orellana \& Galán de Mera subass. nova [encinares toledano-taganos mesomediterráneos sobre calizas].

myrtetosum communis Rivas-Martínez 1987 [encinares térmicos].

+ Pistacio lentisci-Rhamnetalia alaterni RivasMartínez 1975

* Ericion arboreae (Rivas-Matínez ex RivasMartínez, Costa \& Izco 1986) Rivas-Martínez 1987

** Ericenion arboreae

79. Phillyreo angustifoliae-Arbutetum unedonis Rivas Goday \& F. Galiano in Rivas Goday, Borja, Esteve, Galiano, Rigual \& Rivas-Martínez 1960 [Madroñales termomesomediterráneos subhúmedohiperhúmedos, con acusado carácter atlántico, sobre suelos profundos poco alterados].

pistacietosum lentisci Pérez Chiscano 1976 [subasociación termófila seca-subhúmeda]. viburnetosum tini Pérez Chiscano 1976 [subasociación ombrófila subhúmedahúmeda].

QUERCO-FAGETEA Br.-Bl. \& Vlieger in Vlieger 1937

+Quercetalia roboris Tüxen 1931

* Quercion pyrenaicae Rivas Goday ex RivasMartínez 1965

** Quercenion pyrenaicae

80. Arbuto unedonis-Quercetum pyrenaicae (Rivas Goday in Rivas Goday, Esteve, 
Galiano, Rigual \& Rivas-Martínez 1960) Rivas-Martínez 1987

[Melojares mesomediterráneos que se desarrollan sobre cambisoles y regosoles dístricos, bajo ombroclima húmedo].

quercetosum suberis Vicente Orellana \& Galán de Mera subass. nova [enriquecimiento con alcornoques en zonas más húmedas y arcillosas].

var. con Genista falcata [variante de suelos pedregosos].

\section{BIBLIOGRAFÍA}

AMARAL FRANCO, J. -1986- Juniperus L. In Castroviejo, S. (Coord.). Flora Iberica. vol. I. Real Jardín Botánico, CSIC. Madrid.

AMOR, A., M. LADERO y C.J. VALLE -1993Flora y vegetación vascular de la comarca de la vera y laderas meridionales de la Sierra de Tormantos (Cáceres, España). Stud. Bot. 11: 11207.

ANTUNES, J.H.S.C. -1996- Aspectos sinfitossociológicos da Serra de S. Mamede. Silva Lusit. 4(1): 97-107.

BELMONTE, D. -1986- Estudio de la flora y vegetación de la comarca y sierra de Las Corchuelas, Parque Natural de Monfragüe, Cáceres. Memoria Tesis doctoral. Universidad Complutense de Madrid.

BOLÒS, O. \& R. MOLINIER -1969- Vue d'ensemble de la végétation des Îles Baléares. Vegetatio 17: 251-270.

BOLÒS, O., R. MOLINIER \& P. MONTSERRAT -1970- Recherches fitosociologiques dans l'Île de Minorca. Acta Geobot. Barcinon. 5: 1-150.

BOLÒS, O., J. VIGO, R.M. MASALLES \& J.M. NINOT -1993-Flora manual dels països Catalans. Ed. Pòrtic, Barcelona.

BRAUN-BLANQUET, J. -1964Pflanzensoziologie, Grundzüge der Vegetationskunde. Springer Verlag. Wien.

CANO, E., A. RODRÍGUEZ-TORRES, C. PINTO GÓMES, A. GARCÍA-FUENTES, J.A. TORRES, C. SALAZAR, L. RUIZVALENZUELA, A. CANO-ORTIZ \& R.J. MONTILLA -2007- Analysis of the Juniperus oxycedrus L. communities in the centre and south of the Iberian Peninsula (Spain and
Portugal). Acta Bot. Gallica 154: 79-99.

CAPELO, J.H. -1996- Esboço da paisagem vegetal da bacia portuguesa do Rio Guadiana. Silva Lusit. $\mathrm{n}^{\circ}$ especial: $13-64$.

CASTROVIEJO, S. (coord.) -1986-2008- Flora iberica. CSIC, Madrid.

COMISIÓN EUROPEA -2000- Cooperación Transfronteriza España-Portugal. Documento Único de Programación Interreg III 2000-2006. Dirección General de Fondos Comunitarios y Financiación Territorial, Direcção Geral do Desenvolvimento Regional. Bruselas.

CORREIA PERDIGÃO, J. \& A. PEINADOR FERNÁNDES -1976- Carta Geológica de Portugal (1:50000). Noticia explicativa da folha 29-C (Marvão). Direcção Geral de Minas e Serviços Geológicos, Lisboa.

COSTA, J.C., C. AGUIAR, J.H. CAPELO, M. LOUSÃ \& C. NETO -1998- Biogeografía de Portugal continental. Quercetea 0: 5-56.

DEIL, U. \& A. SUNDERMEIER -1992- L'influence $\mathrm{du}$ système agraire sur les groupements messicoles des deux rives du détroit de Gibraltar. Ann. A.N.N.P.P.: 207-212.

DEIL, U. -1997- Vegetation cover and human impact. A comparison of the Almarchal Region (Campo de Gibraltar, Spain) and the Tangier hinterland (Morocco). Lagascalia 19: 745-758.

DEVESA ALCARAZ, J.A. -1995- Vegetación y Flora de Extremadura. Universitas, Badajoz.

DIERSCHKE, H. -1993-Grundlagen und Methoden der Pflanzensoziologie. Ulmer, Stuttgart.

EUROSTAT (s.f.): Portrait of the regions. Vol. 3 . Portugal, Spain, Italy, Greece. Comission of the European Communities.

FRANCO, J. A. -1971, 1984- Nova flora de Portugal : continente e Açores. Vol. I y II. Soc. Astória, Lisboa.

FRANCO, J.A. \& M.L. ROCHA AFONSO -1994, 1999- Nova Flora de Portugal (Continente e Açores). Vol. III, fasc. I y II. Escolar Editora, Lisboa.

GALÁN DE MERA, A. -1993- Flora y vegetación de los términos municipales de Alcalá de los Gazules y Medina Sidonia (Cádiz, España). Servicio de Publicaciones, Universidad Complutense, Madrid.

GALÁN DE MERA, A. -1995- Trifolio pallidiVulpietum geniculatae, nueva asociación del Echio-Galactition para el SW de la Península 
Ibérica. Doc. Phytosoc. 15: 335-339.

GALÁN DE MERA, A., U. DEIL, H. HAUG y J.A. VICENTE ORELLANA -1997- Contribución a la clasificación fitosociológica de los pastizales de la provincia de Cádiz (España). Acta Bot. Malacitana 22: 147-169.

GALÁN DE MERA, A., R. MORALES ALONSO \& J.A. VICENTE ORELLANA -2000a- Pasture communities linked to ovine stock. A synthesis of the Poetea bulbosae class in the western Mediterranean Region. Phytocoenologia 30: 223-267.

GALÁN DE MERA, A., J.E. CORTÉS \& I. SÁNCHEZ GARCÍA -2000b- La vegetación del Peñón de Gibraltar. Acta Bot. Malacitana 25: 107-130.

GARCÍA FUENTES, A. y E. CANO CARMONA -1995- Malas hiervas del olivar jienense. Diputación Provincial de Jaén. Jaén.

GARCÍA NAVARRO, A. y A. LÓPEZ PIÑEIRO 2002- Mapa de los suelos de la provincia de Cáceres, escala 1:300000. Servicio de Publicaciones, Universidad de Extremadura. Badajoz.

GREUTER, W., H.M. BURDET \& G. LONG 1984, 1986, 1989-Med-Cheklist. Conservatoire et Jardin Botaniques, Genève.

GRIERSON, A.J.C. -1975-Leucanthemum Mill. In: Davis, P.H. Flora of Turkey and the East Aegean Islands. Vol. 5, pp. 255-256. University Press, Edinburgh.

HEYWOOD, V.H. -1984- Coleostephus Cass. In: Tutin, T.G., V.H. Heywood, N.A. Burges, D.M. Moore, D.H. Valentine, S.M. Walters \& D.A. Webb (eds.) Flora Europaea. Vol. 4. Cambridge University Press, Cambridge.

HONRADO, J., P. ALVES, H.N. ALVES \& F. BARRETO CALDAS -2004- A vegetaçao do Alto Minho. Quercetea 5: 3-102.

INSTITUTO SUPERIOR DE AGRONOMÍA 2003-Estaçoes climatológicas. AGRIBASE. Secçao de Agricultura. Universidade Técnica de Lisboa.

IZCO, J. y M. COLLADO -1983- Los herbazales con Galactites tomentosa (Coleostepho myconis-Galactitetum) del noroeste ibérico (prov. Cántabro-Atlántica). Colloq. Phytosoc. 12: 597-608.

IZCO, J. y M. DEL ARCO -2003- Código internacional de nomenclatura fitosociológica. Publ. Univ. La Laguna.
JANSEN, J. -2002-Geobotanical guide of the Serra da Estrela. Instituto da Conservação da Natureza, Lisboa.

LADERO, M. -1970a- Contribución al estudio de la flora y vegetación de las comarcas de La Jara, Serrania de Ibor y Guadalupe-Villuercas, en la Oretana Central. Memoria Tesis doctoral. Universidad Complutense. Madrid.

LADERO, M. -1970b- Nuevos táxones para la flora de Extremadura. Anales Inst. Bot. Cavanilles 27: 85-104.

LADERO, M. -1987- La España LusoExtremadurense. In: Peinado Lorca, M. \& S. Rivas-Martínez (eds.): La vegetación de España: 455-486. Ser. Publ. Univ. Alcalá de Henares.

LADERO, M \& A. AMOR -1999- The vegetation of Extremadure: The Badajoz-Talavera de la Reina transect. In: Rivas-Martínez, S., J. Loidi Aguirre, M. Costa Talens, T.E. Díaz González \& A. Penas Merino: Iter Ibericum A.D. MIM. Itinera Geobot. 13: 169-188.

LADERO, M., J.L. PÉREZ-CHISCANO, M.T. SANTOS, C.J. VALLE \& A. AMOR -1990Encinares luso-extremadurenses y sus etapas preclimácicas. Acta Bot. Malacitana 15: 323329.

LADERO, M., A. AMOR \& M.T. SANTOS BOBILLO -1998- Interés ecológico y pascícola de las comunidades vegetales presentes en los Barruecos (Malpartida de Cáceres, Extremadura, España). Stud. Bot. 17: 23-35.

LADERO, M., S. RIVAS-MARTÍNEZ, A. AMOR, M.T. SANTOS \& M.T. ALONSO -1999- New hybrid of genus Silene (Caryophyllaceae) in the Serra da Estrela, Portugal. Bot. J. Linn. Soc. 130: 69-80.

LADERO ÁlVAREZ, M., C. VALLE GUTIÉRREZ, J.L. PÉREZ CHISCANO, M.T. SANTOS BOBILLO, A. AMOR MORALES y F.J. GONZÁLEZ IGLESIA -1994- Memoria de los mapas de vegetación potencial del macizo oriental de las Villuercas (Cáceres, España). Escala 1:50000 y 1:100000. Anais Ins. Sup. Agronom. 44 (2): 755-782.

LAMIN VIEIRA, I. -1997-Região de turismo de S. Mamede/Alto Alenteio. Setúbal.

LEÓN LLAMAZARES, A. DE -1991aCaracterización agroclimática de la provincia de Badajoz. $2^{\circ}$ edición. Dirección General de la Producción Agraria. Ministerio de 
Agricultura, Pesca y Alimentación, Madrid.

LEÓN LLAMAZARES, A. DE -1991bCaracterización agroclimática de la provincia de Cáceres. $2^{\circ}$ edición. Dirección General de la Producción Agraria. Ministerio de Agricultura, Pesca y Alimentación, Madrid.

LOIDI, J., I. BIURRUN, J.A. CAMPOS, I. GARCÍA-MIJANGOS \& M. HERRERA 2007- A survey of heath vegetation of the Iberian Peninsula and Northern Morocco: a biogeographic and bioclimatic approach. Phytocoenologia 37(3-4): 341-370.

LÓPEZ GONZÁLEZ, G. -1990-Rumex L. In: Castroviejo, S. Flora Iberica. Vol. II. Real Jardín Botánico-CSIC, Madrid.

LÓPEZ SÁEZ, J.A. \& A. VELASCONEGUERUELA -1995- Securinegion buxifoliae Rivas Goday 1964 en el suroeste madrileño. Lazaroa 15: 205-209.

MALATO BELIZ, J. -1979- Breve note à propos de la vegetation des paves des rues dans les anciennes villes de la montagne de S. Mamede. Doc. phytosoc. n.s. 4: 659-661.

MALATO BELIZ, J. -1987- L'influence atlántique dans les montagnes portugaises au sud du Tage. Lazaroa 7: 423-432.

MONASTERIO-HUELIN, E. -1998- Rubus L. In Castroviejo, S. (coord.): Flora iberica. Vol. VI. Real Jardín Botánico- CSIC, Madrid.

MONSERRAT RECODER, P. -1975- Aspectos funcionales de los sistemas agropecuarios mediterráneos. Pastos 5: 29-34.

MORA, A. -1997- Geología y minería de Logrosán. In: Cortijo, E., J. Barreiro, M. Pardeza, J. Gil, A. Mora, F. Durán, A. Pizarro, J. Araujo, M. Murillo \& S. Martín. Logrosán: Cultura, Historia y Medio Natural. pp 87-99. I Jornadas Medioambientales y Culturales. Ayuntamiento de Logrosán.

NAVARRO ANDRÉS, F., M.A. SÁNCHEZ-ANTA, M.A. GONZÁLEZ ZAPATERO, F. GALLEGO MARTÍN y J.A. ELENA ROSELLÓ -1987Bosques salmantinos y zamoranos y su relación con las series de vegetación que encabezan. Stud. Bot. 6: 9-24.

NIETO FELINER, G. -1990- Armeria Willd. In Castroviejo, S. (coord.): Flora iberica. Vol. II. Real Jardín Botánico-CSIC, Madrid.

OBERDORFER, E. -1990- Pflanzensoziologische Excursionsflora. Ulmer, Stuttgart.

ORTIZ, S. \& J. RODRÍGUEZ-OUBIÑA -1993-
Synopsis of the rupicolous vegetation of Galicia (North-western Iberian Peninsula). Folia Geobot. Phytotax. 28: 15-49.

PEINADOR FERNÁNDES, A., J. CORREIA PERDIGÃO, H. FIGUEIREDO DE CARVALHO y A. MARTINS PERES -1973Carta Geológica de Portugal (1:50000). Noticia explicativa da folha 28-D (Castelo de Vide). Direcção Geral de Minas e Serviços Geológicos, Lisboa.

PEREIRA COUTINHO, A.X. -1939- Flora de Portugal. Bertrand, Lisboa.

PÉREZ CHISCANO, J.L. -1994- Los adelfares de la provincia corológica Luso-Extremadurense (Península Ibérica). Stud. Bot. 12: 203-218.

PÉREZ LATORRE, A.V., J.M. NIETO CALTERA y B. CABEZUDO -1993-Contribución al conocimiento de la vegetación de Andalucía II. Los Alcornocales. Acta Bot. Malacitana 18: 223-258.

PINTO-GOMES, C., J.C. ESCUDERO-GARCÍA y J. CABEZAS-FERNÁNDEZ -1994Caracterización de las unidades de vegetación del Parque Natural de San Mamede de Portugal. Colloq. Phytosoc. 23: 462-468.

PULGAR, I., S. ORTIZ \& J. RODRÍGUEZOUBIÑA -1996- Minuartio recurvae-Silenetum acutifoliae, un nuevo pastizal vivaz de las cumbres del macizo montañoso de Xurés-Gerês. Lazaroa 17: 129-135.

REIS FREIRE, M.H. -1989- A naturaleza nos usos e costumes da população da Serra de S. Mamede. Clube de Biologia e Geologia Serra de S. Mamede, Portalegre.

RIVAS GODAY, S. -1958- Nuevos órdenes y alianzas de Helianthemetea annuae Br-B1. Anales Inst. Bot. Cavanilles 15: 539-668.

RIVAS GODAY, S. -1964-Vegetación y flórula de la cuenca extremeña del Guadiana. (Vegetación y flórula de la provincia de Badajoz). Publ. Dip. Prov. de Badajoz, Madrid.

RIVAS GODAY, S., J. BORJA, F. ESTEVE, E. FERNÁNDEZ-GALIANO, A. RIGUAL y S. RIVAS-MARTÍNEZ -1959- Contribución al estudio de la Quercetea ilicis hispánica. Anales Inst. Bot. Cavanilles 17(2): 285-403.

RIVAS-MARTÍNEZ, S. -1969- Vegetatio Hispanicae. Notula I. P. Inst. Biol. Apl. 46: 5-34.

RIVAS-MARTÍNEZ, S. -1974- La vegetación de la clase Quercetea ilicis en España y Portugal. Anal. Inst. Bot. Cavanilles 31(2): 205-259. 
RIVAS-MARTÍNEZ, S. -1978- Sinopsis de la vegetación nitrófila rupestre (Parietarietea judaicae). Anales Inst. Bot. Cavanilles 35: 225233.

RIVAS-MARTÍNEZ, S. -1981- Sobre la vegetación de la Serra da Estrela (Portugal). Anales Real Acad. Farm. 47: 435-480.

RIVAS-MARTÍNEZ, S. -1987- Memoria del mapa de series de vegetación de España. ICONA, Madrid.

RIVAS-MARTÍNEZ, S. -1997- Syntaxonomical sinopsis of the potential natural plant communities of North America, I. Itinera Geobot. 10: 5-148.

RIVAS-MARTÍNEZ, S. y D. BELMONTE -1986Sobre el orden Agrostietalia castellanae. Lazaroa 8: 417-419.

RIVAS-MARTÍNEZ, S. y D. BELMONTE -1987Sinopsis de la clase Cytisetea scopario-striati. Folia Bot. Matritensis 3: 1-14.

RIVAS-MARTÍNEZ, S., C. AGUIAR, J.C. COSTA, M. COSTA, J. JANSEN, M. LADERO, M. LOUSÃ \& C. PINTO-GOMES -2000- Dados sobre a vegetação da Serra da Estrela. Quercetea 2: 3-63.

RIVAS-MARTÍNEZ, S., P. CANTÓ, F. FERNÁNDEZ-GONZÁLEZ y D. SÁNCHEZMATA -1988- Ensayo preliminar para una revisión de la clase Quercetea ilicis en España y Portugal. Folia Bot. Matritensis 4: 1-20.

RIVAS-MARTÍNEZ, S., M. COSTA y J. LOIDI 1992- La vegetación de las islas de Ibiza y Formentera (Islas Baleares, España). Itinera Geobot. 6: 99-236.

RIVAS-MARTÍNEZ, S., T.E. DÍAZ, F. FERNÁNDEZ-GONZÁLEZ, J. IZCO, J. LOIDI, M. LOUSÃ \& A. PENAS -2002Vascular plant communities of Spain and Portugal. Addenda to the syntaxonomical checklist of 2001. Part I. Itinera Geobot. 15(1): 5-432.

RIVAS-MARTÍNEZ, S., F. FERNÁNDEZ GONZÁLEZ, J. LOIDI, M. LOUSÃ \& A. PENAS -2001- Syntaxonomical checklist of the vascular plant communities of Spain and Portugal to association level. Itinera Geobot. 14: 5-341.

RIVAS-MARTÍNEZ, S., M. LOUSÃ, T.E. DÍAZ, F. FERNÁNDEZ-GONZÁLEZ \& J.C. COSTA -1990- La vegetación del sur de Portugal (Sado, Alentejo y Algarbe). Itinera Geobot. 3: 5-126.
RIVAS-MARTÍNEZ, S., D. SÁNCHEZ-MATA \& M. COSTA -1999- North American boreal and western temperate forest vegetation. Itinera Geobot. 12: 5-316.

ROMERO ZARCO, C. -1990- Las avenas del grupo barbata en la Península Ibérica y Baleares. Lagascalia 16(2): 243-268.

ROTHMALER, W. -2000- Exkursionsflora von Deutschland, Bd. 3 Gefässplanzen: Atlasband. Spektrum Akademischer Verlag, Heidelberg, Berlin.

SÁNCHEZ MARTÍN, J.M. -1994- Los gradientes climáticos en Extremadura. Método óptimo para la obtención de variables termopluviométricas. Universidad de Extremadura. Fundicot-Extremadura, Cáceres.

SÁNCHEZ-MATA, D. -1989- Flora y vegetación del macizo oriental de la Sierra de Gredos (Ávila). Diputación Provincial de Ávila. Institución Gran Duque de Alba, Ávila.

SANTOS, M.T., M. LADERO y A. AMOR -1989Vegetación de las intercalaciones básicas de la provincia de Cáceres (Extremadura, España). Stud. Bot. 7: 9-147.

TELES, A.N. -1970- Os lameiros de montanha do norte de Portugal. Subsidios para a sua caracterização fitossociologica e química. Agron. Lusit. 31: 5-132.

TEOTONIO PEREIRA, N. \& J. REIS GÓMES 1983- Plano geral de urbanização. Camara Municipal de Castelo de Vide.

TORMO MOLINA, R., T. RUIZ TÉLLEZ y J.A. DEVESA ALCARAZ -1992- Aportación a la bioclimatología de Portugal. Anales Jard. Bot. Madrid 49(2): 245-264.

TUTIN, T.G. et al. -1964-1980- Flora Europaea. Vol. I-V. Cambridge University Press.

VALDÉS, B., S. TALAVERA \& E.F. GALIANO 1987- Flora Vascular de Andalucía Occidental. Ketres, Barcelona.

VICENTE ORELLANA, J.A. -2004- Estudio comparativo de los usos de dos territorios (España/Portugal) mediante estudio fitosociológico de la vegetación. Memoria Tesis doctoral. Universidad CEU-San Pablo, Madrid.

VICENTE ORELLANA, J.A. \& A. GALÁN DE MERA -2003- The vegetation in the Villuercas region (Extremadura, Spain) and in Serra de San Mamede (Alto Alenteio, Portugal). The effect of different land use for the vegetation pattern. Phytocoenologia 33(4): 727-748. 